\title{
Permeability prediction from well log data using multiple regression analysis
}

Janaina Luiza Lobato Pereira

West Virginia University

Follow this and additional works at: https://researchrepository.wvu.edu/etd

\section{Recommended Citation}

Pereira, Janaina Luiza Lobato, "Permeability prediction from well log data using multiple regression analysis" (2004). Graduate Theses, Dissertations, and Problem Reports. 1507.

https://researchrepository.wvu.edu/etd/1507

This Thesis is protected by copyright and/or related rights. It has been brought to you by the The Research Repository @ WVU with permission from the rights-holder(s). You are free to use this Thesis in any way that is permitted by the copyright and related rights legislation that applies to your use. For other uses you must obtain permission from the rights-holder(s) directly, unless additional rights are indicated by a Creative Commons license in the record and/ or on the work itself. This Thesis has been accepted for inclusion in WVU Graduate Theses, Dissertations, and Problem Reports collection by an authorized administrator of The Research Repository @ WVU. For more information, please contact researchrepository@mail.wvu.edu. 


\title{
PERMEABILITY PREDICTION FROM WELL LOG DATA USING MULTIPLE REGRESSION ANALYSIS
}

\author{
Janaina Luiza Lobato Pereira
}

Thesis Submitted to the

College of Engineering and Mineral Resources

At West Virginia University

In Partial Fulfillment of the Requirements

For the Degree of

Master of Science

In

Petroleum and Natural Gas Engineering

\author{
Khashayar Aminian, Ph.D., Chair \\ Samuel Ameri, M.S \\ Daniel Della-Giustina, Ph.D.
}

Department of Petroleum and Natural Gas Engineering

\author{
Morgantown, West Virginia \\ 2004
}

Keywords: Permeability prediction, Flow Units, Multiple Regression Analysis 


\section{ABSTRACT \\ PERMEABILITY PREDICTION FROM WELL LOG DATA USING MULTIPLE REGRESSION ANALYSIS}

\section{Janaina L.L. Pereira}

An accurate reservoir description is very important in reservoir evaluation, and permeability prediction is the key for a successful characterization.

However, despite its importance, obtaining permeability values through the reservoir is not a trivial task. It is costly and time-consuming.

Many are the techniques available in the literature, involving correlations between core and log data that provide means to obtain permeability.

The present work describes how to predict permeability through the statistical analysis multiple regression having log data and limited core data, making it possible to expand the prediction to uncored wells. It also takes into consideration the attributes of flow unit analysis of the field, as a means to ascertain better understanding between reservoir properties and geological variations in the reservoir rock. 


\section{ACKNOWLEDGEMENTS}

I would like to express my gratitude to my academic advisor, Dr. Khashayar Aminian, who has always offered me his support and guidance during the past two years of my graduate program. Thank you very much for the opportunity you gave me. Your help is much appreciated.

I would also like to extend my appreciation to my committee members Dr. Sam Ameri and Dr. Daniel Della-Giustina. Thank you very much for your support.

Next, I wish to express my sincere gratitude to Dr. Shahab Mohaghegh, for his friendship, guidance and valuable contributions during every step of this work.

I would also like to thank Ms. Beverly Matheny for her willingness to help me in basically anything I needed in the department during the past two years.

I could not finish without telling my friend and coworker Anangela Garcia how much I appreciate all her help.

Sincere gratitude and appreciation go also to my mom and brother, Eliana and Paulo Henrique. They are the reason why I am here today. I am looking forward to being with you both.

Lastly, I would like to express my sincere appreciation to my sister and best friend Sahar Khatib (Mimo), for all her encouragement, support, guidance and love. Mimo, your belief in me is what makes me always want to go further and further. Thank you, habibe. 
ABSTRACT

ACKNOWLEDGMENTS

TABLE OF CONTENTS iv

LIST OF TABLES vi

LIST OF FIGURES vii

CHAPTER 1. INTRODUCTION

1.1 Problem Statement 2

1.2 Significance of the Study 2

CHAPTER 2. BACKGROUND AND THEORY

2.1 Determination of Permeability 3

2.1a Pore Level 5

2.1b Core / Field Level 6

2.2 Multiple Regression Analysis $\quad 8$

$\begin{array}{ll}2.3 \text { Flow Units } & 10\end{array}$

CHAPTER 3. OBJECTIVES AND METHODOLOGY

3.1 Field Description $\quad 12$

3.2 Development History 14

3.3 Data Acquisition 16

$\begin{array}{ll}\text { 3.3.1 Core Data } & 18\end{array}$

$\begin{array}{ll}\text { 3.3.2 Log Data } & 18\end{array}$

3.4 Multiple Regression Model 18 
3.4.2 Individual Combinations Used for the Regression - Part 1

3.4.3 Flow Units - Part 2

3.4.4 Assessment of Permeability Obtained Through MRA - Part 3

CHAPTER 4. RESULTS AND DISCUSSIONS

4.1 Analysis of Single Wells

4.1.1 Flow Unit Analysis (Single Wells)

4.2.1 Results of Analyses for Combined Wells P. 11 and B.18 


\section{LIST OF TABLES}

Page

Table 2.1 Permeability Correlations Developed based on the Pore and Grain Properties

Table 3.1 Core Analysis, Stringtown Oilfield

Table 4.1 Coefficiente of Determination $\mathrm{R}^{2}$ for Single Well Regression Analysis

Table 4.2 Individual Contribution for the Predicted Permeability for Well P.9

Table 4.3 Coefficients of Determination for Single Wells Using Flow Units

Table 4.4 Coefficients of Determination $\mathrm{R}^{2}$ for Multiwell Analysis

33

Table 4.5 Coefficients of Determination $\mathrm{R}^{2}$ for Mutiwells Using Flow Units

Table A-1. Geophysical Information from Cored Well P. Horner 11

Table A-2. Geophysical Information from Cored Well P. Horner 9

Table A-3. Geophysical Information from Cored Well Ball 18

Table A-4. Geophysical Information from Cored Well Ball 19

Table A-5. Geophysical Information from Cored Well Thompson 8 


\section{LIST OF FIGURES}

Page

Figure 2.1 Schematic Diagram of a Neural Network with One Hidden Layer

Figure 3.1 Jacksonburgh- Stringtown Field

Figure 3.2 Stratigraphic Column Showing Gordon Sandstones

Figure 3.3 Daily Oil Production for Stringtown Field

Figure 3.4 Cumulative Oil Production for Stringtown Field

Figure 3.5 Location of Wells in Stringtown Field

Figure 3.6 Plot of Density vs Permeability for Well B.18

Figure 3.7 Plot of Density vs Logarithm of Permeability for Well B.18

Figure 3.8a Diagram Involving the 7 Cases of Regressions for Wells P.11 and P.9

Figure 3.8b Diagram Involving the 7 Cases of Regressions for Wells P.11+ B.18+B.19

Figure 4.1 Comparison of the Measured Permeability and Predicted Permeability For P.9

Figure 4.2 Comparison of the Measured Permeability and Predicted Permeability Foor T.8

Figure 4.3a Comparison of Measured Permeability and Predicted Permeability Using Flow Unit 1 for P.9

Figure 4.3b Comparison of Measured Permeability and Predicted Permeability Using Flow Unit 2 for P. 9

Figure 4.4 Permeability Distribution for Wells P.11 and B.18 
Figure 4.5a Permeability Distribution for Wells P.11/ B. 18 Using F.U.1

Figure 4.5b Permeability Distribution for Wells P.11/ B. 18 Using F.U.2

Figure 4.6 Comparison between Predicted Permeability Using 4 Wells and the Permeability Predicted for a Fifth Well

Figure 4.7 Comparison between Predicted Permeability Using 3 Wells and the Permeability Predicted for a Fourth Well

Figure B-1. Multiple Regression Results for P. Horner 11

$(\mathrm{D}+\mathrm{DS}+\mathrm{GR}+\mathrm{GS})$

Figure B-2. Multiple Regression Results for P. Horner 11 (G + GR)

Figure B-3. Multiple Regression Results for P. Horner 11 (GR + Porosity)

Figure B-4. Multiple Regression Results for P. Horner 11 (D + DS)

Figure B-5. Multiple Regression Results for P. Horner 11 (D+GR + GS)

Figure B-6. Multiple Regression Results for P. Horner 11 (D + DS + GR)

Figure B-7. Multiple Regression Results for P. Horner 11 (run D + DS + GS)

Figure B-8. Multiple Regression Results for P. Horner 11 Using Flow Units (Run D + DS + GR + GS)

Figure B-9. Multiple Regression Results for P. Horner 11 Using Flow Units (Run D + GR)

Figure B-10. Multiple Regression Results for P. Horner 11 Using Flow Units 
(Run D + DS)

Figure B-11. Multiple Regression Results for P. Horner 11 Using Flow Units

$$
\text { (Run D + GR + GS) }
$$

Figure B-12. Multiple Regression Results for P. Horner 11 Using Flow Units (Run D + DS + GR)

Figure B-13. Multiple Regression Results for P. Horner 11 Using Flow Units (Run D + DS +GS)

Figure B-14. Multiple Regression Results for Ball 18 (run D + DS + GR + GS)

Figure B-15. Multiple Regression Results for Ball 18 (run D + GR)

Figure B-16. Multiple Regression Results for Ball 18 (run D + GR)

Figure B-17. Multiple Regression Results for Ball 18 (run D + DS)

Figure B-18. Multiple Regression Results for Ball 18 (run D + GR + GS)

Figure B-19. Multiple Regression Results for Ball 18 (run D + DS + GR)

Figure B-20. Multiple Regression Results for Ball 18 (run D + DS + GS)

Figure B-22. Multiple Regression Results for Ball 18 Using Flow Units (D + DS) 58 Figure B-23. Multiple Regression Results for Ball 18 Using Flow Units 
$(D+G R+G S)$

Figure B-24. Multiple Regression Results for Ball 18 Using Flow Units $(\mathrm{D}+\mathrm{DS}+\mathrm{GR})$

Figure B-25. Multiple Regression Results for Ball 18 Using Flow Units $(\mathrm{D}+\mathrm{DS}+\mathrm{GS})$

Figure B-26. Multiple Regression Results for Ball 19 (run D + DS + GR + GS)

Figure B-27. Multiple Regression Results for Ball 19 (run D + GR)

Figure B-28. Multiple Regression Results for Ball 19 (run D + DS)

Figure B-29. Multiple Regression Results for Ball 19 (run D + GR + GS)

Figure B-30. Multiple Regression Results for Ball 19 (run D + DS + GR)

Figure B-31. Multiple Regression Results for Ball 19 (run D + DS + GS)

Figure B-32. Multiple Regression Results for Ball 19 Using Flow Units $(\mathrm{D}+\mathrm{DS}+\mathrm{GR}+\mathrm{GS})$

Figure B-33. Multiple Regression Results for Ball 19 Using Flow Units (D + GR)

Figure B-34. Multiple Regression Results for Ball 19 Using Flow Units (D + DS)

Figure B-35. Multiple Regression Results for Ball 19 Using Flow Units $(\mathrm{D}+\mathrm{GR}+\mathrm{GS})$

Figure B-36. Multiple Regression Results for Ball 19 Using Flow Units 


$$
(\mathrm{D}+\mathrm{DS}+\mathrm{GR})
$$

Figure B-37. Multiple Regression Results for Ball 19 Using Flow Units (D + DS + GS)

Figure B-38. Multiple Regression Results for Thompson 8

$(\mathrm{D}+\mathrm{DS}+\mathrm{GR}+\mathrm{GS})$

Figure B-39. Multiple Regression Results for Thompson 8 (D + GR)

Figure B-40. Multiple Regression Results for Thompson 8 (GR + Porosity)

Figure B-41. Multiple Regression Results for Thompson 8 (D + DS)

Figure B-42. Multiple Regression Results for Thompson 8 (D + GR + GS)

Figure B-43. Multiple Regression Results for Thompson 8 (D + DS + GR)

Figure B-44. Multiple Regression Results for Thompson 8 (D + DS + GS)

Figure C-1. Multiple Regression Results for P11 + B18 (D + GR)

Figure C-2. Multiple Regression Results for P11 + B18 (D + DS)

Figure C-3. Multiple Regression Results for P11 + B18 (D + GR + GS)

Figure C-4. Multiple Regression Results for P11 + B18 (D + DS + GR)

Figure C-5. Multiple Regression Results for P11 + B18 (D + DS + GS)

Figure C-6. Multiple Regression Results for P11 + B18 + B19 (D + GR + DS + GS) 72

Figure C-7. Multiple Regression Results for P11 + B18 + B19 (D + GR) 
Figure C-8. Multiple Regression Results for P11 + B18 + B19 (GR + Porosity)

Figure C-9. Multiple Regression Results for P11 + B18 + B19 (D + DS)

Figure C-10. Multiple Regression Results for P11 + B18 + B19 (D + GR +GS)

Figure C-11. Multiple Regression Results for P11 + B18 + B19 (D + DS +GR)

Figure C-12. Multiple Regression Results for P11 + B18 + B19 (D + DS +GS)

Figure C-14. Multiple Regression Results for P11 + B18 + B19 + T 8 (D + GR)

Figure C-15. Multiple Regression Results for P11 + B18 + B19 + T 8 (D + DS)

Figure C-16. Multiple Regression Results for P11 + B18 + B19 + T 8 (D + GR + GS)

Figure C-17. Multiple Regression Results for P11 + B18 + B19 + T 8 (D + DS + GR)

Figure C-18. Multiple Regression Results for P11 + B18 + B19 + T 8 (D + DS + GS)

Figure C-19. Multiple Regression Results for P11 + P9 (D + DS + GR + GS)

Figure C-20. Multiple Regression Results for P11 + P9 (D + GR)

Figure C-21. Multiple Regression Results for P11 + P9 (GR + Porosity)

Figure C-22. Multiple Regression Results for P11 + P9 (D + DS)

Figure C-23. Multiple Regression Results for P11 + P9 (D + GR + GS) 78

Figure C-24. Multiple Regression Results for P11 + P9 (D + GS + GR) 
Figure C-25. Multiple Regression Results for P11 + P9 (D + GS + GS)

Figure C-26. Multiple Regression Results for P11 + P9 + B18 (D + DS + GR + GS)

Figure C-27. Multiple Regression Results for P11 + P9 + B18 (D + GR)

Figure C-28. Multiple Regression Results for P11 + P9 + B18 (GR + Porosity)

Figure C-29. Multiple Regression Results for P11 + P9 + B18 (D + DS)

Figure C-30. Multiple Regression Results for P11 + P9 + B18 (D + GR + GS)

Figure C-31. Multiple Regression Results for P11 + P9 + B18 (D + DS + GR)

Figure C-32. Multiple Regression Results for P11 + P9 + B18 (D + DS + GS) 


\section{CHAPTER ONE}

\section{INTRODUCTION}

Obtaining reliable information about reservoir properties is essential in reservoir characterization. The latter involves gathering records on petrophysical parameters which will, ultimately, offer more details on the behavior of the flow of fluids within the formation. Among these parameters, permeability is one of the most important, and its knowledge is decisive in developing an effective reservoir description. However, predicting permeability is not a trivial problem, due either to the unavailability of sufficient data or to economical issues involving loss of production in well test data collection. Consequently, searching for reliable alternative procedures is essential in order to overcome the problem.

One of the techniques used for predicting permeability is to develop a relationship between permeability and porosity. Significant changes in reservoir properties may take place within a given sedimentary body of the reservoir, leading to the so-called flow units $^{1}$. Flow units are regions in the sedimentary sequence that control the flow of fluids within the reservoir. The flow units defined have minimum variation of permeability internally and a maximum variation among zones ${ }^{2}$. The study of flow units as a potential means for better understanding the variations of permeability has been vastly emphasized in the literature.

Another technique also used in predictions of permeability is the Multiple Regression Analysis. Through this statistical method, which associates a dependent variable - here, permeability - to independent variables - here, well log data - it is possible to get to fairly close and acceptable prediction of permeability. Previous studies have established a general procedure for permeability prediction by multiple variation regression ${ }^{3}$. 
The application of Artificial Neural Networks was also investigated in the past as another means of permeability prediction, presenting very good results. However, those studies do not take into account the variances in porosity and grain pore that are characteristic within individual flow strata, which may favor, in fact, results that do not really represent the reality of flow fluids.

\subsection{Statement of the Problem}

It is well known among the petroleum community that in order to have a complete and accurate reservoir characterization, it is essential to have means to obtain values of permeability for the particular field in study. In spite of being almost impossible and highly costly to have core analysis for all the wells present in the field, the necessity of permeability data is not reduced. In fact, new methodologies are often been proposed with the objective of optimize time, results and reduce costs related to permeability measures.

Having the Stringtown field, located in West Virginia, as the subject of this study, it will be shown how Multiple Regression Analysis and the use of flow units can be used in order to predict permeability values accurately and comparable to those determined by core analysis. Ultimately, the results can be applied to adjacent wells without core data.

\subsection{Significance of the Study}

Previous studies involving permeability predictions have been done using Single Regression Analysis, Artificial Neural Networks and the concept of Flow Units. Even though successful results were obtained from those techniques, it is essential to always look for alternative ways to improve the techniques involving permeability due to its importance in any reliable reservoir characterization.

The present study aims to obtain extra information and maybe improved results when using Multiple Regression Analysis based on several log data, and also try to better understand the relationship between permeability and other reservoir parameters, which could not have been established prior with ANN analysis. 


\section{CHAPTER TWO}

\section{BACKGROUND AND THEORY}

Defined as the measure of the ease with which a fluid flows through a porous medium, permeability is undoubtedly, a critical aspect to be accounted for in any reservoir description. Permeability data can be obtained in laboratories (core analysis), in reservoirs (pressure transient tests) and through well logs. However, the conventional methods of prediction of permeability are either time-consuming or they involve loss of productivity, becoming economically unfavorable. Therefore, scientifically sound and geologically compatible procedures must be sought to allow for a reliable calculation of permeability distribution in wells ${ }^{4}$.

\subsection{Determination of Permeability}

There are various techniques used to estimate permeability in the literature. A brief summary of the most relevant methods will be given in this section.

Estimation of permeability from rock properties can be categorized as:

\section{Pore Level}

2. Core/field Level

Both techniques relate permeability to porosity ${ }^{5}$. Many different correlations have been proposed between the two properties. These equations were suitably applicable for synthetic porous medium. Table 2.1 below covers the correlations developed using different pore and grain characteristics. 
Table 2.1 Permeability correlations developed based on the pore and grain properties.

\begin{tabular}{|c|c|c|}
\hline Model & Equation & Variables \\
\hline KC (1938) & $k=\frac{\varphi^{3}}{\left[f \tau A_{g}^{2}(1-\varphi)^{2}\right]}$ & Specific surface area, tortuosity. \\
\hline KC (Modified after Archie) & $k=\frac{r_{\text {eff }}^{2}}{8 F}$ & $\begin{array}{l}\text { Effective pore radius, formation } \\
\text { factor }\end{array}$ \\
\hline Krumbein and Monk(1943) & $k=760 D_{g}^{2} \exp \left(-1.3 \sigma_{D}\right)$ & $\begin{array}{c}\text { Geometric mean of grain } \\
\text { diameter, standard deviation of } \\
\text { grain diameter }\end{array}$ \\
\hline Berg (1970) & $k=80.8 \phi^{5.1} D^{2} e^{-1.385 p}$ & Median grain diameter \\
\hline Van Baaren (1979) & $k=10 D_{d}^{2} \phi^{3.64+m} C^{-3.64}$ & Dominant Grain Size \\
\hline Timur (1968) & $k=0.136 \frac{\phi^{4.4}}{S_{w i r}^{2}}$ & Irreducible Water Saturation \\
\hline Coates and Denoo(1981) & $k=\left[\frac{100 \phi_{e}^{2}\left(1-S_{w i}\right)}{S_{w i}}\right]^{2}$ & Irreducible Water Saturation \\
\hline Sen et al.(1990) & $k=10^{-0.1}\left(\phi^{m} T_{1}\right)^{2.15}$ & $\begin{array}{l}\text { Volume }\left(\mathrm{V}_{\mathrm{p}}\right) \text { to surface }(\mathrm{S}) \text { ratio, } \\
\text { exchange cation molarity }\left(\mathrm{Q}_{\mathrm{v}}\right) \text {, } \\
\text { proton NMR decay constant }\left(\mathrm{T}_{1}\right)\end{array}$ \\
\hline \multirow[t]{2}{*}{ Swanson (1981) } & $k=a\left[\frac{S_{b}}{P_{c}}\right]_{\max }^{c}$ & $\begin{array}{c}\text { Maximum Capillary pressure and } \\
\text { saturation percent }\end{array}$ \\
\hline & $k=4.6 \phi^{4} T_{2 l m}^{2}$ & $\begin{array}{l}\text { Logarithmic mean of the } \\
\text { distribution, } T_{2}, N M R \text { porosity }\end{array}$ \\
\hline Quintero et al. (1999) & $k=C p f 4.6 \phi^{4} T_{2 l m}^{2}$ & $\begin{array}{l}\text { Width of } \mathrm{T}_{2} \text { distribution at a } \\
\text { specific depth interval }\end{array}$ \\
\hline Amaefule et al. (1993) & $k=1014(F Z I)^{2}\left[\frac{\phi_{e}^{3}}{\left(1-\phi_{e}\right)^{2}}\right]$ & Reservoir quality index \\
\hline Ohen et al.(1995) & $k=1014(F Z I)^{2}\left[\frac{\phi_{e}^{3}}{\left(1-\phi_{e}\right)^{2}}\right]$ & $F Z I=\left(\frac{b(1-N M R S)}{1+a(N M R S-1}\right)^{1 / c}$ \\
\hline
\end{tabular}


After careful analysis of the methods presented above, it was decided that a detailed description of all of them would be out of the scope of this work. A brief description will be given for some of them.

\section{1a Pore Level}

Starting with the pioneer works of Kozeny and Carman, in which they established a relationship between permeability and porosity using the concept introduced by Darcy’s Law (equation 1).

$$
k=\frac{r^{2}}{8} \phi \ldots \ldots \ldots \ldots \ldots \ldots
$$

Their correlation introduces a new constant which accounts for tortuosity, and varies from 5 to 100 for most reservoirs. The equation proposed is shown below:

$$
k=\frac{\phi_{e}^{3}}{\left(1-\phi_{e}\right)^{2}} * \frac{1}{f_{s} \tau^{2} s_{g v}^{2}} \ldots \ldots \ldots \ldots \ldots \ldots
$$

Studies that consider the rock properties such as irreducible water saturation, shale content, grain size and grain size distribution, can also be classified as pore scale models.

Maghshool at al, introduced his equation making use of the Flow Zone Indicator concept. His studies associate fundamentals of geology and physics of flow at pore scale, by attributing the nature of interdependence between permeability and porosity to geological variations in the rock.

The following equation was proposed: 


$$
k=1014(f z i)^{2} * \frac{\phi_{e}^{3}}{\left(1-\phi_{e}\right)^{2}}
$$

\section{1 b Core / Field Level}

This category includes techniques involving well log data rather than rock properties. Multiple Regression Analysis (MRA) and Artificial Neural Networks (ANN) are part of this group, as well as Single Regression Analysis. A short description of ANN will be given here, leaving a separate section for MRA.

Artificial Neural Networks are general-purpose systems that attempt to achieve good performance by dense interconnection of simple computational elements ${ }^{5}$. It is expected that ANN will succeed in solving complex problems because it utilizes similar methods used by millions of neurons in the brain to solve everyday problems. This type of problem solving method has shown great successes in pattern recongnition ${ }^{2}$.

The solution to the problems is 'learned' by supplying examples of previously solved problems to the networks. Once the network learned how to solve the problem, it is said to be 'trained'. The term 'supervised network' is used for this kind of training. There are plenty of types of ANNs, out of which Probabilistic Neural Network (PNN), General Regression Neural Network (GRNN), Backpropagation Neural Network (BNN) and Radial Neural Networks (RNN) are the most common ones.

Followed are the components of a general neural network:

- Neurons;

- Connections;

- Weights;

- Activation Function;

Figure 2.1 shows the layout for a general neural network. 


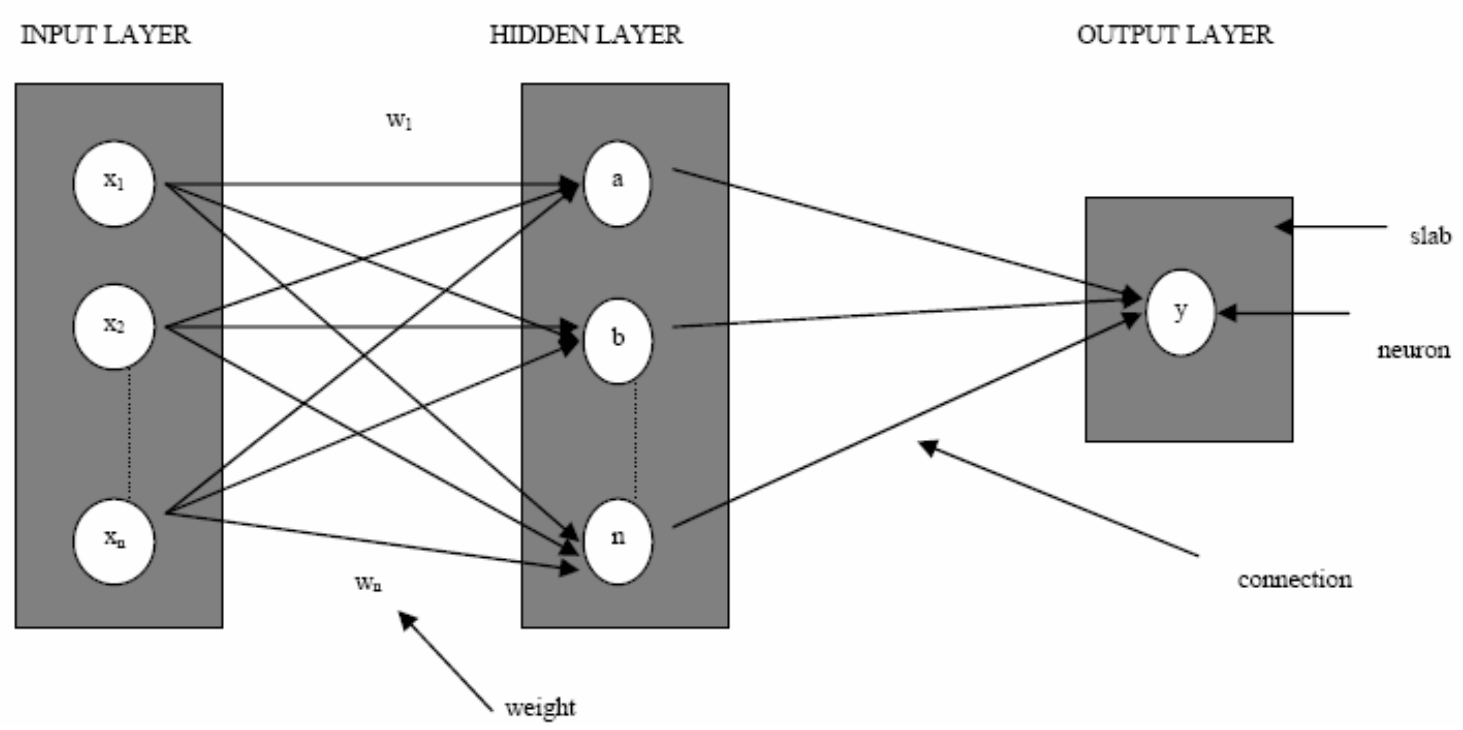

Figure 2.1 Schematic Diagram of a Neural Network with One Hidden Layer.

The training process ${ }^{6}$ involves the weighting and passing along of the input values of the first layer to the hidden layer. Outputs will be produced by the neurons in the hidden layer through the activation function with the sum of the weighted input values. The resulting outputs are then weighted by the connection between the hidden and the output layer. The desired results are then generalized in the output layer.

Previous studies on permeability predictions have proven to be successful when Artificial Neural Networks are used. Oyerokun at al showed that by using pre-specified test sets in training the network, improved results of permeability and other petrophysical parameters could be predicted. His approach was also applied to predict the permeabilities in the uncored wells located in the field. 


\subsection{Multiple Regression Analysis}

In characterizing a reservoir, permeability presents itself as the most difficult property to measure and / or estimate. Nevertheless, this difficulty does not free it from playing a major role in reservoir characterization. Therefore, proposing new methodologies that can prove themselves to be scientifically accepted and economically feasible is a key initiative in reservoir characterization.

The regression approach uses statistics in order to predict a conditional average, or expectation of permeability. The general purpose of multiple regressions is to learn more about the relationship between several independent or predictor variables and a dependent or criterion variable. It can be understood as being an extension of the regression analysis using though more independent variables. The regression line can no longer be visualized in the two dimensional space as it happens in a single regression, but it can be computed just as easily. In general then, multiple regression procedures will estimate a linear equation of the form:

$$
\mathrm{Y}=\mathrm{a}+\mathrm{b}_{1} * \mathrm{X}_{1}+\mathrm{b}_{2} * \mathrm{X}_{2}+\ldots+\mathrm{b}_{\mathrm{n}} * \mathrm{X}_{\mathrm{n}}
$$

In the equation above, the regression coefficients or ' $b$ terms' represent the independent contributions of each independent variable to the prediction of the dependent variable. The regression line expresses the best prediction of the dependent variable $(Y)$, given the independent variables $(X)$. However, there is usually substantial variation of the observed points around the fitted regression line. The deviation of a particular point from the regression line (its predicted value) is called the residual value.

The smaller the variability of the residual values around the regression line relative to the overall variability, the better is our prediction. For example, if there is no relationship between the $X$ and $Y$ variables, then the ratio of the residual variability of the $Y$ variable to the original variance is equal to 1.0. If $X$ and $Y$ are perfectly related then there is no residual variance and the ratio of variance would be 0.0 . In most cases, the ratio would 
fall somewhere between these extremes, that is, between 0.0 and 1.0. 1.0 minus this ratio is referred to as $R$-square or the coefficient of determination.

Customarily, the degree to which two or more predictors (independent or $X$ variables) are related to the dependent $(Y)$ variable is expressed in the correlation coefficient $R$, which is the square root of $R$-square. In multiple regressions, $R$ can assume values between 0 and 1. To interpret the direction of the relationship between variables, one looks at the signs (plus or minus) of the regression or $B$ coefficients. If a $B$ coefficient is positive, then the relationship of this variable with the dependent variable is positive; if the $B$ coefficient is negative then the relationship is negative. Of course, if the $B$ coefficient is equal to 0 then there is no relationship between the variables.

Microsoft Excell was used in performing all the multiple regression analyses, which involved the so called function LINEST.

The work is based on linear regression analysis that provides an array that best describes the line for the data provided.

After performing the analysis, the following regression statistics are returned:

\begin{tabular}{|c|c|c|c|c|c|c|}
\hline & $\mathrm{A}$ & $\mathrm{B}$ & $\mathrm{C}$ & $\mathrm{D}$ & $\mathrm{E}$ & $\mathrm{F}$ \\
\hline 1 & $\mathrm{~m}_{\mathrm{n}}$ & $\mathrm{m}_{\mathrm{n}-1}$ & $\cdots$ & $\mathrm{m}_{2}$ & $\mathrm{~m}_{1}$ & $\mathrm{~b}$ \\
\hline 2 & $\mathrm{~S}_{\mathrm{en}}$ & $\mathrm{S}_{\mathrm{en}-1}$ & $\cdots$ & $\mathrm{S}_{\mathrm{e} 2}$ & $\mathrm{~S}_{\mathrm{e} 1}$ & $\mathrm{~S}_{\mathrm{eb}}$ \\
\hline 3 & $\mathrm{r}_{2}$ & $\mathrm{~S}_{\mathrm{ev}}$ & & & & \\
\hline 4 & $\mathrm{~F}$ & $\mathrm{~d}_{\mathrm{f}}$ & & & & \\
\hline 5 & $\mathrm{SS}_{\text {reg }}$ & $\mathrm{SS}_{\text {resid }}$ & & & & \\
\hline
\end{tabular}

Where: 


\section{Statistic}

$\mathrm{S}_{\mathrm{e} 1}, \mathrm{~S}_{\mathrm{e} 2}, \ldots, \mathrm{S}_{\mathrm{en}} \quad$ The standard error values for the coefficients $\mathrm{m} 1, \mathrm{~m} 2, \ldots, \mathrm{mn}$.

$\mathrm{S}_{\mathrm{eb}} \quad$ The standard error value for the constant $\mathrm{b}$ (seb = \#N/A when const is FALSE).

$\mathrm{r}_{2} \quad$ The coefficient of determination. Compares estimated and actual $\mathrm{y}$-values, and ranges in value from 0 to 1 . If it is 1 , there is a perfect correlation in the sample - there is no difference between the estimated $y$-value and the actual $y$-value. At the other extreme, if the coefficient of determination is 0 , the regression equation is not helpful in predicting a y-value. For information about how r2 is calculated, see "Remarks" later in this topic.

$\mathrm{S}_{\mathrm{ey}} \quad$ The standard error for the y estimate.

F The F statistic, or the F-observed value. Use the F statistic to determine whether the observed relationship between the dependent and independent variables occurs by chance.

$\mathrm{d}_{\mathrm{f}} \quad$ The degrees of freedom. Use the degrees of freedom to help you find Fcritical values in a statistical table.

SS $\quad$ The regression sum of squares.

SS resid The residual sum of squares.

\subsection{Flow Units}

Flow units are regions in the sedimentary sequence that control the flow of fluids within the reservoir. These sedimentary sequences are identified by the relationship they present between porosity and permeability based on lithology of the field.

Because of that characteristic, flow units have been vastly studied as a potential tool in permeability prediction, and they can be obtained either from core or log data. It is a very useful and realistic approach because it incorporates a variety of geological and petrophysical characteristics of the reservoir. Through identification of the units for single wells it is possible to extend the analysis, and subsequent results, to adjacent wells searching for continuity of strata.

Mustafa at al in his work showed that determination of flow units was possible using a statistical method. Statistical technique is general and can be used to correlate any 
reservoir property or related data, such as logarithmic permeability and log density. It is assumed that permeability data is available for adjacent wells at different depths.

After individual wells are divided into different flow units, calculation is done for each kind of data individually that has been used to characterize the reservoir. Using a linear relationship between density, obtained from logs, and logarithm of core permeability, permeability was predicted for wells without core data. By using those values, the statistical zonation technique was extended to wells also without core data. The accuracy of the methodology is verified by comparing the original flow units with the predicted flow units in the wells with core data. 


\section{CHAPTER THREE}

\section{OBJECTIVES AND METHODOLOGY}

The main objectives of the present work are:

- To develop a relationship between permeability and well log data using multiple regression analysis;

- To use flow units definition in order to enhance the relationship between core and log data;

- To predict permeability using an optimum relationship derived from the multiple regression analysis.

The methodology used to develop the present study was outlined as followed:

1. Field Selection/description;

2. Data Collection;

3. Multiple Regression Analysis;

- Wells not divided into flow units;

- Wells divided into flow units.

4. Check for accuracy of results obtained.

\subsection{Field Description}

Located in the northwestern part of West Virginia, in Tyler, Wetzel and Doddridge Counties (Fig. 3.1), the Stringtown field is the study subject for this research ${ }^{7}$. The producing horizon in this field is the Upper Devonian Gordon Sandstone. The field was discovered in 1895, and shows a pay zone in the range of 10 to $25 \mathrm{ft}$ in thickness, starting at a depth of 2950 feet. It has a productive area of approximately 8900 acres, presenting oil with a viscosity of $3.5 \mathrm{cp}$ at atmospheric pressure and $75^{\circ} \mathrm{F}$, gravity of $44^{\circ} \mathrm{API}$ at 60 ${ }^{\circ} \mathrm{F}$. Permeability can range from less than $5 \mathrm{mD}$ to values up to $250 \mathrm{mD}$. 


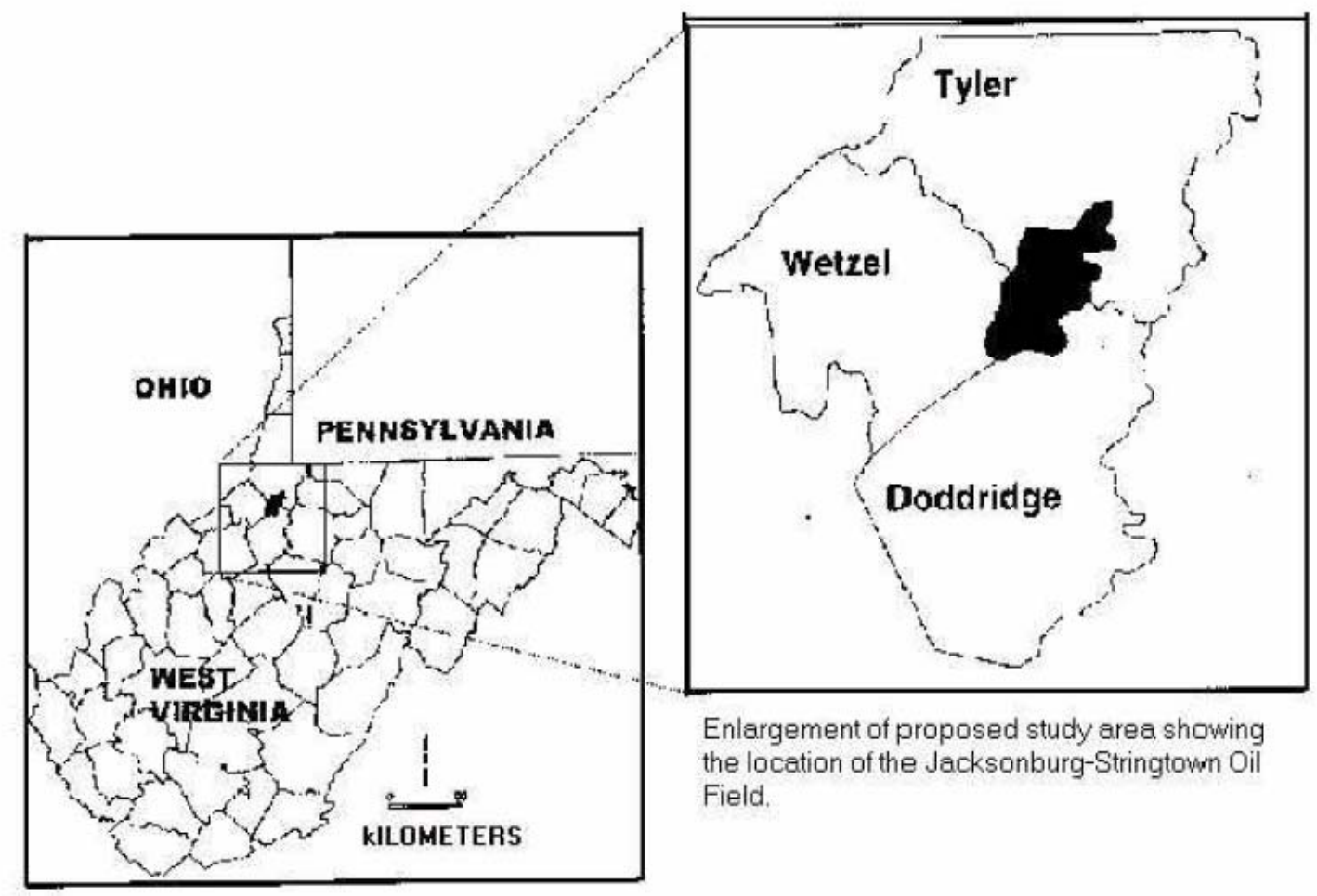

Figure 3.1 Jacksonburgh-Stringtown Field

Gordon sandstones are part of thick, Upper Devonian sedimentary section. Sandstones of this interval are known by informal terminology developed by drillers exploring for oil and gas during the 1800s. "Gantz", "Bayard”, “Gordon”, and "Fifty-Foot” are samples of informal names used. In West Virginia, the Upper Devonian sedimentary section is referred to as the Hampshire Formation (Fig.3.2). Within the field, the Gordon interval consists of productive sandstones and thin inter-bedded shales and conglomerates. 


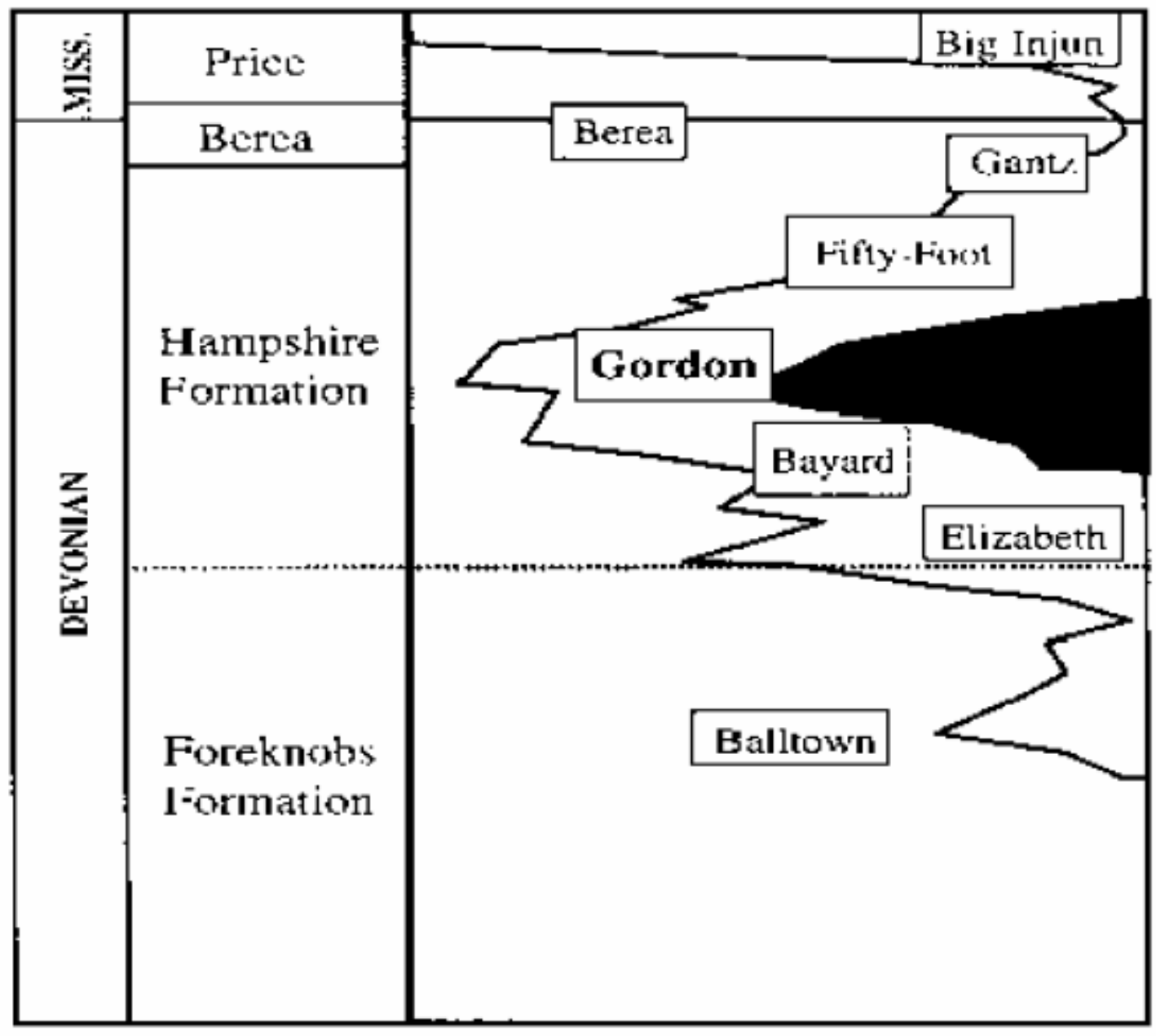

Figure 3.2 Stratigraphic Column Showing Gordon Sandstones

\subsection{Development History}

Productive development started in early 1980s but with very low recovery. Over 500 wells were drilled in the field between 1897 and 1901, with spacing of 13 acres per well. However, most of those wells were plugged by 1910. Initial production was 72 barrels of oil per day (BOPD), with a range of 0 to 300 BOPD. The field experienced gas injection starting in 1934, with an averaged recovery of 154 BOPA over a limited portion of the filed. 
A waterflood recovery started in 1990, having ever since, more than 100 new wells drilled for water injection and 40 wells drilled for production. The full-scale waterflood was installed after a successful pilot waterflood was experienced in 1981, in which the averaged recovery was 1300 BOPA in 4 years.

The daily and cumulative oil productions from 1897 to 1991 are shown in Figures 3.3 and 3.4, respectively.

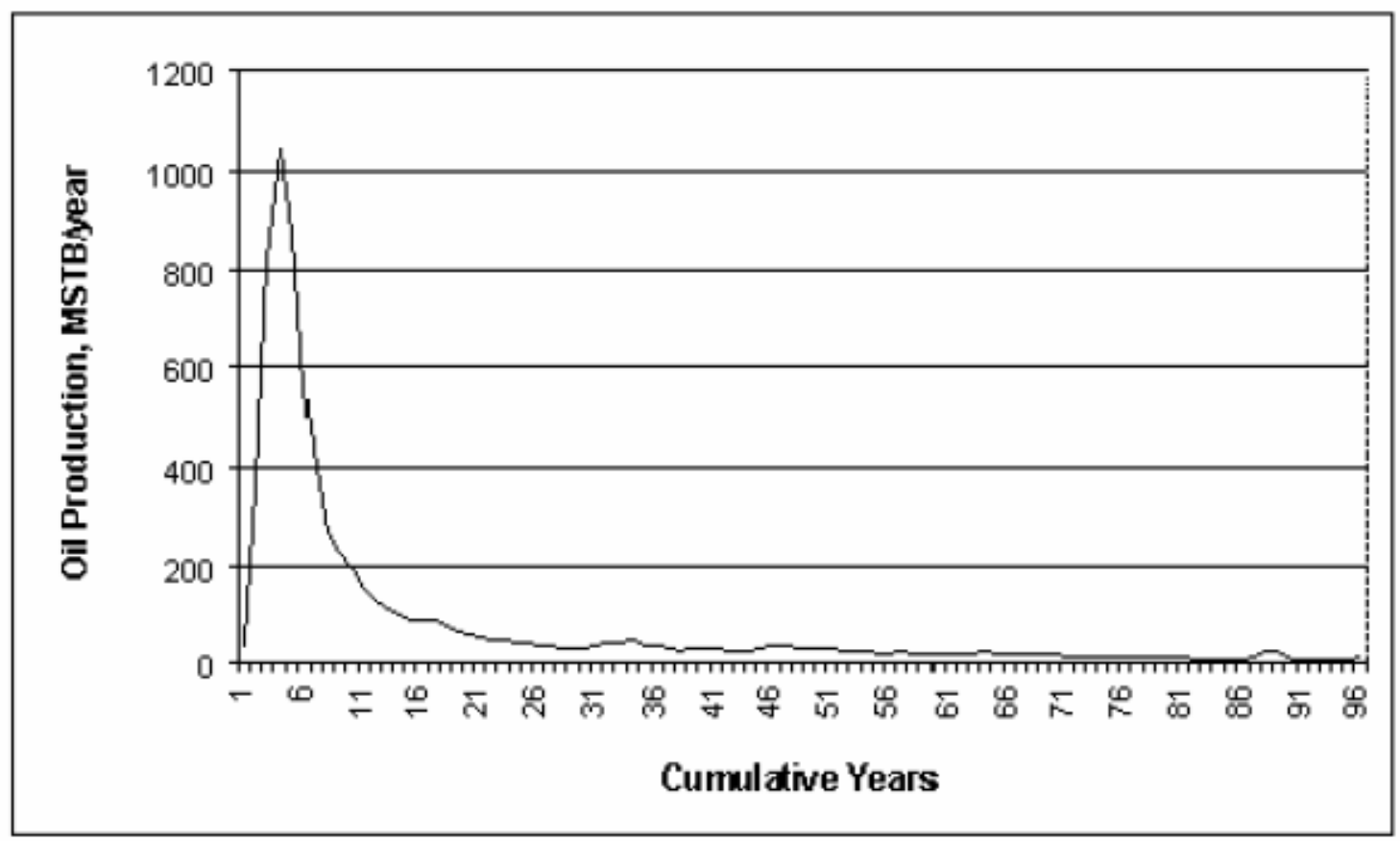

Figure 3.3 Daily Oil Production for Stringtown Field 


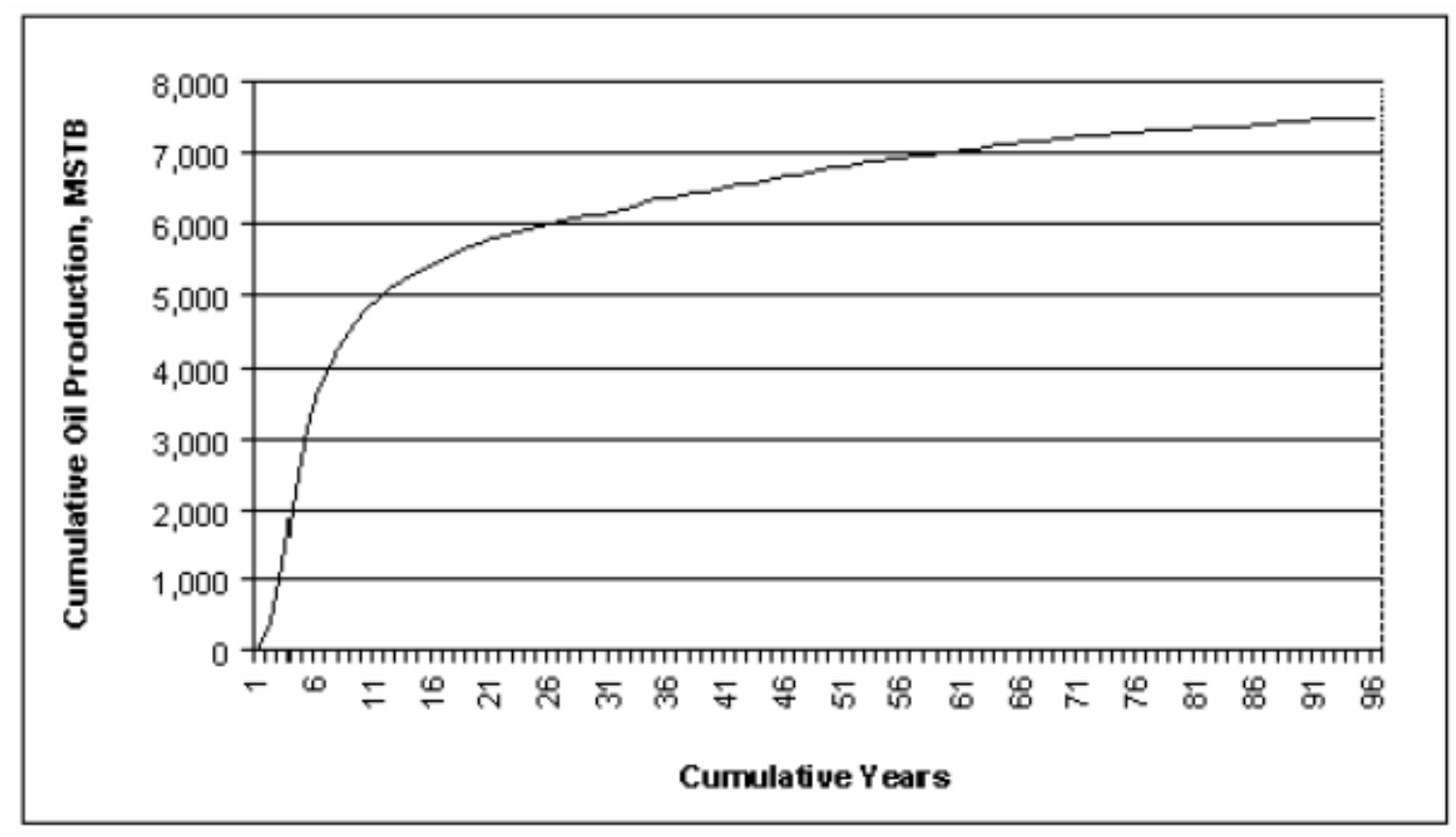

Figure 3.4 Cumulative Oil Production for Stringtown Field

\subsection{Data Acquisition}

The data used in this research was retrieved from "Reservoir Characterization of Upper Devonian Gordon Sandstone” project. The latter was a cooperation effort between Petroleum and Natural Gas Engineering and West Virginia Geologic and Economic Survey. Data were analyzed from cores and logs, as well as information from geologic interpretation of Gordon sandstone.

\subsubsection{Core Data}

The results of core analysis were made available from six wells located around the field as shown in Figure 3.5 . 


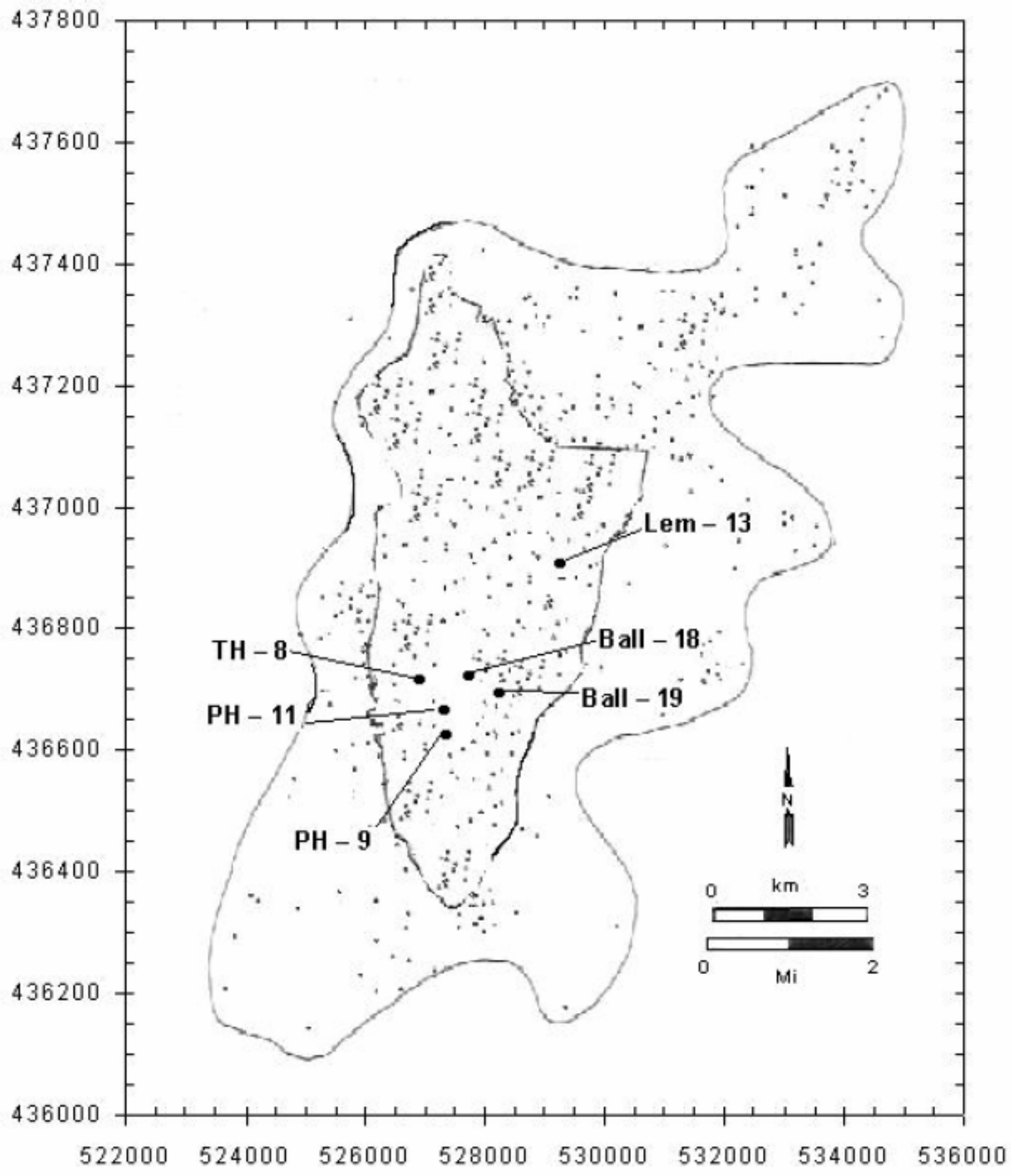

Figure 3.5 Locations of Wells in Stringtown Field

The five wells studied in this project were:
1. T.8
2. P.9
3. P.11
4. B.18 
5. B.19

And table 3.1 shows the measured core permeability for those wells.

Table 3.1 Core Analysis, Stringtown Oilfield

\begin{tabular}{|c|c|c|c|c|c|}
\hline Well & $\begin{array}{c}\text { Cored Interval, } \\
\mathbf{f t}\end{array}$ & Thickness, ft & $\begin{array}{c}\text { Aver. Porosity, } \\
\text { \% }\end{array}$ & \multicolumn{2}{|c|}{ Permeability averages, mD } \\
\hline & & & & Arithmetic & Geometric \\
\hline P. 9 & $2891.5-2907.5$ & 16 & 18.2 & 106 & 57 \\
\hline P.11 & $3083.7-3100.5$ & 16.8 & 18.8 & 72 & 19 \\
\hline T. 8 & $2781.5-2796.5$ & 15 & 12.4 & 6.5 & 0.75 \\
\hline B.18 & $2988.5-3005.5$ & 17 & 14.7 & 52 & 2.7 \\
\hline B .19 & $3086.5-3114.5$ & 28 & 14.9 & 41 & 6.2 \\
\hline
\end{tabular}

\subsubsection{Log Data}

Logs available from the field included Gamma Ray (GR), Density (RHOB), Neutron, Porosity and Induction logs, out of which Gamma Ray and Density were readily available in the studied wells. A group of 115 digitized logs with both Gamma Ray and Density had been subjected to autocorrelation in order to check for accuracy.

\subsection{Multiple Regression Model}

Based on the literature review, there are many techniques available for permeability determination. The selection of a method would depend on parameters such as available data, cost, and the reservoir characteristics. Among the methods discussed earlier, statistical methods are the most practical and reliable for permeability assessment with subsequent determination of flow units. Flow units are very important parameters in describing reservoir flow behavior. The latter are derived from permeability distribution, but as it is well known, it is economically impractical and time-consuming to measure permeability for all the wells drilled at all depths. Therefore, the methodology presented in this paper, will show how to develop a relationship between values from limited core data and four different well log parameters, namely, density, gamma ray, and its 
respective derivatives, using multiple regression. The results can then be used to predict the permeability in wells with available logs.

The first step in the development of a regression model is the selection of the variables.

It is actually possible to use as many predictor variables as one can think of and usually at least a few of them will come out to be significant. However it is not very practical to simply 'plug in' multiple variables that altogether will not show any relationship with the chosen dependent variable.

Some considerations should be given in choosing which parameters would be best used as independent variables, and which one would be best used as the dependent variable. Aspects such as how important a particular variable would influence the analysis in question, or how reliably the values for the variable can be obtained should be studied carefully. It is well known that formation density influences the permeability, and as so, density is chosen to be one of the independent variables in this study. The other chosen variables are Gamma Ray, and derivative values for density and Gamma Ray. The logarithm of permeability is taken as the dependent variable because permeability seems to be best described by a log-normal distribution. This assumption is better understood in the next section. For simplicity and further references, every time the dependent variable is mentioned, it should be understood as the logarithm of permeability.

As it was stated earlier, density has a major impact on permeability, and it seems logical to include density as an independent variable in any study whose objective is to predict reservoir permeability. Figures 3.6 and 3.7 will show more clearly the relationship between the density and permeability as a comparison with density and logarithm of permeability. 


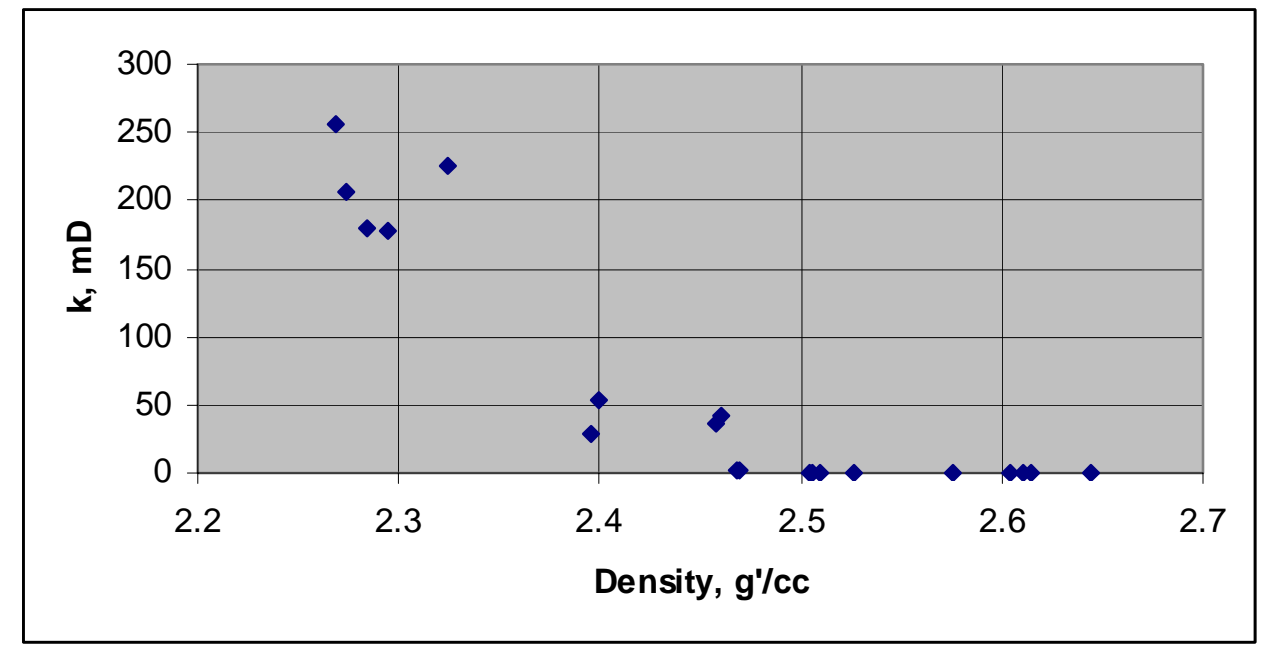

Figure 3.6: Plot of Density vs. Permeability data from well B.18

The lack of linearity between permeability and well log density is visible in the plot.

As a solution to better approach the problem, the use of log permeability was taken, following the equation below:

$$
\mathrm{Y}=\log \mathrm{k}
$$

In order to better assess the new relationship, a new plot was built, now using logarithm of permeability versus well log density for the same well.

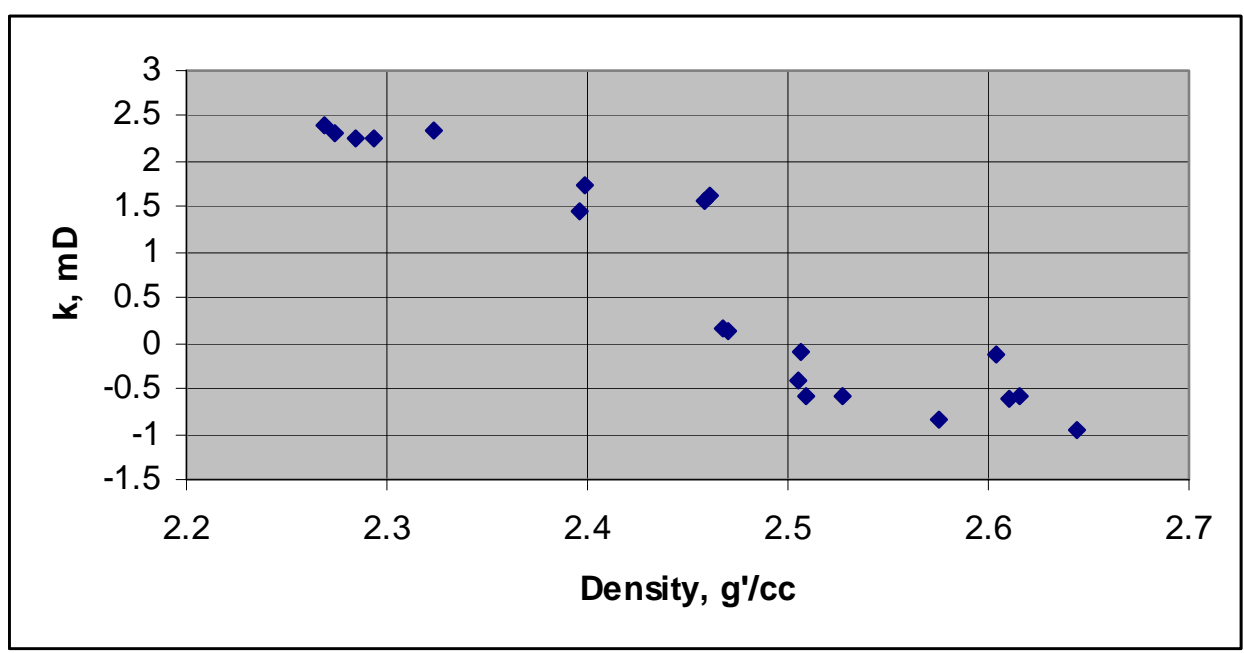

Figure 3.7: Plot of Density vs. Logarithm of Permeability data from well B.18 
As it can be seen in the figure above, there is a much better linearity between logarithm of permeability and density.

\subsubsection{Description of the Combinations Used in the Multiple Regressions}

Altogether 7 combinations between the dependent variable (logarithm of permeability) and the 4 independent variables (Gamma Ray, Density, and its respective derivatives) were used in the study. Each of those combinations was applied to the 5 single wells separately, followed by analysis among the same 7 multiple regressions and a series of 11 different arrangements of the single wells together.

All the previous analyses were then repeated using this time the flow units separately.

\subsubsection{Individual Combinations Used for the Regression - Part 1}

The first step in the work involved applying variations of multiple regressions containing 2 independent variables for a single well. Those arrangements were as follows:

- Gamma Ray + Density (GR + D)

- Gamma Ray + Porosity (GR + P)

- Density + Density Derivative (D + DS)

The regression would return an equation of the type:

$$
\mathbf{y}=\mathbf{m}_{1} * \mathbf{x}_{1}+\mathbf{m}_{2} * \mathbf{x}_{2} \ldots \mathbf{m}_{\mathbf{n}} * \mathbf{x}_{\mathbf{n}}+\mathbf{b}
$$

where the ' $m$ ' terms refer to the regression coefficients and the ' $x$ 's refer to independent variables used in the analysis.

It is important to know that the correlation between the regression coefficients and the variables used followed the order in which the variables were presented in the specific run, in order to assess the permeability. For example, in the first run, (GR $+D), x_{1}$ is 
directly related to Gamma Ray, and $\mathrm{x}_{2}$ is related to Density. For simplicity, this criterion will be assumed for the entire description of the regressions.

The combination of independent variables $(G R+D)$ was applied to each of the 5 wells individually. The same procedure was repeated the other two combinations, $(\mathrm{GR}+\mathrm{P})$ and (D+ DS).

Once the regression analyses involving two variables for individual wells were completed, three independent variables were considered for individual wells. The arrangements used were as follows:

- Density + Gamma Ray + Derivative of Gamma Ray (D + GR + GS)

- Density + Derivative of Density + Gamma Ray (D + DS + GR)

- Density + Derivative of Density + Derivative of Gamma Ray (D + DS + GS)

Once again, the previous three regressions were applied to each of the 5 wells individually.

The last step in the single well analyses involved a regression using all the four variables, Gamma Ray + Derivative of Gamma Ray + Density + Derivative of Density. This combination was designated as (GR + GS + D +DS).

The analysis was performed having the following correspondence between independent variables and regression coefficients:

\begin{tabular}{|c|c|c|c|c|}
\hline & $\mathbf{X}_{1}$ & $\mathbf{X}_{2}$ & $\mathbf{X}_{3}$ & $\mathbf{X}_{4}$ \\
\hline Gamma Ray & $* * * * * * * *$ & & & \\
\hline G. R. Derivative & & $* * * * * * * *$ & & \\
\hline Density & & & $* * * * * * * *$ & \\
\hline Density Derivative & & & & $* * * * * * *$ \\
& & & & \\
\hline
\end{tabular}

The second part of the work involved use of 2, 3 and 4 independent variables for a series of combinations of the 5 wells. The well combinations included 2, 3, 4 and finally using all 5 wells

The first combinations involving two wells are presented below: 
- (P.11 + P.9)

- $($ P.11 + B.18)

- $($ P.11 + B.19)

- $($ P.9 + B.19)

The multiple regression analyses described earlier were applied to each of the arrangements of two wells listed above. The following diagram will exemplify the case in which (P.11 + P.9) were considered:

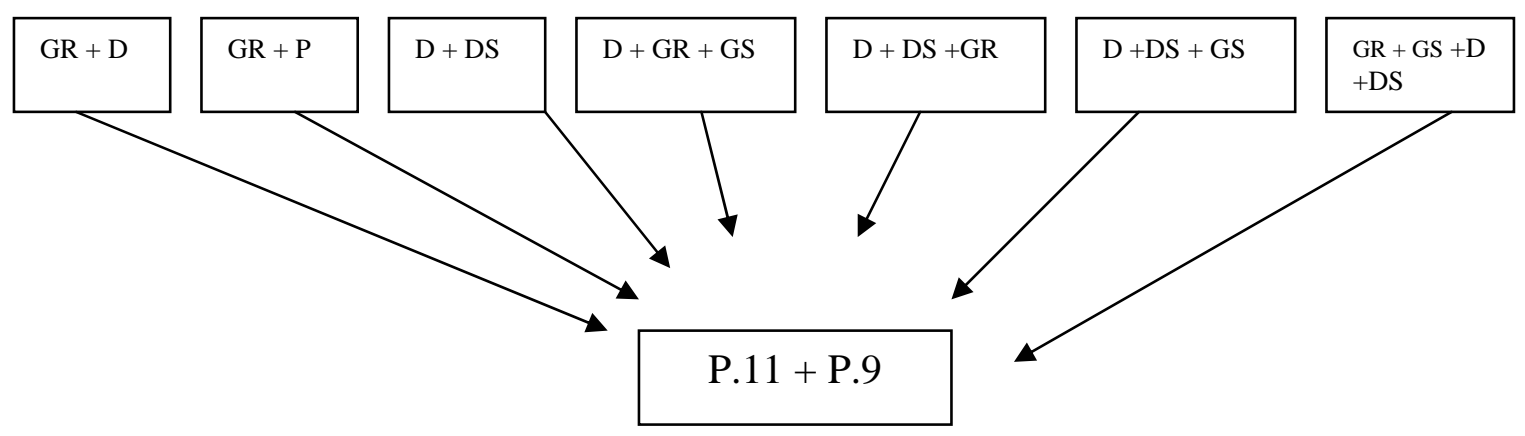

Figure 3.8a: Diagram involving the 7 cases of regressions for wells P.11 + P.9.

The next step involved combining the wells in groups of three. Those arrangements are presented below:

- $($ P.11 + B.18+ B.19)

- $\quad($ P.11 + B.18+ T.8)

- $($ P.11 + B.19+ T.8)

- $($ P.11 + P.9 + B.18)

- $($ P.11 + P.9+ T.8)

- $($ P.9 + B.18+ T 8)

For each of the combinations presented above, all the seven multiple regression types were applied, as it happened in the case of pairs of wells. The following sketch illustrates the case in which (P.11 + B.18 + B.19) combinations was studied. 


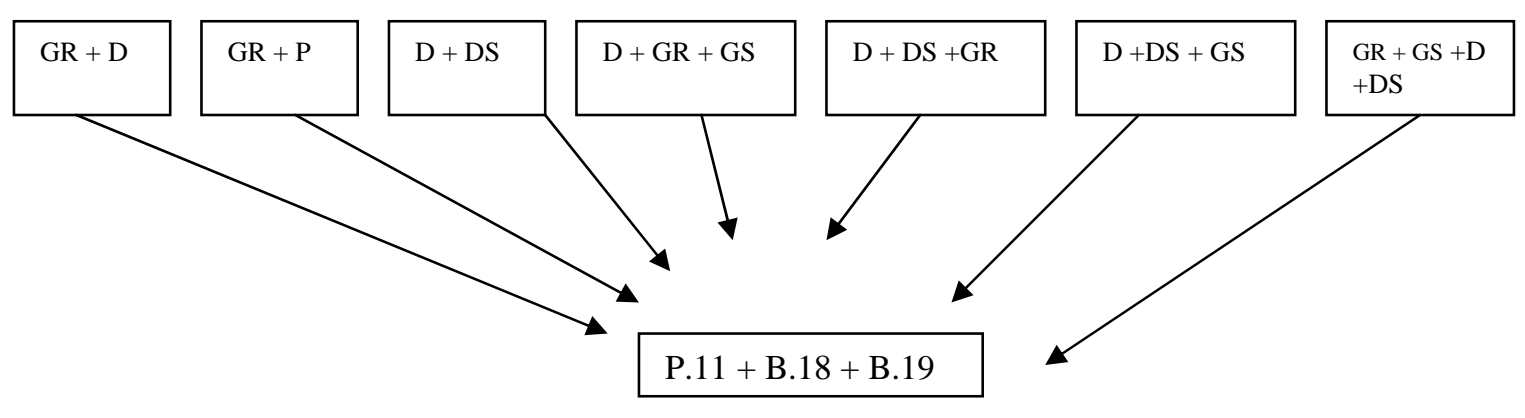

Figure 3.8b: Diagram involving the 7 cases of regressions for wells P.11 + B.18 + B.19.

Finalizing this part of the work, two last groups containing first 4 wells and then all the 5 wells were evaluated using the multiple regression analysis. The group involving 4 wells excluded P.9, i.e. (P.11 + B.18+B.19+ T.8). The reason for that lies in the fact that P.9 differs significantly from the other wells concerning lithology.

\subsubsection{Flow Units - Part 2}

The second part of this work involved the use of Flow Units as one of the independent variables in Multiple Regression Analysis (MRA). The flow unit descriptions were obtained from a previous study characterization. The flow unit divisions for each well can be found in appendix A.

The procedure followed in this part was similar to the procedure used in part 1 . In other words, the same combinations of wells and the same number of regressions; but this time, the data from various wells were divided into two parts: flow unit 1 and 2. Separated regression analysis was performed for each flow unit. It should be noted that when flow unit regression was applied to combinations of wells which involved T. 8, only flow unit 1 was performed once that well lacked the second flow zone, and thus the application of regression analysis to flow unit 2 of these arrangements of wells would provide the same results as for calculations including flow unit 1. 
To show how the analyses were performed using the flow units, an example will be given using the case in which (P.11) was evaluated with 4 variables. The well data from P.11 was divided into two flow units, and the variables associated to each of these units are presented below:

Flow Unit 1

\begin{tabular}{|c|c|c|c|}
\hline $\mathbf{G R}, \mathbf{x}_{\mathbf{1}}$ & $\mathbf{G S}, \mathbf{x}_{\mathbf{2}}$ & $\mathbf{D}, \mathbf{x}_{\mathbf{3}}$ & $\mathbf{D S}, \mathbf{x}_{\mathbf{4}}$ \\
\hline 35.262 & 1.102 & 2.498 & -0.038 \\
\hline 36.915 & 6.61 & 2.479 & 0.042 \\
\hline 45.73 & -16.53 & 2.349 & -0.302 \\
\hline 33.058 & -7.714 & 2.314 & 0.008 \\
\hline 29.201 & 5.51 & 2.33 & -0.008 \\
\hline
\end{tabular}

Flow Unit 2

\begin{tabular}{|c|c|c|c|}
\hline $\mathbf{G R}, \mathbf{x}_{\mathbf{1}}$ & $\mathbf{G S}, \mathbf{x}_{\mathbf{2}}$ & $\mathbf{D}, \mathbf{x}_{\mathbf{3}}$ & $\mathbf{D S}, \mathbf{x}_{\mathbf{4}}$ \\
\hline 47.383 & 22.038 & 2.309 & 0.034 \\
\hline 53.994 & 4.408 & 2.34 & 0.066 \\
\hline 62.81 & 20.936 & 2.503 & 0.346 \\
\hline 46.832 & -8.816 & 2.501 & 0.008 \\
\hline
\end{tabular}

Each of these two flow units was evaluated separately using the multiple regression, and returned individual regression coefficients, which ultimately would allow prediction of the corresponding permeability for that particular Flow Unit. The statement above means that all the analyses performed involving single wells, which summed up to 35 in total (7 regressions * 5 wells), and the analyses involving arrangements of wells, which reached a total of 84 runs (7 regressions * 12 groups of wells) were repeated separately for each Flow Unit.

\subsubsection{Assessment of Permeability Obtained Through MRA - Part 3}

After all the analyses were performed, a directed assessment of the permeability values obtained was done, using the coefficient of determination, $\mathrm{R}^{2}$. Having all the regression coefficients available, and making use of each equation that would describe the specific analysis, it was possible to predict the permeability for every case studied in this work, 
either with good or not very good agreement. The results are displayed in the next chapter.

Ultimately, the main objective would be to be able to extend those predictions taking for example 4 wells and trying to predict the permeability for a fifth one. This validation process was done in order to access how accurate the model can be used to predict the permeability of wells without core data. 


\section{CHAPTER 4}

\section{RESULTS AND DISCUSSIONS}

The objective of this research was to develop a correlation between permeability and well log data using Multiple Regression Analysis.

Data available from Stringtown Oil Field, WV, included log parameters such as density and gamma ray, as well as limited core permeability from the 5 wells studied in this project.

Identification of the different flow units in the field was also aimed after estimation of permeability values in order to compare with flow unit results previously obtained for the field.

The following sections will explain in details some of the results obtained during this study. Attempt will be made to fully interpret the relevance of the results.

\subsection{Analysis of Single Wells}

Results of the coefficients of determination $\mathrm{R}^{2}$ for all the analysis done are presented in table 4.1.

Table 4.1.: Coefficients of determination $\mathrm{R}^{2}$ for single well regression analysis.

\begin{tabular}{|c|c|c|c|c|c|c|c|c|}
\hline \multirow[b]{2}{*}{ well } & \multicolumn{7}{|c|}{ Coefficient of Determination $\mathrm{R}^{2}$} & \multirow[b]{2}{*}{$d+d s+g r+g r s$} \\
\hline & single var. & gr+dens & $g r+p$ & d+ds & $d+g r+g r s$ & $d+d s+g r$ & $d+d s+g r s$ & \\
\hline P. 9 & 0.92 & 0.96 & 0.95 & 0.8 & 0.97 & 0.98 & 0.97 & 0.98 \\
\hline P.11 & 0.7 & 0.73 & 0.77 & 0.78 & 0.85 & 0.78 & 0.85 & 0.86 \\
\hline B.18 & 0.79 & 0.85 & 0.83 & 0.85 & 0.85 & 0.85 & 0.85 & 0.85 \\
\hline B.19 & 0.68 & 0.57 & 0.41 & 0.6 & 0.6 & 0.65 & 0.6 & 0.65 \\
\hline T. 8 & 0.95 & 0.86 & 0.98 & 0.85 & 0.92 & 0.86 & 0.88 & 0.96 \\
\hline
\end{tabular}

The regression analysis involving 4 variables returned the best results as far as coefficients of determination are concerned. 
Following are the analyses for two of the single wells using this run (GR + GS + D +DS), which turned out to be the most accurate of the results obtained.

The run $(G R+G S+D+D S)$ returned the following equation as a result of MRA for P.9:

$\log k=-0.01845 * \mathbf{G R}+0.009798 * \mathbf{G S}-3.8276 * \boldsymbol{D}+5.138405 * \boldsymbol{D S}+11.87575$

The correspondence between core permeability and assessed permeability is shown in Figure 4.1.

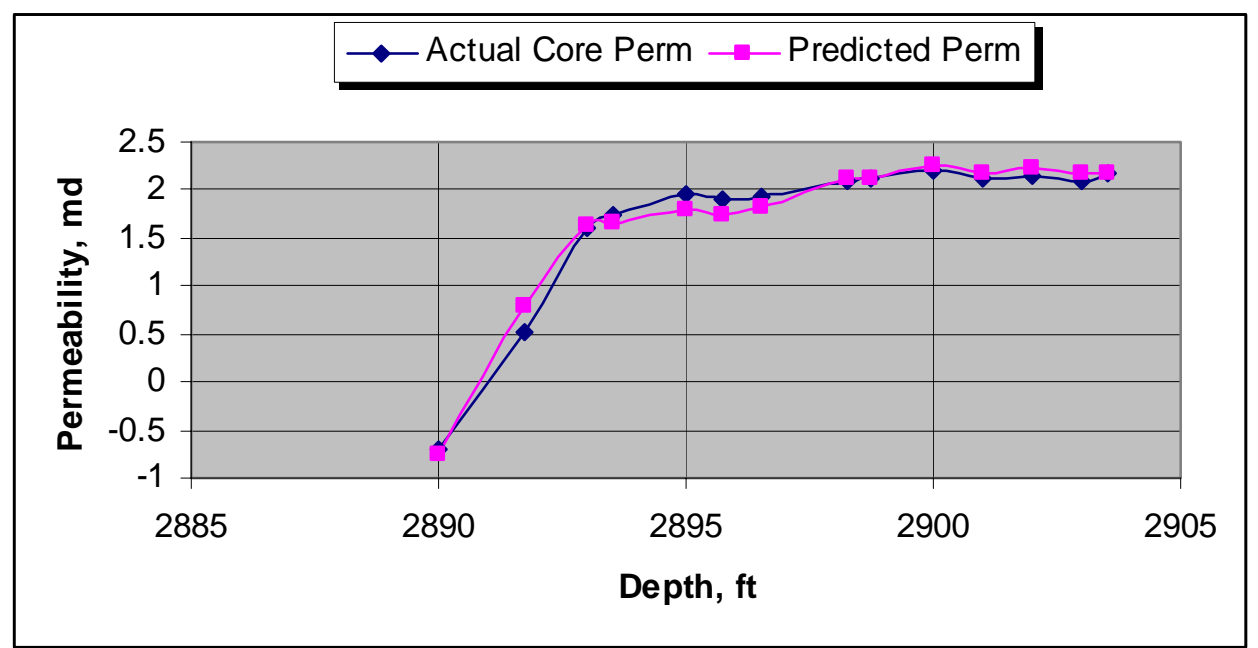

Figure 4.1 Comparison of the measured permeability and predicted permeability for $P .9$

It can be seen in the graph that there is an excellent agreement between the predicted and measured permeability at different depths for this particular well. The returned coefficient of determination was equal to 0.98 , which shows an almost perfect agreement.

Calculating the equation obtained from the regression analysis, it can be seen that, after the term ' $b$ ', density is the parameter that contributes more for the permeability, followed by gamma ray. The derivatives have less impact on the permeability according to the regressions. The following table shows the contributions of each of the 4 parameters for the predicted permeability. 
Table 4.2: Individual Contribution for the Predicted Permeability for Well

P.9

\begin{tabular}{|c|c|c|c|c|c|}
\hline \multicolumn{7}{|c|}{ Contributions of Each Parameter } \\
\hline \multirow{7}{*}{} & Pred. k & gr & grs & d & ds \\
\cline { 2 - 6 } & -0.7547 & -1.80943 & -0.53983 & -10.0551 & -0.22609 \\
\cline { 2 - 6 } & 0.781737 & -0.76239 & -0.12955 & -9.791 & -0.41107 \\
\cline { 2 - 6 } & 1.630525 & -0.64042 & -0.0108 & -9.48097 & -0.11304 \\
\cline { 2 - 6 } & 1.650491 & -0.60992 & -0.03239 & -9.40824 & -0.17471 \\
\cline { 2 - 6 } & 1.798812 & -0.73189 & 0.053967 & -9.25514 & -0.14388 \\
\cline { 2 - 6 } & 1.742624 & -0.78272 & -0.0108 & -9.11352 & -0.22609 \\
\cline { 2 - 6 } & 1.831024 & -0.77256 & -0.02159 & -8.98338 & -0.2672 \\
\cline { 2 - 6 } & 2.122117 & -0.76239 & 0 & -8.96041 & -0.03083 \\
\cline { 2 - 6 } & 2.129509 & -0.77256 & 0.021595 & -8.93362 & -0.06166 \\
\cline { 2 - 6 } & 2.252704 & -0.84372 & 0.053987 & -8.76138 & -0.07194 \\
\cline { 2 - 6 } & 2.170237 & -0.93521 & 0.032392 & -8.73076 & -0.07194 \\
\cline { 2 - 6 } & 2.237949 & -0.96571 & 0.021595 & -8.70396 & 0.010277 \\
\cline { 2 - 6 } & 2.169006 & -1.02669 & 0.010797 & -8.74224 & 0.051384 \\
\cline { 2 - 6 } & 2.173729 & -1.02669 & 0 & -8.75755 & 0.082214 \\
\hline STDEV & 0.809868 & 0.294828 & 0.15095 & 0.426299 & 0.134643 \\
\hline AVR & 1.649709 & -0.80983 & $-\mathbf{0 . 0 2 6 6 5}$ & $\mathbf{- 8 . 4 8 3 4}$ & -0.10133 \\
\hline
\end{tabular}

A quick analysis of the averaged numbers in the table above in conjunction with the bterm in the equation shows that density is responsible for about $39 \%$ of the predicted permeability. Gamma ray comes next with $3.80 \%$, and major contribution due to the bterm which for this case is equal to $56 \%$. The derivative parameters in the regression account for the small difference.

The significant contribution of the b-term can be attributed to correlations between reservoir properties, such as permeability and porosity.

The best scenario for the well T.8 will be shown below. The same run (GR + GS + D + DS) returned the following equation as a result for T.8:

$\log k=-0.04674 * \mathbf{G R}+0.071418 * \mathbf{G S}-12.5784 * \boldsymbol{D}-10.655 * \mathbf{D S}+33.25733$

And the correspondence between core permeability and assessed permeability is shown in Figure 4.2. 


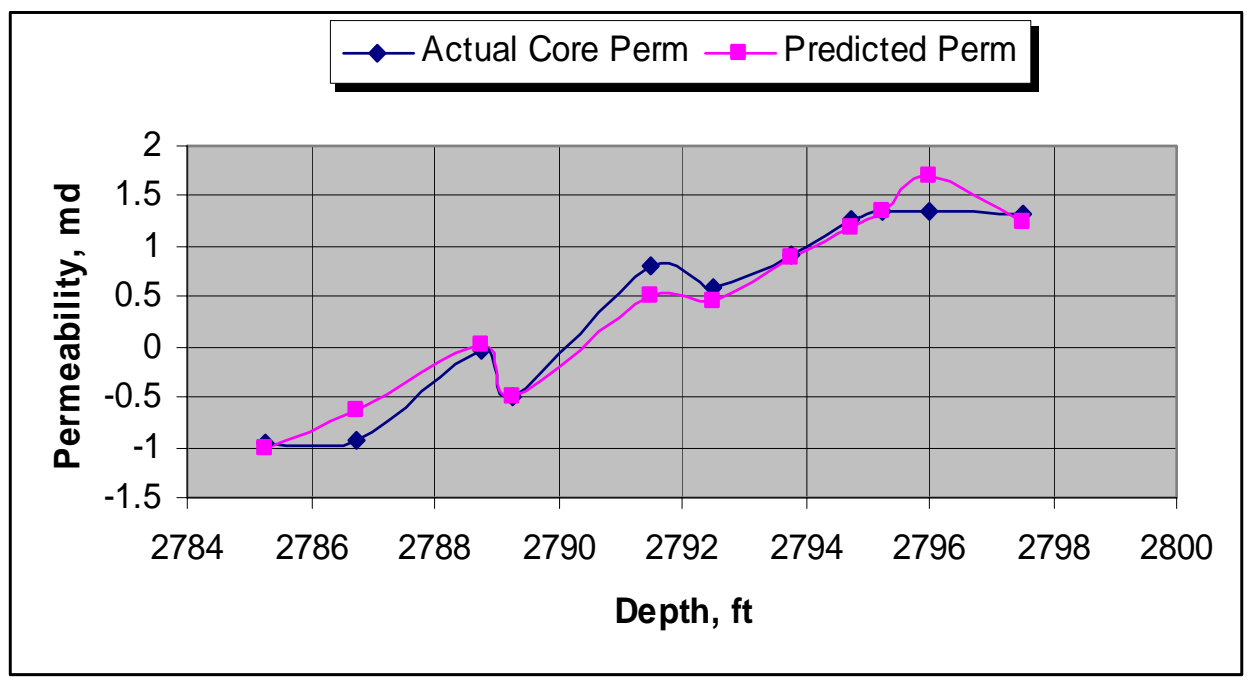

Figure 4.2 Comparison of the measured permeability and predicted permeability for T. 8

For T.8, the analysis also presented a good correspondence between core and predicted permeability. The coefficient of determination here was equal to 0.96 . When calculating the percentage of contributions for each parameter, the following numbers were obtained for the well T. 8: b-term is responsible for 52.23\%, density comes after with a contribution of $44.08 \%$, followed by gamma ray with a percentage of 3.27 to the total predicted permeability.

The results and plots involving all the single wells for this particular run and the other runs having different independent variables can be seen in the appendix B.

\subsubsection{Flow Unit Analyses (Single Wells)}

The run D + DS + GR + GS was then performed for the single wells as a first test, using flow units to group the data. Results of P.9 will be shown here. Table 4.3 presents the coefficients of determination $\mathrm{R}^{2}$ for single wells using flow unit distribution. 
Table 4.3 Coefficients of determination for single wells using flow units.

\begin{tabular}{|c|c|c|c|c|c|c|c|c|cc|c|}
\hline \multicolumn{10}{|c|}{ Coefficient of Determination R } \\
\hline well & flow & points & $\begin{array}{c}\text { single } \\
\text { var. }\end{array}$ & gr+dens & gr+p & d+ds & d+gr+grs & d+ds+gr & d+ds+grs & d+ds+gr+grs \\
\hline & 1 & 7 & 0.96 & 0.96 & 0.97 & 0.88 & 0.97 & 0.99 & 0.99 & 0.99 \\
P. 9 & 2 & 7 & 0.08 & 0.04 & 0.013 & 0.26 & 0.43 & 0.54 & 0.55 & 0.66 \\
\hline & 1 & 5 & 0.81 & 0.65 & 0.74 & 0.68 & 0.84 & 0.71 & 0.89 & 1 \\
P. 11 & 2 & 4 & 1 & 1 & 1 & 1 & 1 & 1 & 1 & 1 \\
\hline & 1 & 15 & 0.64 & 0.66 & 0.69 & 0.66 & 0.67 & 0.67 & 0.66 & 0.67 \\
B.18 & 2 & 5 & & 0.83 & 0.75 & 0.88 & 0.99 & 0.88 & $0 . .94$ & 1 \\
\hline & 1 & 18 & 0.53 & 0.39 & 0.22 & 0.42 & 0.43 & 0.48 & 0.43 & 0.49 \\
B.19 & 2 & 5 & 0.54 & 0.94 & 0.93 & 0.72 & 0.98 & 0.94 & 0.82 & 0.54 \\
\hline T. 8 & 1 & 11 & 0.95 & 0.86 & 0.98 & 0.85 & 0.92 & 0.8 & 0.88 & 0.96 \\
\hline
\end{tabular}

Figure 4.3a and b shows the correspondence between core and predicted permeability for flow units 1 and 2 respectively.

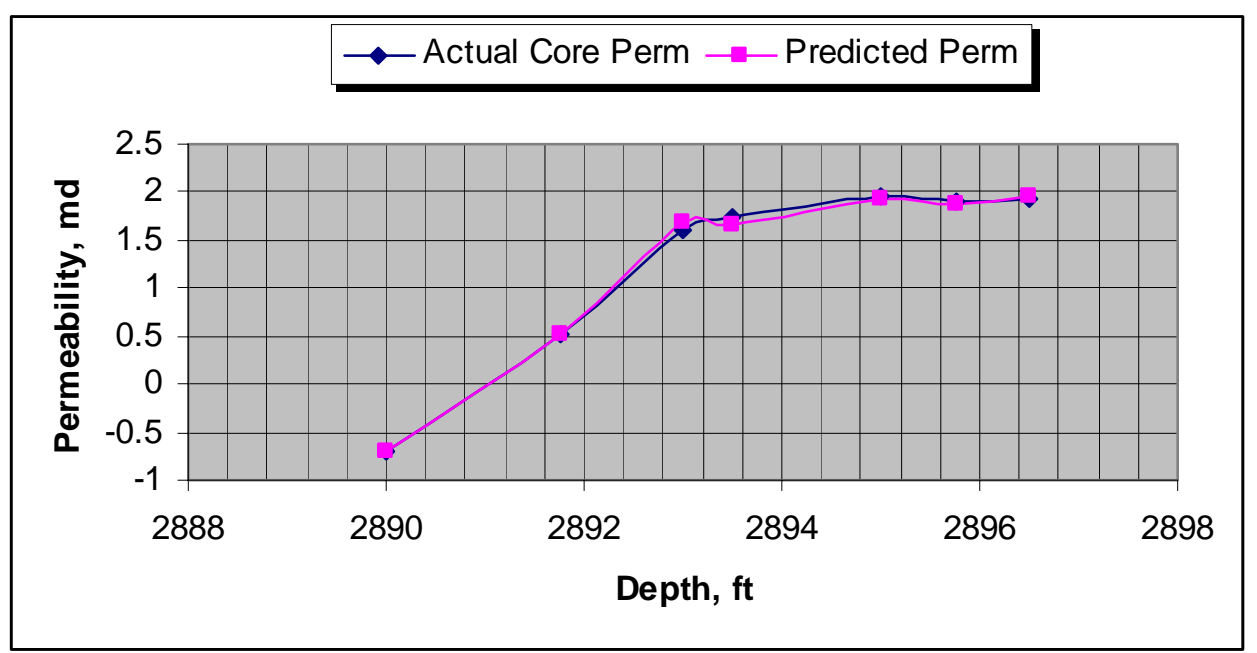

Figure 4.3 a: Comparison of Measured Permeability and Predicted Permeability Using Flow Unit 1 for P.9 


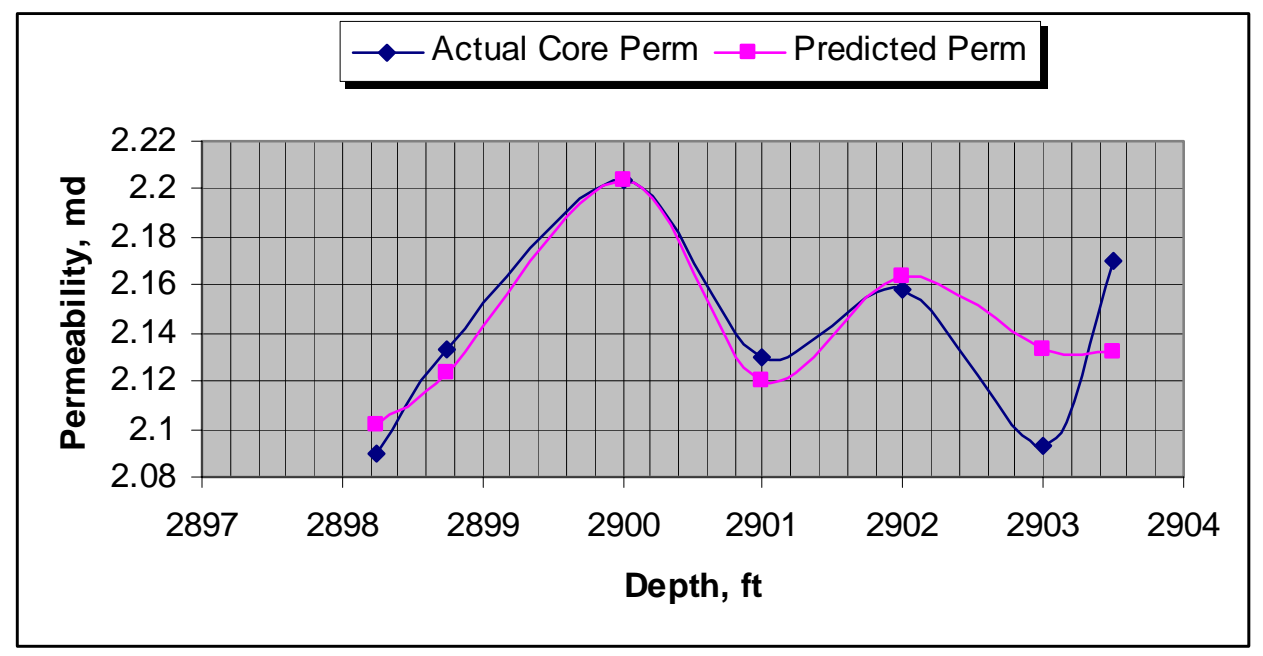

Figure 4.3 b: Comparison of Measured Permeability and Predicted Permeability Using Flow Unit 2 for P.9

The regression using flow unit 1 returned a coefficient of determination equal to 0.99, whereas for flow unit 2, this value dropped to 0.66. One possible explanation for lower $\mathrm{R}^{2}$ for flow unit 2 could be the limited number of data in this unit. Another possibility is the presence of a Transition Zone between the two Flow Units as described by previous studies. It should be however noted, that dividing the data to more units will cause too few data for statistical analysis.

\subsection{Analysis of Combinations of Wells}

After the analyses involving the 5 single wells were performed, a series of 12 combinations involving the wells in groups of 2, 3, 4 and finally 5 wells were subjected to all the seven types of MRA selected, using 2, 3 and 4 independent variables.

As a multiplicity of results was obtained, a complete presentation of all of them would make this section extremely prolix. Therefore, detailed explanation of one of the cases will be presented in the next sections. Complete results can be seen at the appendix C.

Table 4.4 shows the coefficients of determination, $\mathrm{R}^{2}$ for the various combinations used, excluding those involving flow units. 
Table 4.4: Coefficients of determination $\mathbf{R}^{2}$ for multiwell analysis.

\begin{tabular}{|ccccccccc|}
\hline & \multicolumn{10}{c|}{ Coefficient of Determination $\mathbf{R}^{2}$} \\
\hline well & single var. & gr+dens & gr+p & $\mathbf{d + d s}$ & $\mathbf{d + g r + g r s}$ & $\mathbf{d + d s + g r}$ & $\mathbf{d + d s + g r s ~}$ & $\mathbf{d + d s + g r + g r s ~}$ \\
\hline All wells & 0.73 & 0.74 & 0.68 & 0.62 & 0.74 & 0.74 & 0.74 & 0.74 \\
P 11+ B 18 & 0.76 & 0.83 & 0.82 & 0.84 & 0.84 & 0.84 & 0.84 & 0.84 \\
P 11 + B 18 + B 19 & 0.67 & 0.75 & 0.68 & 0.75 & 0.75 & 0.75 & 0.75 & 0.75 \\
P 11 + B 18 + B 19 + T 8 & 0.64 & 0.74 & 0.65 & 0.74 & 0.74 & 0.74 & 0.74 & 0.74 \\
P 11 + P 9 & 0.79 & 0.75 & 0.82 & 0.72 & 0.76 & 0.76 & 0.76 & 0.77 \\
P 11 + P 9 + B18 & 0.79 & 0.82 & 0.82 & 0.81 & 0.82 & 0.82 & 0.81 & 0.82 \\
P 11 + P 9 + T 8 & 0.74 & 0.72 & 0.79 & 0.71 & 0.72 & 0.72 & 0.72 & 0.72 \\
P 11 + B 19 & 0.56 & 0.61 & 0.51 & 0.61 & 0.61 & 0.62 & 0.61 & 0.62 \\
P 11 + B 19 + T 8 & 0.54 & 0.65 & 0.48 & 0.64 & 0.65 & 0.65 & 0.65 & 0.65 \\
P 9 + B 19 & 0.73 & 0.65 & 0.57 & 0.68 & 0.65 & 0.68 & & 0.79 \\
P 9 + B 18 + T 8 & 0.76 & 0.8 & 0.8 & 0.79 & & 0.8 & 0.79 & 0.80 \\
P11 + B18 + T8 & 0.7 & 0.81 & 0.77 & 0.81 & 0.81 & 0.81 & 0.82 & 0.82 \\
\hline
\end{tabular}

It can be noted in the table above that in general, all the regressions involving multiple variables provided higher $\mathrm{R}^{2}$ values compared to single variable regressions. Following the other analyses, the combination of 4 dependent variables returned improved results.

\subsubsection{Result of Analyses for Combined Wells P.11 and B.18}

The combination of wells that presented best agreement in terms of core permeability to predicted permeability was obtained when P.11 and B.18 were grouped together. Out of the 7 combinations of multiple regressions used, 5 returned a $\mathrm{R}^{2}$ of 0.84 for this group of wells. Following the example presented in previous sections, the run (GR + GS + D + DS) will be presented to clarify the results.

Figure 4.4 shows the permeability distribution for wells P.11 and B.18. 


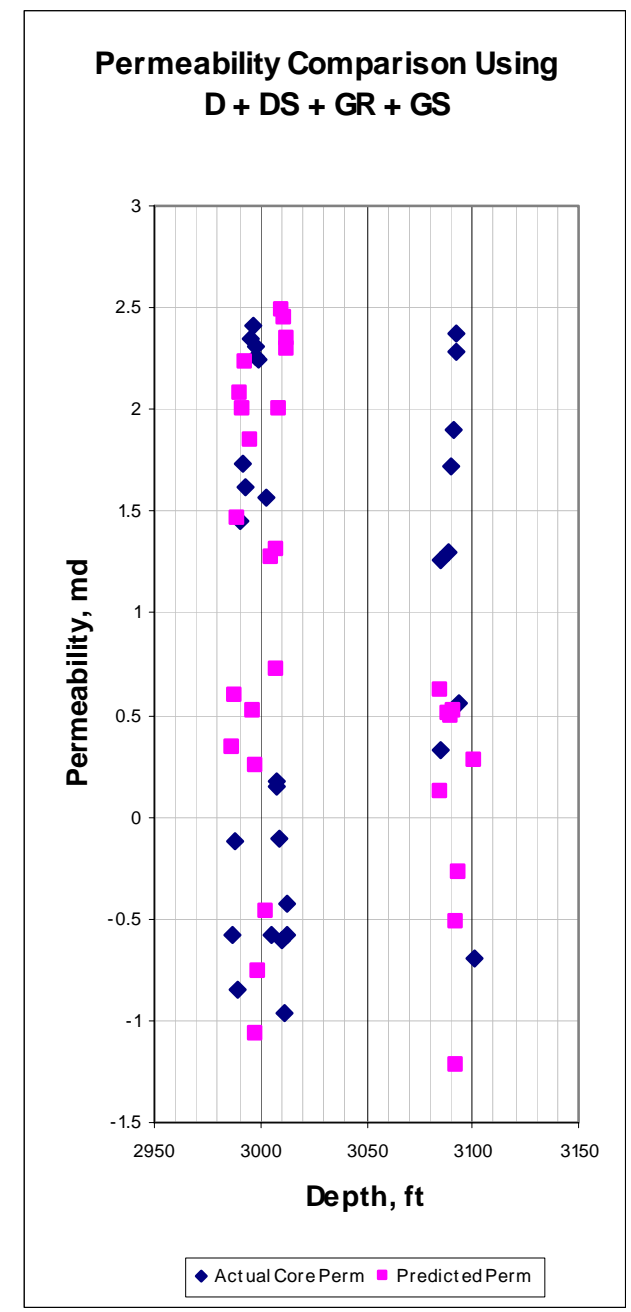

Figure 4.4 Permeability distribution for wells P.11 and B. 18

This run returned a coefficient of determination, $\mathrm{R}^{2}$ of 0.84 and as it can be seen on the plot above, there is good agreement between core and predicted permeability.

\subsubsection{Flow Unit Analysis (Combined Wells)}

The same runs involving the 4 independent variables, i.e. Gamma Ray, Density, and derivatives were used this time having the wells divided into their two flow units. Following are the results for P.11 and B.18, last run.

Table 4.5 also presents the coefficients of determination, $\mathrm{R}^{2}$ for the various combinations used with flow unit distribution. 
Table 4.5: Coefficients of Determination $\mathbf{R}^{2}$ for Multiwells Using Flow Units

\begin{tabular}{|c|c|c|c|c|c|c|c|c|c|c|}
\hline \multicolumn{11}{|c|}{ Coefficient of Determination $\mathrm{R}^{2}$} \\
\hline well & flow & points & $\begin{array}{l}\text { single } \\
\text { var. }\end{array}$ & $g r+d$ & $g r+p$ & $d+d s$ & d+gr+grs & $d+d s+g r$ & $d+d s+g r s$ & $\begin{array}{c}\text { d+ds+gr+ } \\
\text { grs }\end{array}$ \\
\hline \multirow[t]{2}{*}{ All wells } & 1 & 52 & 0.62 & 0.60 & 0.56 & 0.59 & 0.60 & 0.60 & 0.60 & 0.60 \\
\hline & 2 & 19 & 0.06 & 0.09 & 0.02 & 0.09 & 0.36 & 0.096 & 0.35 & 0.37 \\
\hline \multirow[t]{2}{*}{ P.11+ B.18 } & 1 & 22 & 0.73 & 0.70 & 0.79 & 0.71 & 0.71 & 0.71 & 0.71 & 0.37 \\
\hline & 2 & 7 & 0 & 0.45 & 0.46 & 0.24 & 0.51 & 0.58 & 0.40 & 0.59 \\
\hline \multirow{2}{*}{$\begin{array}{l}\text { P. } 11+\text { B. } 18 \\
+ \text { B. } 19\end{array}$} & 1 & 40 & 0.64 & 0.60 & 0.49 & 0.60 & 0.61 & 0.60 & 0.60 & 0.61 \\
\hline & 2 & 12 & 0.1 & 0.31 & 0.19 & 0.18 & 0.31 & 0.43 & 0.45 & 0.56 \\
\hline $\begin{array}{l}\text { P. } 11+\text { B. } 18+ \\
\text { B. } 19+\text { T. } 8\end{array}$ & 1 & 23 & 0.62 & 0.61 & 0.46 & 0.61 & 0.61 & 0.61 & 0.61 & 0.61 \\
\hline \multirow[t]{2}{*}{ P. $11+$ P. 9} & 1 & 14 & 0.81 & 0.66 & 0.78 & 0.61 & 0.66 & 0.66 & 0.66 & 0.67 \\
\hline & 2 & 9 & 0 & 0.06 & 0.02 & 0.47 & 0.86 & 0.91 & 0.89 & 0.93 \\
\hline \multirow{2}{*}{$\begin{array}{c}\text { P. } 11+\text { P. } 9+ \\
\text { B. } 18\end{array}$} & 1 & 29 & 0.75 & 0.70 & 0.73 & 0.68 & 0.70 & 0.70 & 0.69 & 0.70 \\
\hline & 2 & 14 & 0 & 0.99 & 0.04 & 0.01 & 0.46 & 0.16 & 0.42 & 0.48 \\
\hline $\begin{array}{c}\text { P. } 11+\text { P. } 9+ \\
\text { T. } 8\end{array}$ & 1 & 25 & 0.66 & 0.60 & 0.74 & 0.59 & 0.60 & 0.60 & 0.59 & 0.60 \\
\hline \multirow[t]{2}{*}{ P. $11+$ B. 19} & 1 & 25 & 0.60 & 0.45 & 0.35 & 0.45 & 0.45 & 0.45 & 0.45 & 0.46 \\
\hline & 2 & 7 & 0.26 & 0.68 & 0.61 & 0.34 & 0.73 & 0.81 & 0.48 & 0.85 \\
\hline $\begin{array}{c}\text { P. } 11+\text { B. } 19 \\
+ \text { T. } 8\end{array}$ & 1 & 36 & 0.60 & 0.53 & 0.33 & 0.52 & 0.53 & 0.53 & 0.53 & 0.54 \\
\hline \multirow[t]{2}{*}{ P. $9+$ B. 19} & 1 & 25 & 0.57 & 0.48 & 0.40 & 0.52 & 0.48 & 0.52 & 0.52 & 0.53 \\
\hline & 2 & 12 & 0.31 & 0.29 & 0.11 & 0.26 & 0.29 & 0.30 & 0.31 & 0.33 \\
\hline $\begin{array}{c}\text { P. } 9+\text { B. } 18+ \\
\text { T. } 8\end{array}$ & 1 & 33 & 0.63 & 0.66 & 0.70 & 0.65 & 0.66 & 0.66 & 0.65 & 0.66 \\
\hline $\begin{array}{c}\text { P.11 + B.18+ } \\
\text { T.8 }\end{array}$ & 1 & 33 & 0.68 & 0.70 & 0.69 & 0.71 & 0.71 & 0.71 & 0.71 & 0.71 \\
\hline
\end{tabular}

The results for this run returned lower values for $\mathrm{R}^{2}$ as compared to the case where the data was not divided into two flow units. Figure 4.5 ' $a$ ' and 'b' shows permeability distribution for flow units 1 and 2, in which run 1 (gr/gs/d/ds) was the one performed. 


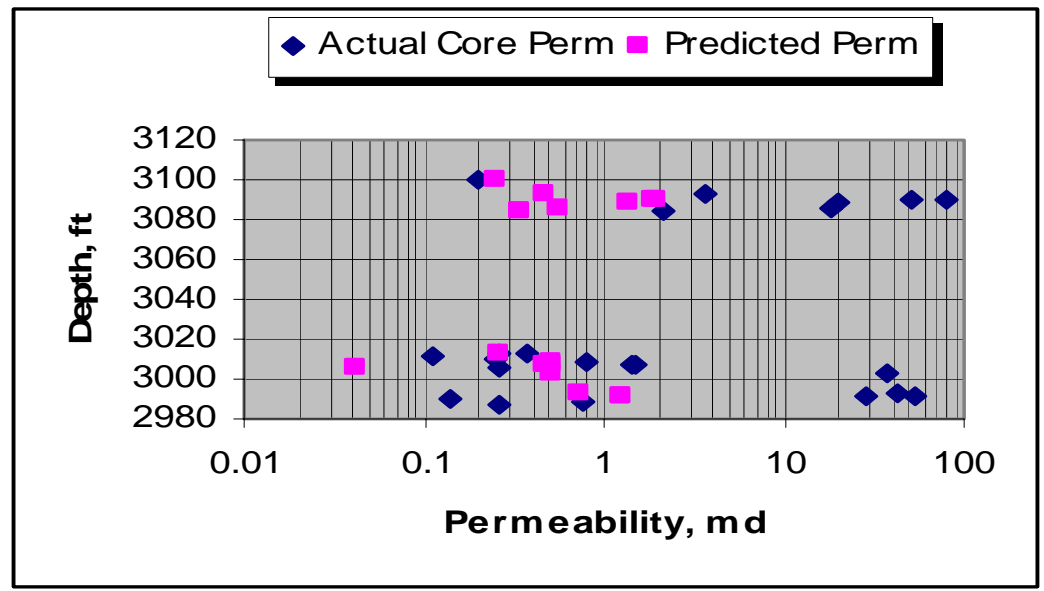

Figure 4.5 a: Permeability Distribution for Wells P. 11/ B.18 Using Flow Unit 1

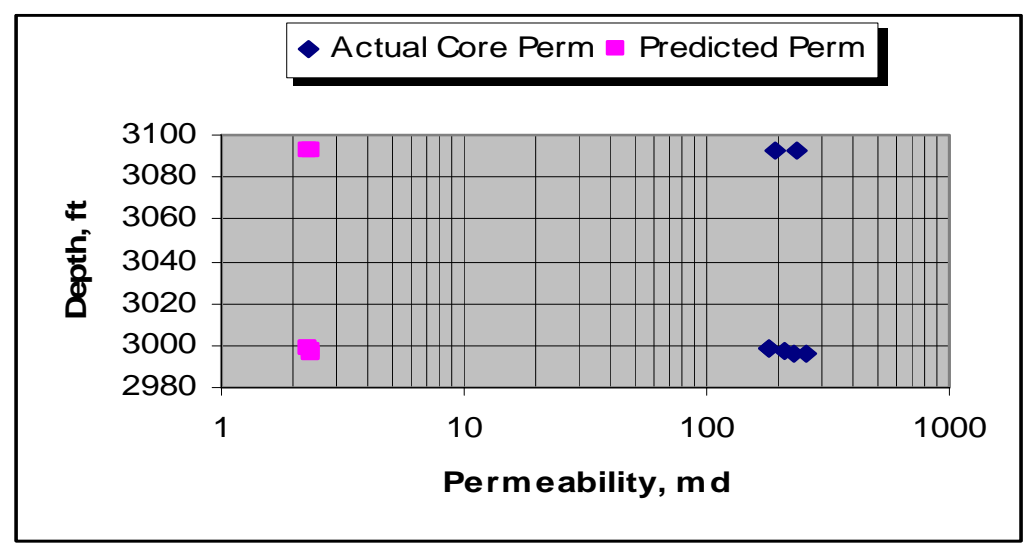

Figure 4.5 b: Permeability Distribution for Wells P. 11/ B.18 Using Flow Unit 2

Analysis involving flow unit 1 returned a coefficient of determination, $\mathrm{R}^{2}$ equal to 0.72 , whereas for flow unit 2, the coefficient was 0.59. This result was mostly common through the study, i.e. even though flow unit 2 usually presents a higher permeability average distribution, the regression for that particular part, returned lower numbers in terms of agreement than those analyses using flow unit 1. The explanations for these results are not yet well known. One possibility to be taken into account is the number of data points used for flow unit 1 and 2. This number is almost in every case, smaller for flow unit 2 than the number of data points available for flow unit 1, which could result in a worse agreement for predicted permeability using flow unit 2. 
Another possibility could be a not so accurate boundary definition for the selected flow units, which would invariably reflect on the results with an erroneous analysis. Further investigation on flow unit distribution should be performed.

A third possibility is that the permeability within Flow Unit 2 is controlled by other variables not included in the regression analysis. Potentially, three variables include irreducible water saturation, pore throat size distribution, grain size distribution, etc. It should be noted that these variables were not available from the field data to be included in regression analysis. The Flow Unit, while it separates the data with major characteristic differences, does not provide for variations of permeability within the Flow Unit.

\subsubsection{Analysis Validation}

In order to say that the proposed study is valid and accurate, it is necessary to be able to extent the prediction of permeability to wells without core data, which is ultimately, the main objective of this work. The results were then compared with the measured permeability.

To illustrate how the validation was done, two examples will be provided next. The first case of multiwells P.11 + B.18 + B.19+ T.8 will be used in order to predict the permeability for the well P.9. The predicted permeability for this group of wells was obtained from the following equation:

$k=0.000513 * G R+0.004427 * G S-9.30939 * D-0.02168 * D S+23.50$

Using the terms returned from the regression, and the variables pertaining to P.9, it was possible to obtain a prediction for the permeability for that well. The results were plotted against the original measured permeability for well P.9. Figure 4.6 illustrate the correspondence between measured permeability and predicted permeability for well P.9 using the arrangement P.11 + B.18 + B.19 + T.8. 


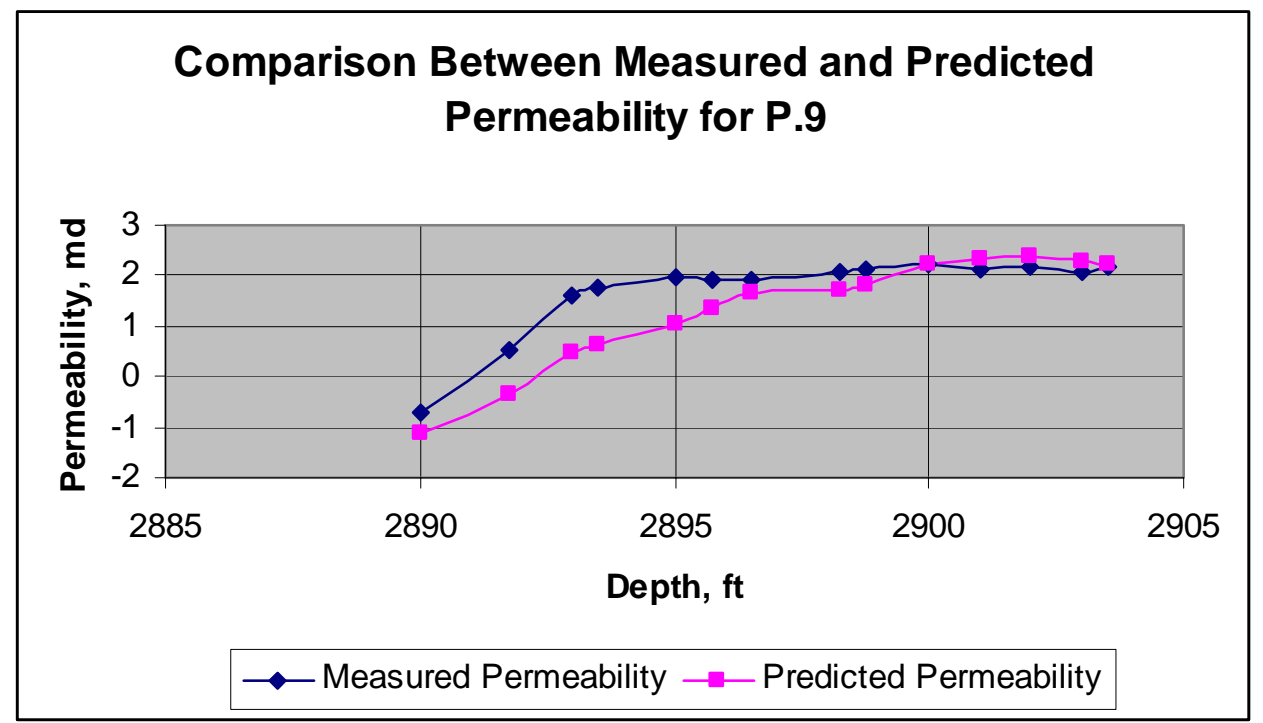

Figure 4.6: Comparison between predicted permeability using 4 wells and the permeability predicted for a fifth well.

It can be seen in the plot that even though the agreement between the two cases is not perfect, the predicted permeability exhibited a very similar trend to measured permeability values.

In the second case, the arrangement of wells P.9+ B.18 + T.8 was used to predict the permeability of the well B.19. Figure 4.7 shows the comparison between predicted and extended permeability for this case. 


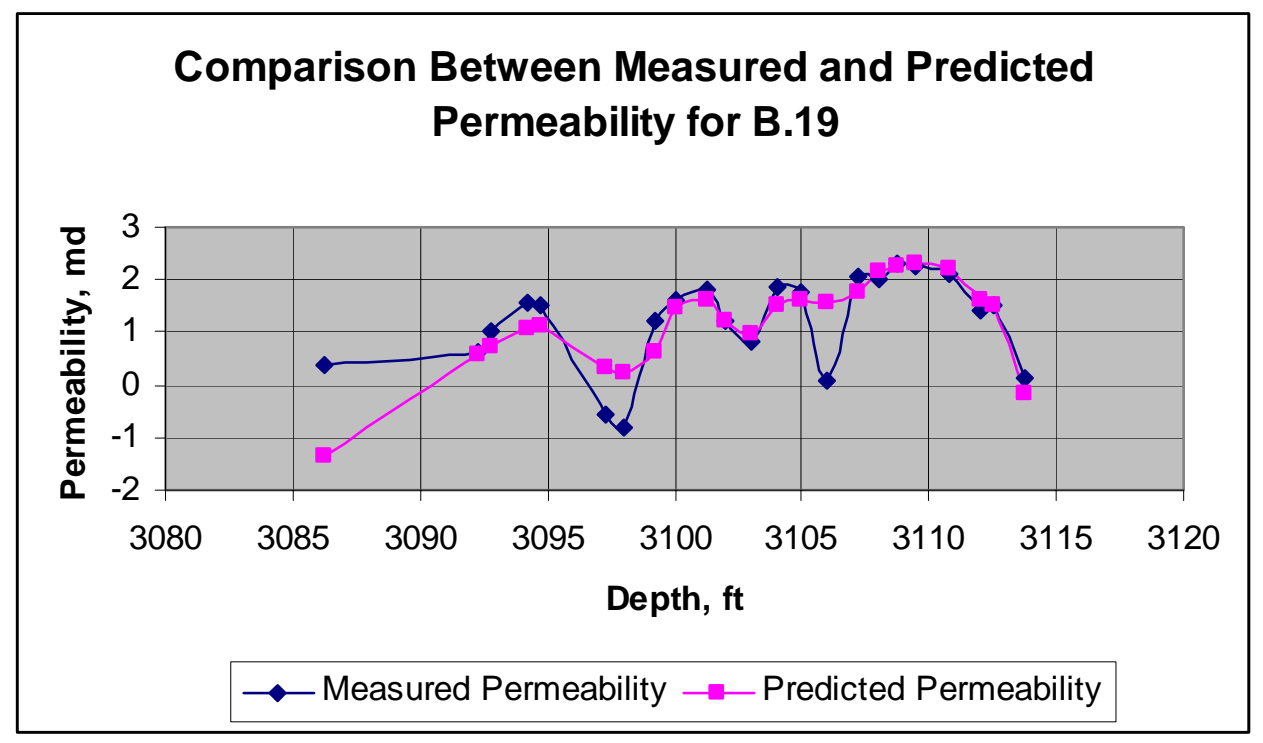

Figure 4.7: Comparison between predicted permeability using 3 wells and the permeability predicted for a fourth well.

This case also presented a good agreement between the predicted and the measured permeability.

In general, good results were obtained when the verification method was applied to other combination of wells. 


\section{CHAPTER 5 \\ CONCLUSIONS}

Based on the results obtained from this study, it is possible to make the following conclusions:

1. A relationship between permeability and well log data using multiple regression analyses was develop.

2. Best case scenarios are those in which the multiple regression analyses involve the four independent variables, i.e. density, derivative of density, gamma ray and the derivative of gamma ray, either for single or combined wells.

3. In case of combined wells, the pair P.11 and B.18 presented as the best group, showing very good agreement between the core and predicted permeability.

4. Flow units definition was used in order to enhance the relationship between core and log data.

5. The results of predicted permeability using the flow units' concept showed improvement with regard to flow unit 1 , but not necessarily for flow unit 2 in every case.

6. The accuracy of the methodology was verified by comparing the core permeability with the predicted permeability obtained from the MRA's and also by extending the prediction to wells without data. 


\section{REFERENCES}

1. Aminian, K., Thomas, B., Ameri, S., "A New Approach for Reservoir Charaterization”, Paper SPE 78710, October, 2002.

2. Mustafa, R.: "Application of Statistical Methods for Flow Unit Identification and Characterization of a Reservoir Using Well Log and Core Data”, Master's Thesis, West Virginia University (2003).

3. Mohaghegh, S., Balan, B., Ameri, S., "Permeability Determination from Well Log Data”, Paper SPE 30979, September, 1997.

4. Maghsood A., Hikari F., Fujio F., "Permeability Prediction by Hydraulic Flow Units”, Paper SPE 30158, March 1-3, 1995.

5. Babadagli T., "Improvement of Permeability Prediction for Carbonate Reservoirs Using Well Log Data”, Paper SPE 77889, October, 2001.

6. Oyerokun, A., "A New Approach for Training and Testing Artificial Neural Networks for Permeability Predictions”, Master's Thesis, West Virginia University, 2002.

7. Hohn, M., Avary, K. L., McDowell, R., Matchen, D., "Reservoir Oilfield, Northwestern West Virginia”, WVU and Appalachian Oil and Natural Gas Research Consortium, Final Report, October 2001.

8. Al-Ajmi, F. "Permeability Estimation Using Flow Units in a Central Arabia Reservoir”, Paper SPE 63254, October, 2000.

9. Aminian, K., Ameri, S., "Prediction of Flow Units and Permeability Using Artificial Neural Networks”, Paper SPE 83586, May, 2003. 
APPENDIX A

WELL LOG AND CORE DATA USED 
Table A-1. Geophysical Information from Cored Well P. Horner 11

\begin{tabular}{|c|c|c|c|c|c|c|c|c|}
\hline Well Name & x Coord & $y$ Coord & DEPTH & $\begin{array}{c}\text { Flow } \\
\text { unit }\end{array}$ & gr & density & GR Slope & RHOB slope \\
\hline $\begin{array}{c}\text { P. Horner \# } \\
11\end{array}$ & 1662865 & 348286.1 & 3084.5 & 1 & 35.262 & 2.498 & 1.102 & -0.038 \\
\hline $\begin{array}{c}\text { P. Horner \# } \\
11\end{array}$ & 1662865 & 348286.1 & 3085.25 & 1 & 36.915 & 2.479 & 6.61 & 0.042 \\
\hline $\begin{array}{c}\text { P. Horner \# } \\
11\end{array}$ & 1662865 & 348286.1 & 3088.75 & 2 & 45.73 & 2.349 & -16.53 & -0.302 \\
\hline $\begin{array}{c}\text { P. Horner \# } \\
11\end{array}$ & 1662865 & 348286.1 & 3088.75 & 2 & 45.73 & 2.349 & -16.53 & -0.302 \\
\hline $\begin{array}{c}\text { P. Horner \# } \\
11\end{array}$ & 1662865 & 348286.1 & 3089.5 & 2 & 33.058 & 2.314 & -7.714 & 0.008 \\
\hline $\begin{array}{c}\text { P. Horner \# } \\
11\end{array}$ & 1662865 & 348286.1 & 3090.5 & 2 & 29.201 & 2.33 & 5.51 & -0.008 \\
\hline $\begin{array}{c}\text { P. Horner \# } \\
11\end{array}$ & 1662865 & 348286.1 & 3092 & 2 & 47.383 & 2.309 & 22.038 & 0.034 \\
\hline $\begin{array}{c}\text { P. Horner \# } \\
11\end{array}$ & 1662865 & 348286.1 & 3092.5 & 2 & 53.994 & 2.34 & 4.408 & 0.066 \\
\hline $\begin{array}{c}\text { P. Horner \# } \\
11\end{array}$ & 1662865 & 348286.1 & 3093.25 & 2 & 62.81 & 2.503 & 20.936 & 0.346 \\
\hline $\begin{array}{c}\text { P. Horner \# } \\
11\end{array}$ & 1662865 & 348286.1 & 3093.25 & 2 & 62.81 & 2.503 & 20.936 & 0.346 \\
\hline $\begin{array}{c}\text { P. Horner \# } \\
11\end{array}$ & 1662865 & 348286.1 & 3100.5 & 2 & 46.832 & 2.501 & -8.816 & 0.008 \\
\hline
\end{tabular}


Table A-2. Geophysical Information from Cored Well P. Horner 9

\begin{tabular}{|c|c|c|c|c|c|c|c|c|}
\hline Well Name & x Coord & y Coord & DEPTH & Flow unit & $g r$ & density & $\begin{array}{c}\text { GR } \\
\text { Slope }\end{array}$ & $\begin{array}{l}\text { RHOB } \\
\text { slope } \\
\end{array}$ \\
\hline $\begin{array}{l}\text { P. Horner \# } \\
9\end{array}$ & 1663331 & 347187.1 & 2890 & 1 & 98.072 & 2.627 & -55.096 & -0.044 \\
\hline $\begin{array}{l}\text { P. Horner \# } \\
9\end{array}$ & 1663331 & 347187.1 & 2891.75 & 1 & 41.322 & 2.558 & -13.222 & -0.08 \\
\hline $\begin{array}{l}\text { P. Horner \# } \\
9 \\
\end{array}$ & 1663331 & 347187.1 & 2893 & 1 & 34.711 & 2.477 & -1.102 & -0.022 \\
\hline $\begin{array}{l}\text { P. Horner \# } \\
9 \\
\end{array}$ & 1663331 & 347187.1 & 2893 & 1 & 34.711 & 2.477 & -1.102 & -0.022 \\
\hline $\begin{array}{l}\text { P. Horner \# } \\
9\end{array}$ & 1663331 & 347187.1 & 2893.5 & 1 & 33.058 & 2.458 & -3.306 & -0.034 \\
\hline $\begin{array}{c}\text { P. Horner \# } \\
9\end{array}$ & 1663331 & 347187.1 & 2895 & 1 & 39.669 & 2.418 & 5.508 & -0.028 \\
\hline $\begin{array}{l}\text { P. Horner \# } \\
9 \\
\end{array}$ & 1663331 & 347187.1 & 2895.75 & 1 & 42.424 & 2.381 & -1.102 & -0.044 \\
\hline $\begin{array}{l}\text { P. Horner \# } \\
9\end{array}$ & 1663331 & 347187.1 & 2896.5 & 1 & 41.873 & 2.347 & -2.204 & -0.052 \\
\hline $\begin{array}{l}\text { P. Horner \# } \\
9\end{array}$ & 1663331 & 347187.1 & 2898.25 & 2 & 41.322 & 2.341 & 0 & -0.006 \\
\hline $\begin{array}{l}\text { P. Horner \# } \\
9 \\
\end{array}$ & 1663331 & 347187.1 & 2898.25 & 2 & 41.322 & 2.341 & 0 & -0.006 \\
\hline $\begin{array}{c}\text { P. Horner \# } \\
9\end{array}$ & 1663331 & 347187.1 & 2898.75 & 2 & 41.873 & 2.334 & 2.204 & -0.012 \\
\hline $\begin{array}{l}\text { P. Horner \# } \\
9\end{array}$ & 1663331 & 347187.1 & 2900 & 2 & 45.73 & 2.289 & 5.51 & -0.014 \\
\hline $\begin{array}{l}\text { P. Horner \# } \\
9 \\
\end{array}$ & 1663331 & 347187.1 & 2901 & 2 & 50.689 & 2.281 & 3.306 & -0.014 \\
\hline $\begin{array}{l}\text { P. Horner \# } \\
9\end{array}$ & 1663331 & 347187.1 & 2902 & 2 & 52.342 & 2.274 & 2.204 & 0.002 \\
\hline $\begin{array}{l}\text { P. Horner \# } \\
9\end{array}$ & 1663331 & 347187.1 & 2903 & 2 & 55.647 & 2.284 & 1.102 & 0.01 \\
\hline $\begin{array}{l}\text { P. Horner \# } \\
9 \\
\end{array}$ & 1663331 & 347187.1 & 2903 & 2 & 55.647 & 2.284 & 1.102 & 0.01 \\
\hline $\begin{array}{l}\text { P. Horner \# } \\
9\end{array}$ & 1663331 & 347187.1 & 2903.5 & 2 & 55.647 & 2.288 & 0 & 0.016 \\
\hline
\end{tabular}


Table A-3. Geophysical Information from Cored Well Ball 18

\begin{tabular}{|c|c|c|c|c|c|c|c|c|}
\hline Well Name & x Coord & y Coord & DEPTH & $\begin{array}{l}\text { Flow } \\
\text { unit }\end{array}$ & gr & density & $\begin{array}{c}\text { GR } \\
\text { Slope }\end{array}$ & $\begin{array}{l}\text { RHOB } \\
\text { slope }\end{array}$ \\
\hline F. R. Ball \# 18 & 1664052 & 350419.4 & 2987.25 & 1 & 72.022 & 2.615 & -34.348 & -0.026 \\
\hline F. R. Ball \# 18 & 1664052 & 350419.4 & 2988.25 & 1 & 41.551 & 2.604 & -16.62 & -0.02 \\
\hline F. R. Ball \# 18 & 1664052 & 350419.4 & 2989.75 & 1 & 46.537 & 2.575 & 5.54 & -0.142 \\
\hline F. R. Ball \# 18 & 1664052 & 350419.4 & 2989.75 & 1 & 46.537 & 2.575 & 5.54 & -0.142 \\
\hline F. R. Ball \# 18 & 1664052 & 350419.4 & 2990.75 & 1 & 33.795 & 2.396 & -12.188 & 0 \\
\hline F. R. Ball \# 18 & 1664052 & 350419.4 & 2991.5 & 1 & 30.471 & 2.399 & -3.324 & 0.014 \\
\hline F. R. Ball \# 18 & 1664052 & 350419.4 & 2993.5 & 1 & 27.147 & 2.461 & -2.216 & -0.014 \\
\hline F. R. Ball \# 18 & 1664052 & 350419.4 & 2994 & 2 & 27.147 & 2.454 & 1.108 & -0.03 \\
\hline F. R. Ball \# 18 & 1664052 & 350419.4 & 2995.5 & 2 & 39.335 & 2.324 & 12.188 & -0.082 \\
\hline F. R. Ball \# 18 & 1664052 & 350419.4 & 2995.5 & 2 & 39.335 & 2.324 & 12.188 & -0.082 \\
\hline F. R. Ball \# 18 & 1664052 & 350419.4 & 2996.25 & 2 & 45.429 & 2.269 & 4.432 & -0.034 \\
\hline F. R. Ball \# 18 & 1664052 & 350419.4 & 2997.5 & 2 & 48.753 & 2.274 & 2.216 & 0.02 \\
\hline F. R. Ball \# 18 & 1664052 & 350419.4 & 2998.25 & 2 & 49.307 & 2.284 & 1.108 & 0.008 \\
\hline F. R. Ball \# 18 & 1664052 & 350419.4 & 2999 & 2 & 52.632 & 2.294 & 11.08 & 0.028 \\
\hline F. R. Ball \# 18 & 1664052 & 350419.4 & 2999.75 & 2 & 63.712 & 2.35 & 25.484 & 0.038 \\
\hline F. R. Ball \# 18 & 1664052 & 350419.4 & 2999.75 & 2 & 63.712 & 2.35 & 25.484 & 0.038 \\
\hline F. R. Ball \# 18 & 1664052 & 350419.4 & 3002.75 & 1 & 72.022 & 2.458 & 1.108 & 0.028 \\
\hline F. R. Ball \# 18 & 1664052 & 350419.4 & 3005.25 & 1 & 72.576 & 2.509 & 5.54 & -0.024 \\
\hline F. R. Ball \# 18 & 1664052 & 350419.4 & 3007.25 & 1 & 50.97 & 2.47 & -11.08 & -0.014 \\
\hline F. R. Ball \# 18 & 1664052 & 350419.4 & 3007.75 & 1 & 43.767 & 2.468 & -22.162 & -0.014 \\
\hline F. R. Ball \# 18 & 1664052 & 350419.4 & 3009 & 1 & 41.551 & 2.506 & 16.62 & 0.286 \\
\hline F. R. Ball \# 18 & 1664052 & 350419.4 & 3009 & 1 & 41.551 & 2.506 & 16.62 & 0.286 \\
\hline F. R. Ball \# 18 & 1664052 & 350419.4 & 3009.75 & 1 & 57.064 & 2.611 & 43.214 & 0.102 \\
\hline F. R. Ball \# 18 & 1664052 & 350419.4 & 3011 & 1 & 86.981 & 2.644 & -1.108 & -0.008 \\
\hline F. R. Ball \# 18 & 1664052 & 350419.4 & 3012.25 & 1 & 58.726 & 2.527 & -47.644 & -0.08 \\
\hline F. R. Ball \# 18 & 1664052 & 350419.4 & 3013 & 1 & 43.213 & 2.505 & 1.108 & 0 \\
\hline
\end{tabular}


Table A-4. Geophysical Information from Cored Well Ball 19

\begin{tabular}{|c|c|c|c|c|c|c|c|c|}
\hline Well Name & x Coord & y Coord & DEPTH & $\begin{array}{l}\text { Flow } \\
\text { unit }\end{array}$ & gr & density & $\begin{array}{c}\text { GR } \\
\text { Slope }\end{array}$ & $\begin{array}{l}\text { RHOB } \\
\text { slope }\end{array}$ \\
\hline F. R. Ball \# 19 & 1665845 & 349375.8 & 3086.25 & 1 & 84.211 & 2.652 & -13.296 & -0.022 \\
\hline F. R. Ball \# 19 & 1665845 & 349375.8 & 3086.25 & 1 & 84.211 & 2.652 & -13.296 & -0.022 \\
\hline F. R. Ball \# 19 & 1665845 & 349375.8 & 3092.25 & 1 & 29.917 & 2.492 & 5.54 & -0.03 \\
\hline F. R. Ball \# 19 & 1665845 & 349375.8 & 3092.75 & 1 & 32.687 & 2.476 & 6.648 & -0.042 \\
\hline F. R. Ball \# 19 & 1665845 & 349375.8 & 3094.25 & 1 & 37.119 & 2.429 & 3.324 & -0.016 \\
\hline F. R. Ball \# 19 & 1665845 & 349375.8 & 3094.75 & 1 & 39.889 & 2.424 & 5.54 & -0.01 \\
\hline F. R. Ball \# 19 & 1665845 & 349375.8 & 3097.25 & 1 & 37.119 & 2.509 & 3.324 & 0.006 \\
\hline F. R. Ball \# 19 & 1665845 & 349375.8 & 3097.25 & 1 & 37.119 & 2.509 & 3.324 & 0.006 \\
\hline F. R. Ball \# 19 & 1665845 & 349375.8 & 3098 & 1 & 40.997 & 2.519 & 7.756 & -0.036 \\
\hline F. R. Ball \# 19 & 1665845 & 349375.8 & 3099.25 & 1 & 42.659 & 2.473 & -5.54 & -0.016 \\
\hline F. R. Ball \# 19 & 1665845 & 349375.8 & 3100 & 1 & 37.119 & 2.396 & -8.864 & -0.112 \\
\hline F. R. Ball \# 19 & 1665845 & 349375.8 & 3101.25 & 1 & 36.565 & 2.369 & 3.324 & -0.012 \\
\hline F. R. Ball \# 19 & 1665845 & 349375.8 & 3102 & 1 & 41.551 & 2.399 & 7.756 & 0.096 \\
\hline F. R. Ball \# 19 & 1665845 & 349375.8 & 3103 & 1 & 43.767 & 2.432 & 0 & 0.008 \\
\hline F. R. Ball \# 19 & 1665845 & 349375.8 & 3104 & 1 & 44.321 & 2.377 & 2.216 & -0.04 \\
\hline F. R. Ball \# 19 & 1665845 & 349375.8 & 3105 & 1 & 43.213 & 2.365 & 4.432 & -0.004 \\
\hline F. R. Ball \# 19 & 1665845 & 349375.8 & 3106 & 1 & 43.767 & 2.367 & -4.432 & 0.004 \\
\hline F. R. Ball \# 19 & 1665845 & 349375.8 & 3107.25 & 2 & 39.335 & 2.358 & 1.108 & -0.08 \\
\hline F. R. Ball \# 19 & 1665845 & 349375.8 & 3107.25 & 2 & 39.335 & 2.358 & 1.108 & -0.08 \\
\hline F. R. Ball \# 19 & 1665845 & 349375.8 & 3108 & 2 & 40.443 & 2.307 & 5.54 & -0.008 \\
\hline F. R. Ball \# 19 & 1665845 & 349375.8 & 3108.75 & 2 & 43.767 & 2.293 & -1.108 & -0.01 \\
\hline F. R. Ball \# 19 & 1665845 & 349375.8 & 3109.5 & 2 & 42.659 & 2.286 & -2.216 & -0.014 \\
\hline F. R. Ball \# 19 & 1665845 & 349375.8 & 3110.75 & 2 & 40.443 & 2.3 & -8.864 & 0.018 \\
\hline F. R. Ball \# 19 & 1665845 & 349375.8 & 3112 & 2 & 44.321 & 2.355 & 9.972 & 0.06 \\
\hline F. R. Ball \# 19 & 1665845 & 349375.8 & 3112.5 & 2 & 50.97 & 2.36 & 21.054 & 0.096 \\
\hline F. R. Ball \# 19 & 1665845 & 349375.8 & 3113.75 & 2 & 83.657 & 2.503 & 16.62 & 0.188 \\
\hline F. R. Ball \# 19 & 1665845 & 349375.8 & 3113.75 & 2 & 83.657 & 2.503 & 16.62 & 0.188 \\
\hline
\end{tabular}


Table A-5. Geophysical Information from Cored Well Thompson 8

\begin{tabular}{|c|c|c|c|c|c|c|c|c|}
\hline Well Name & x Coord & y Coord & DEPTH & $\begin{array}{c}\text { Flow } \\
\text { unit }\end{array}$ & gr & density & $\begin{array}{c}\text { GR } \\
\text { Slope }\end{array}$ & $\begin{array}{c}\text { RHOB } \\
\text { slope }\end{array}$ \\
\hline $\begin{array}{c}\text { Thompson Hrs } \\
\text { \# 8 }\end{array}$ & 1661311 & 350310.2 & 2785.25 & 1 & 38.44 & 2.519 & -12.258 & -0.008 \\
\hline $\begin{array}{c}\text { Thompson Hrs } \\
\text { \# 8 }\end{array}$ & 1661311 & 350310.2 & 2786.75 & 1 & 38.44 & 2.544 & 2.228 & 0.024 \\
\hline $\begin{array}{c}\text { Thompson Hrs } \\
\text { \# 8 }\end{array}$ & 1661311 & 350310.2 & 2788.75 & 1 & 51.811 & 2.495 & 3.342 & -0.03 \\
\hline $\begin{array}{c}\text { Thompson Hrs } \\
\text { \# 8 }\end{array}$ & 1661311 & 350310.2 & 2789.25 & 1 & 51.253 & 2.488 & -6.684 & -0.038 \\
\hline $\begin{array}{c}\text { Thompson Hrs } \\
\text { \# 8 }\end{array}$ & 1661311 & 350310.2 & 2789.25 & 1 & 51.253 & 2.488 & -6.684 & -0.038 \\
\hline $\begin{array}{c}\text { Thompson Hrs } \\
\text { \# 8 }\end{array}$ & 1661311 & 350310.2 & 2791.5 & 1 & 39.554 & 2.473 & 3.342 & 0.004 \\
\hline $\begin{array}{c}\text { Thompson Hrs } \\
\text { \# 8 }\end{array}$ & 1661311 & 350310.2 & 2792.5 & 1 & 47.911 & 2.467 & 4.456 & -0.014 \\
\hline $\begin{array}{c}\text { Thompson Hrs } \\
\text { \# 8 }\end{array}$ & 1661311 & 350310.2 & 2793.75 & 1 & 51.811 & 2.392 & -1.114 & -0.02 \\
\hline $\begin{array}{c}\text { Thompson Hrs } \\
\text { \# 8 }\end{array}$ & 1661311 & 350310.2 & 2794.75 & 1 & 49.025 & 2.384 & -2.228 & -0.034 \\
\hline $\begin{array}{c}\text { Thompson Hrs } \\
\text { \# 8 }\end{array}$ & 1661311 & 350310.2 & 2795.25 & 1 & 49.025 & 2.365 & 1.114 & -0.004 \\
\hline $\begin{array}{c}\text { Thompson Hrs } \\
\text { \# 8 }\end{array}$ & 1661311 & 350310.2 & 2795.25 & 1 & 49.025 & 2.365 & 1.114 & -0.004 \\
\hline $\begin{array}{c}\text { Thompson Hrs } \\
\text { \# 8 }\end{array}$ & 1661311 & 350310.2 & 2796 & 1 & 52.925 & 2.359 & 5.57 & -0.018 \\
\hline $\begin{array}{c}\text { Thompson Hrs } \\
\text { \# 8 }\end{array}$ & 1661311 & 350310.2 & 2797.5 & 1 & 74.652 & 2.354 & 21.17 & 0.038 \\
\hline \begin{tabular}{c} 
Thon \\
\hline
\end{tabular}
\end{tabular}


APPENDIX B

MULTIPLE REGRESSION RESULTS FOR SINGLE WELLS 
Plot B-1. Multiple Regression Results for P. Horner 11 (D + DS + GR + GS)

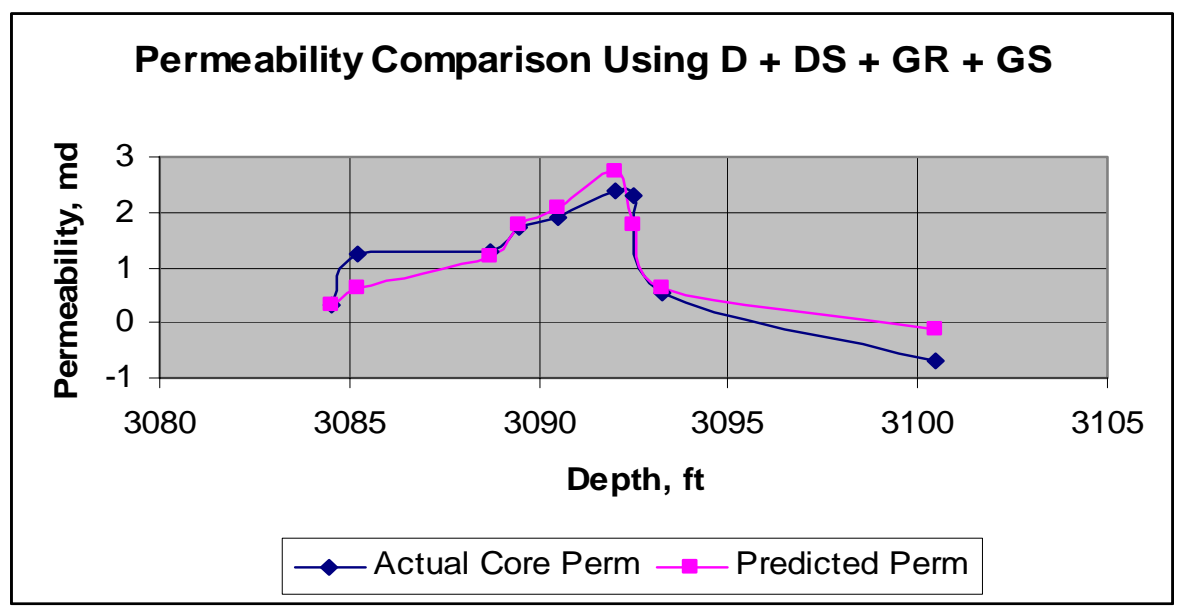

Plot B-2. Multiple Regression Results for P. Horner 11 (G + GR)

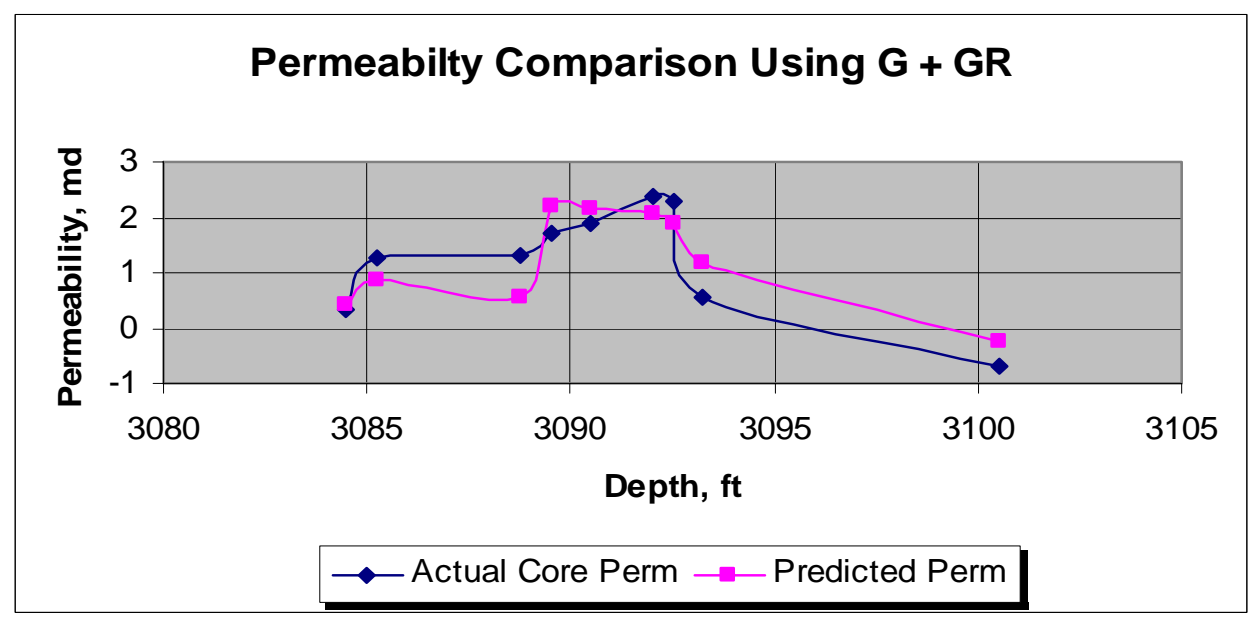

Plot B-3. Multiple Regression Results for P. Horner 11 (GR + Porosity)

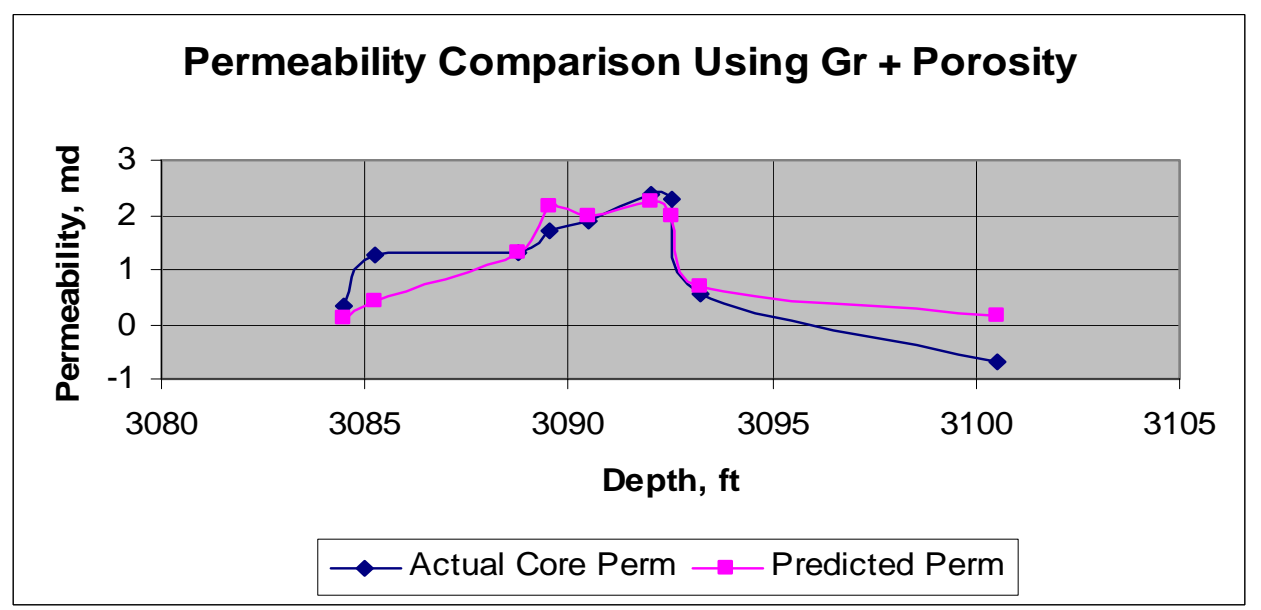


Plot B-4. Multiple Regression Results for P. Horner 11 (D + DS)

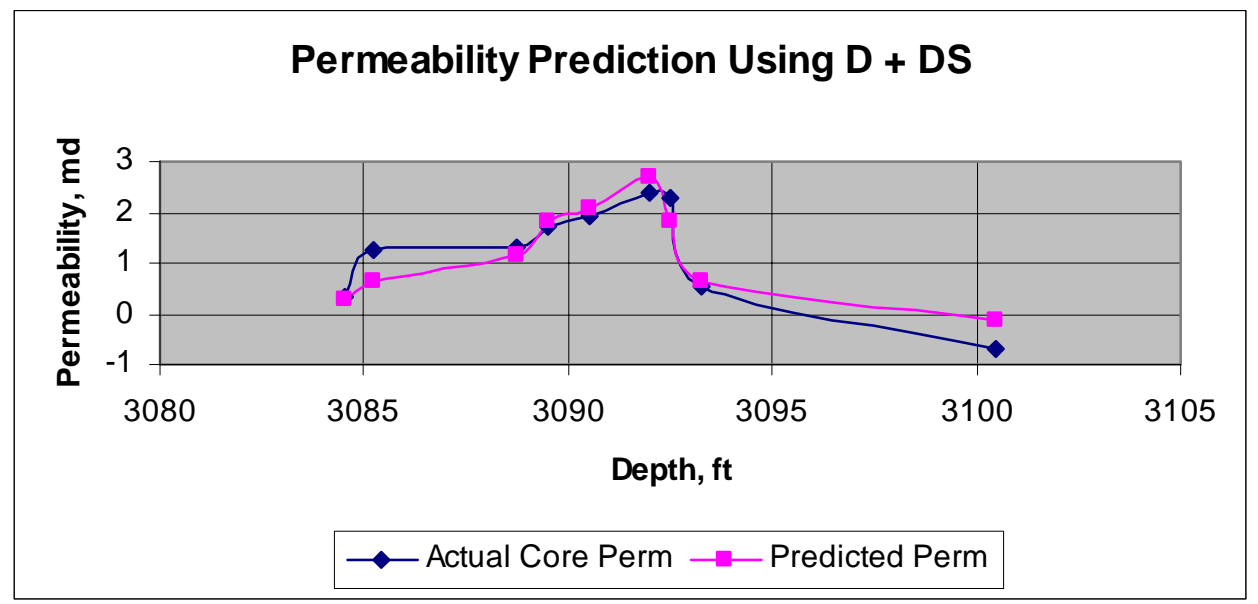

Plot B-5. Multiple Regression Results for P. Horner 11 (D+GR + GS)

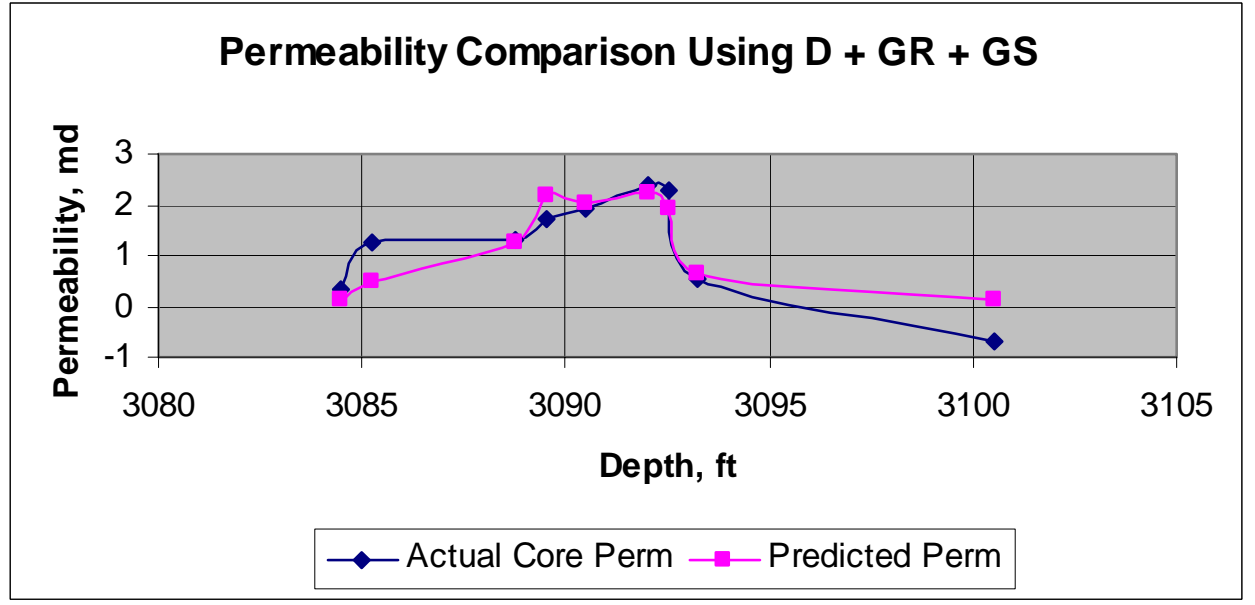

Plot B-6. Multiple Regression Results for P. Horner 11 (D + DS + GR)

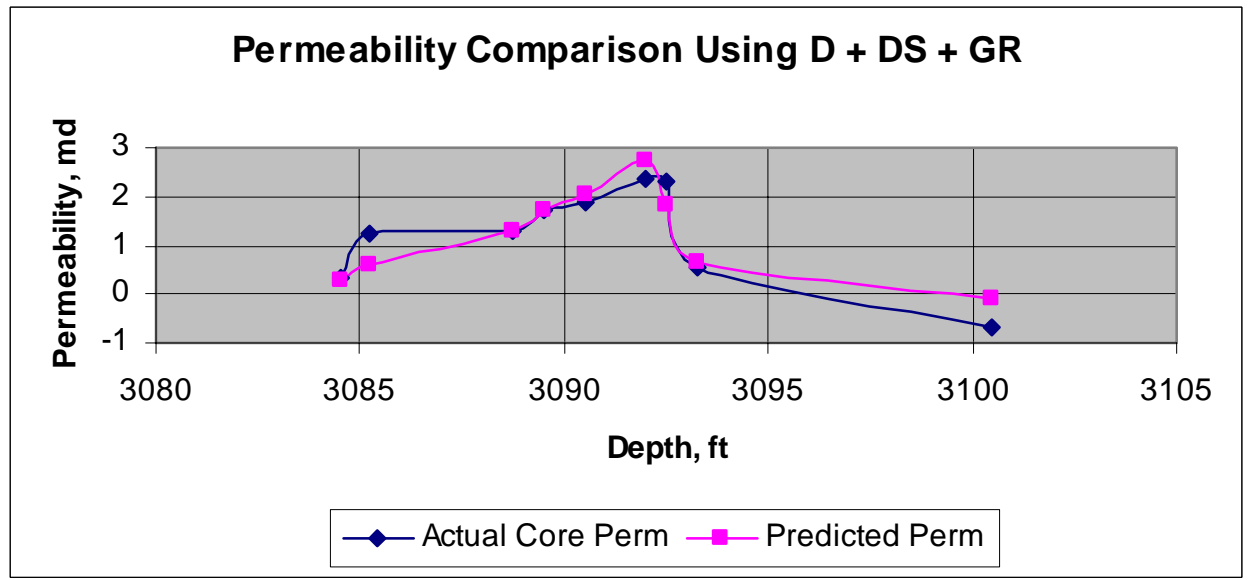


Plot B-7. Multiple Regression Results for P. Horner 11 (run D + DS + GS)

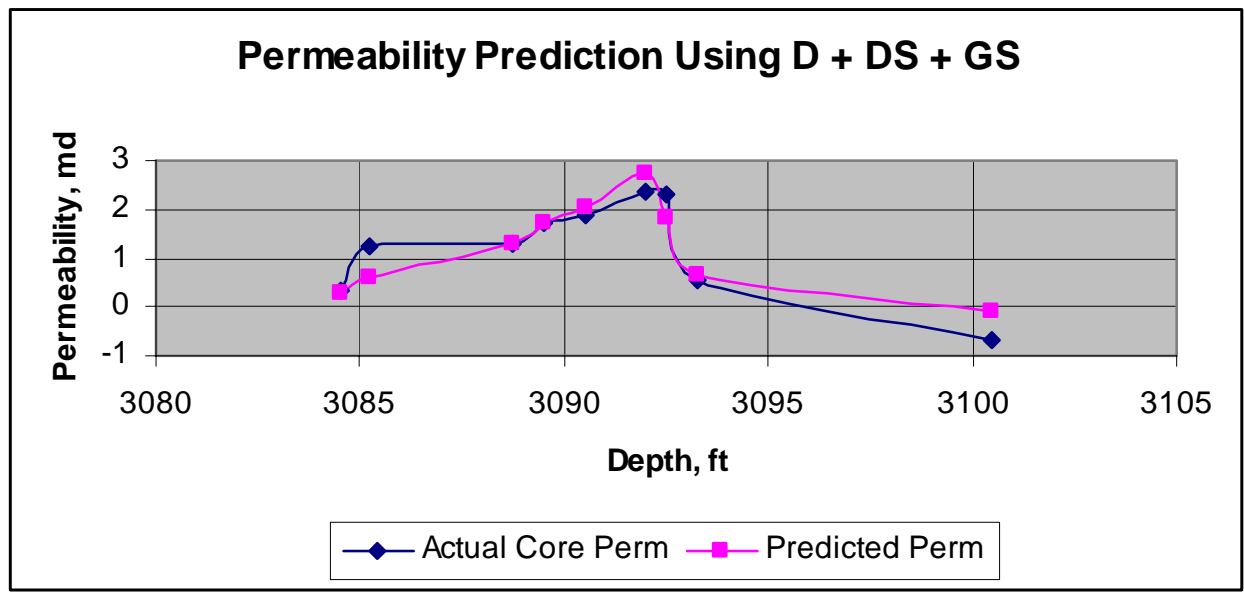


Figure B-8. Multiple Regression Results for P. Horner 11 Using Flow Units

$($ Run D + DS + GR + GS)
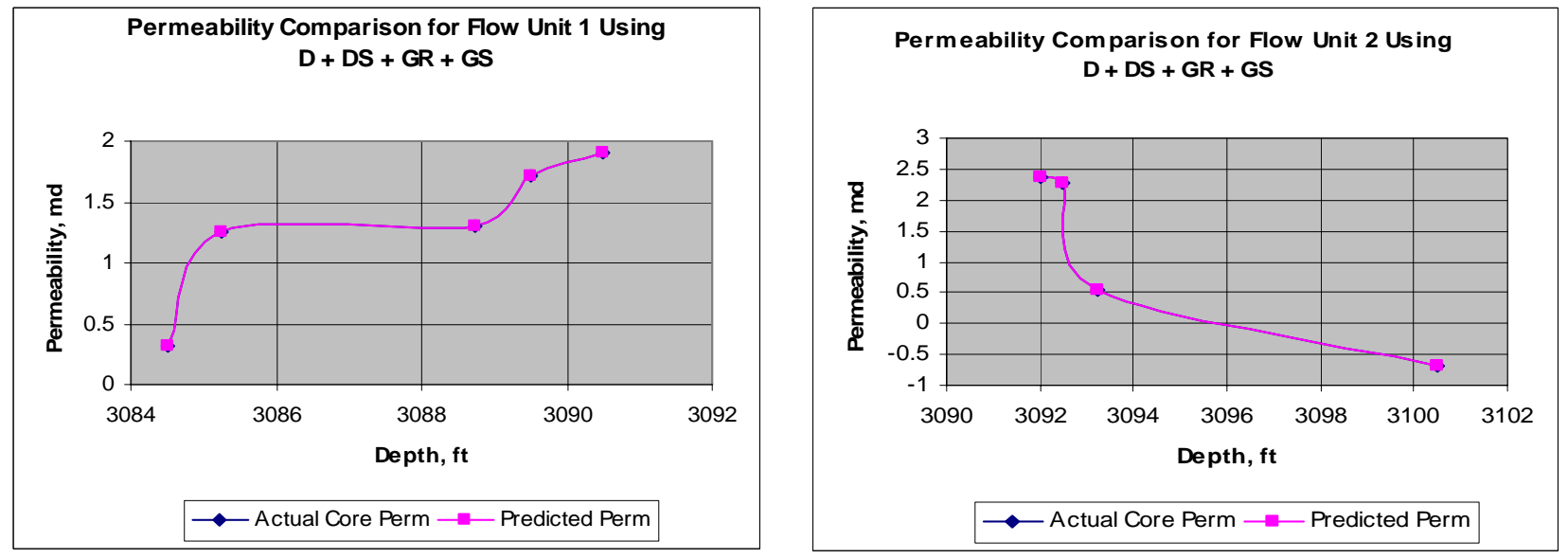

Figure B-9. Multiple Regression Results for P. Horner 11 Using Flow Units (Run D + GR)
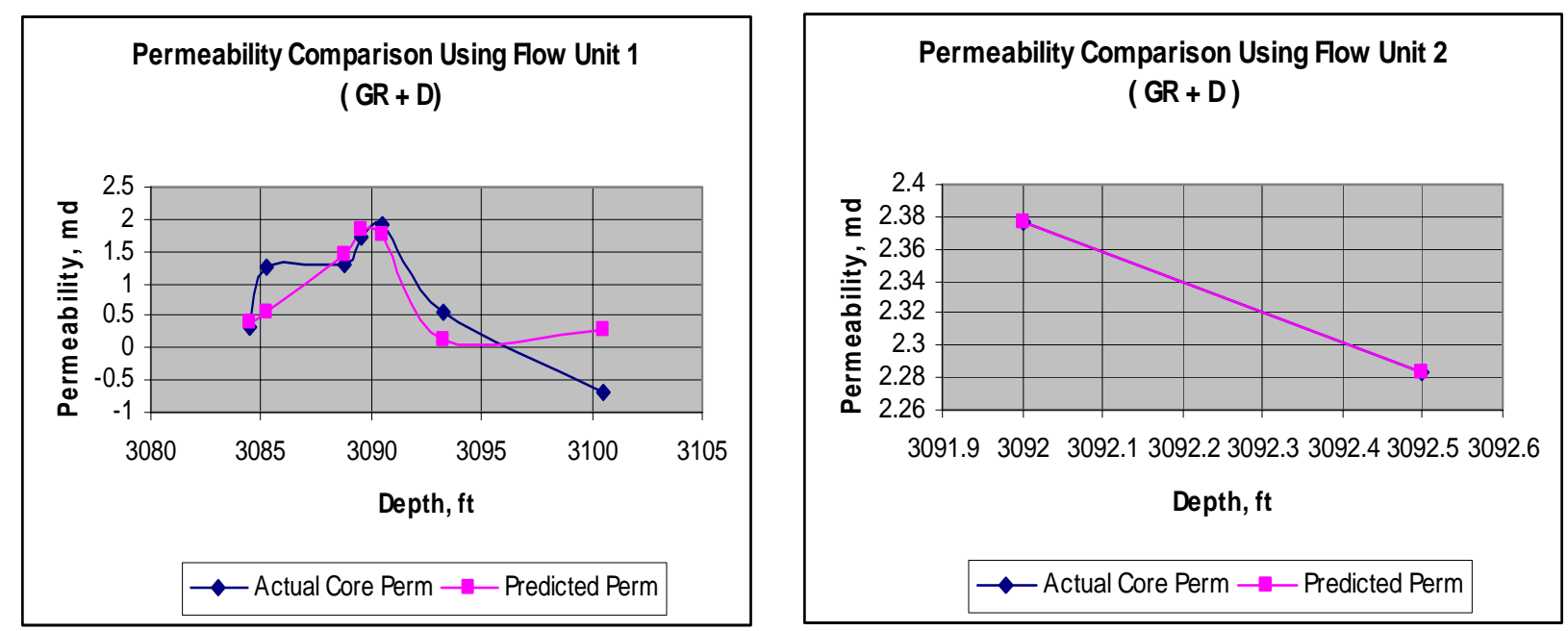
Figure B-10. Multiple Regression Results for P. Horner 11 Using Flow Units (Run D + DS)
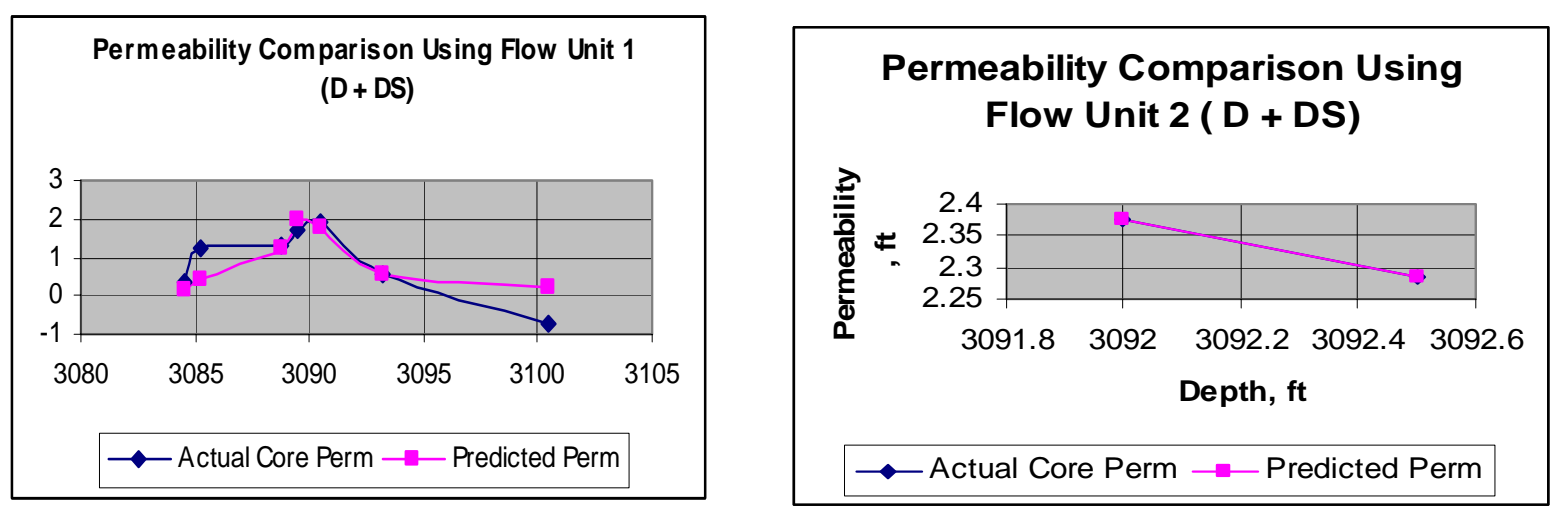

Figure B-11. Multiple Regression Results for P. Horner 11 Using Flow Units (Run D + GR + GS)
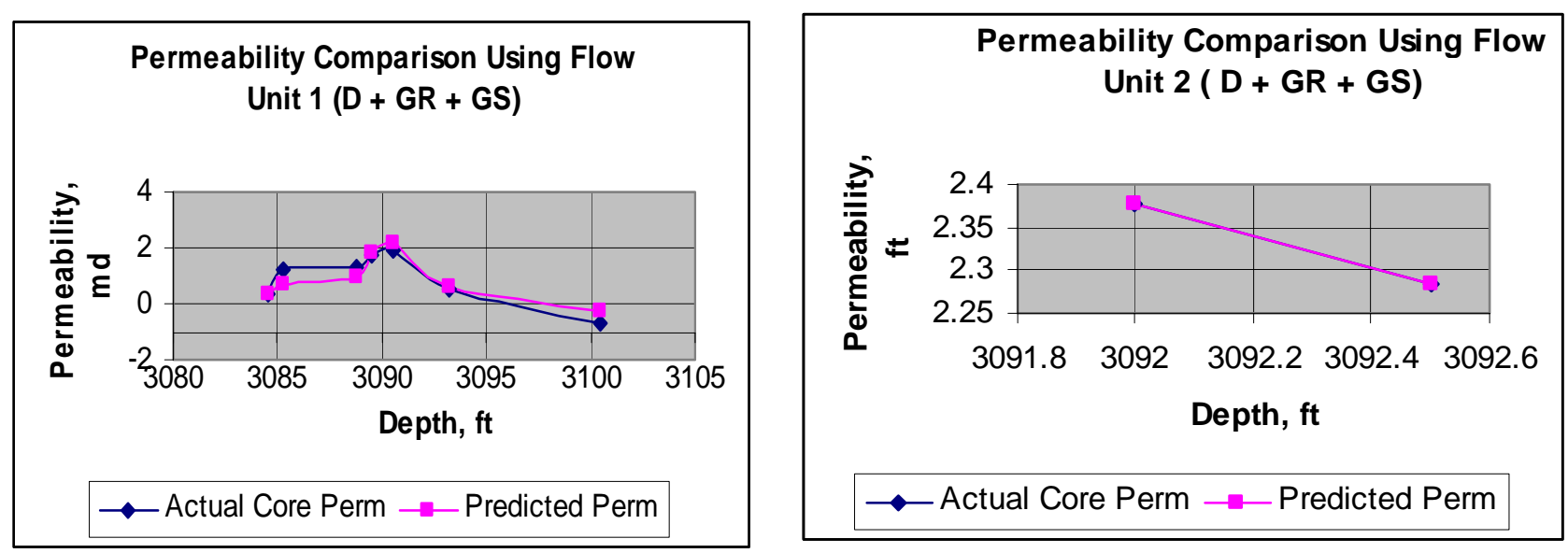
Figure B-12. Multiple Regression Results for P. Horner 11 Using Flow Units (Run D + DS + GR)
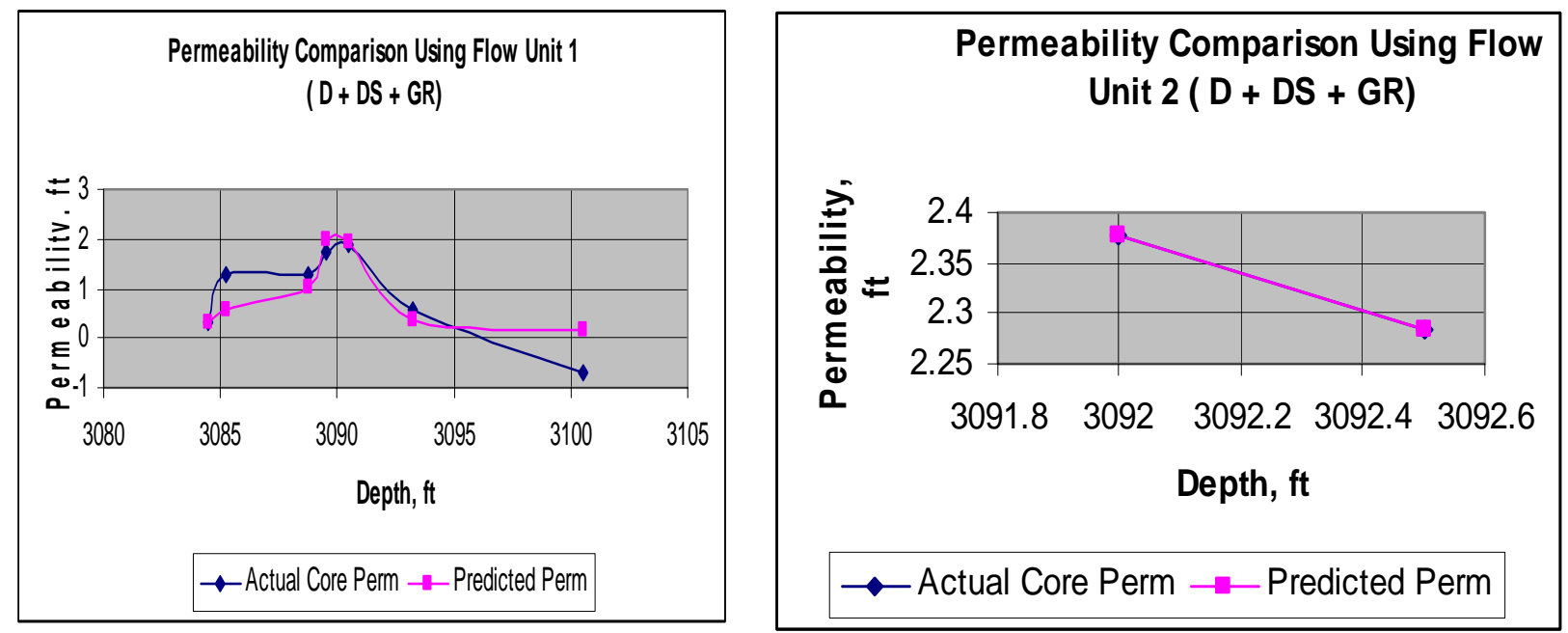

Figure B-13. Multiple Regression Results for P. Horner 11 Using Flow Units (Run D + DS +GS)
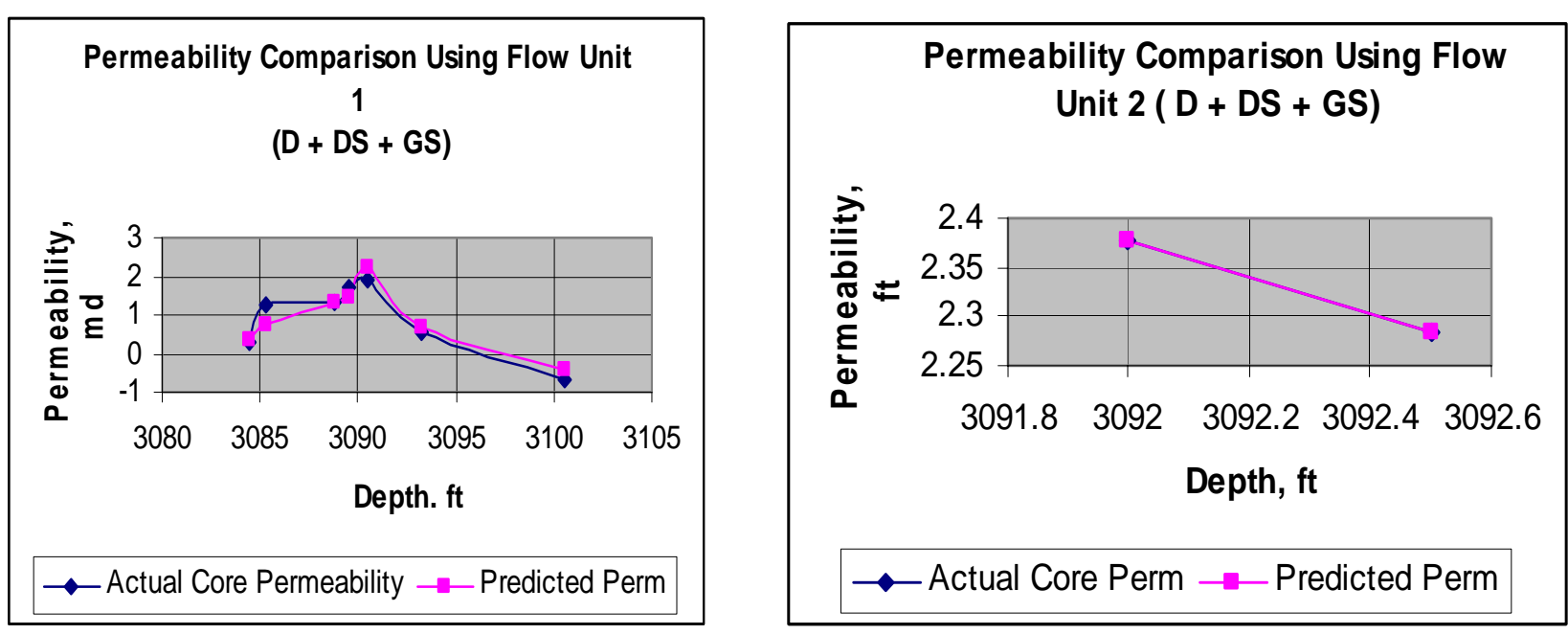
Figure B-14. Multiple Regression Results for Ball 18 (run D + DS + GR + GS)

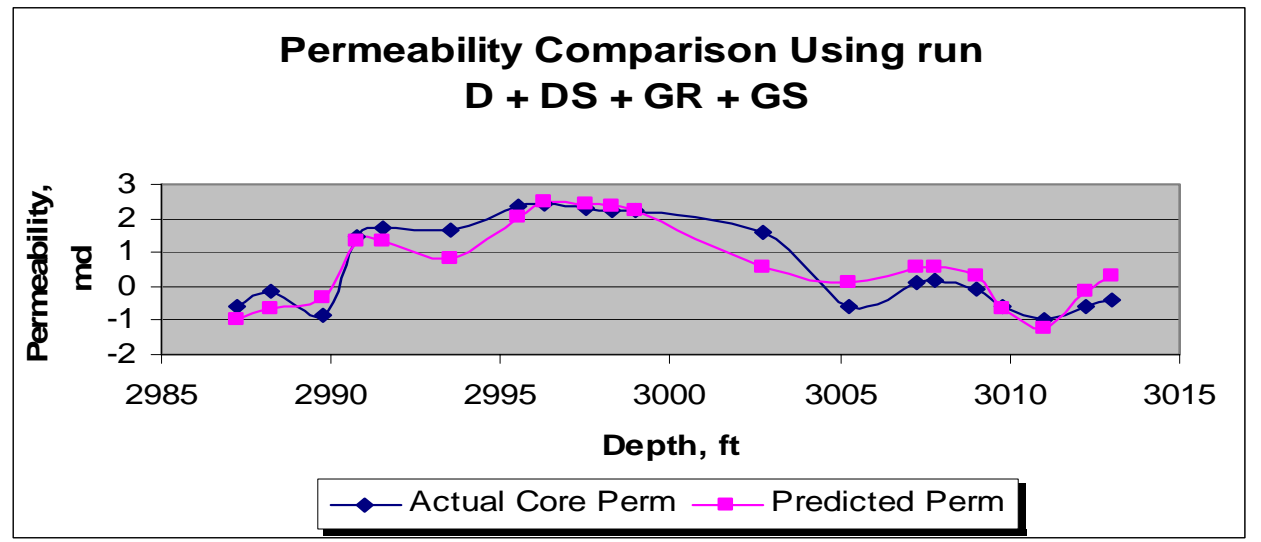

Figure B-15. Multiple Regression Results for Ball 18 (run D + GR)

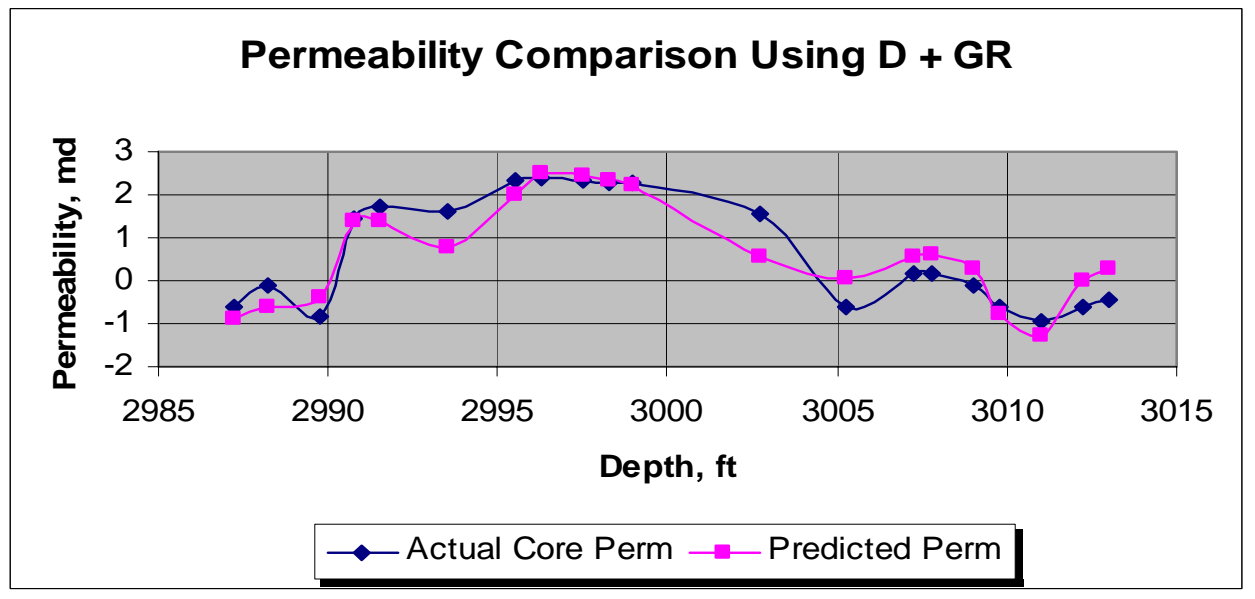

Figure B-16. Multiple Regression Results for Ball 18 (run D + GR)

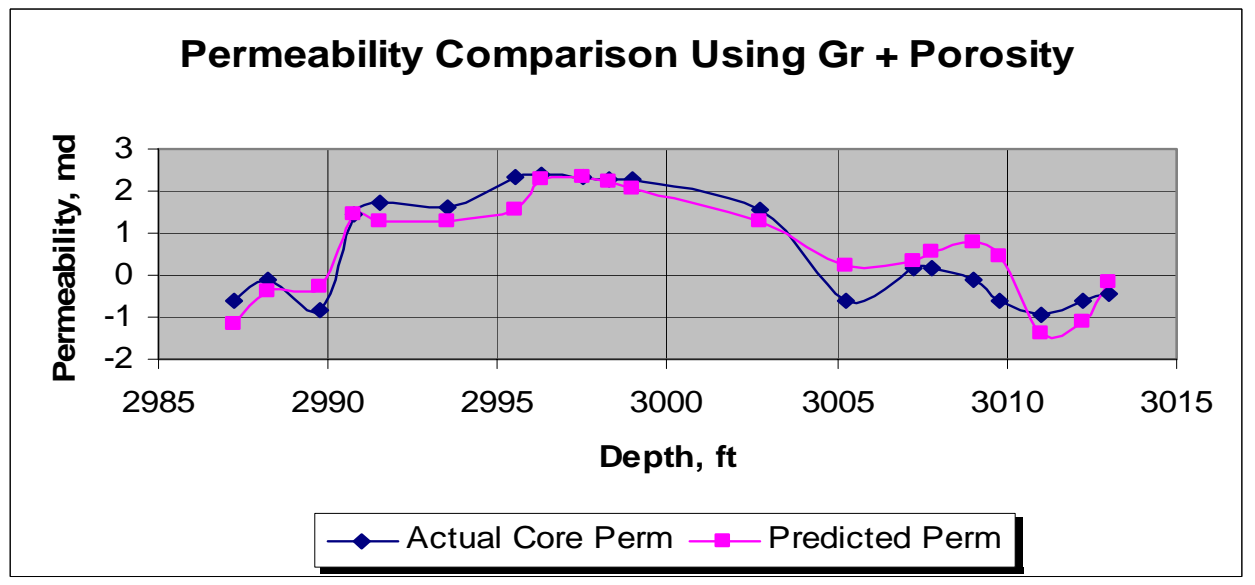


Figure B-17. Multiple Regression Results for Ball 18 (run D + DS)

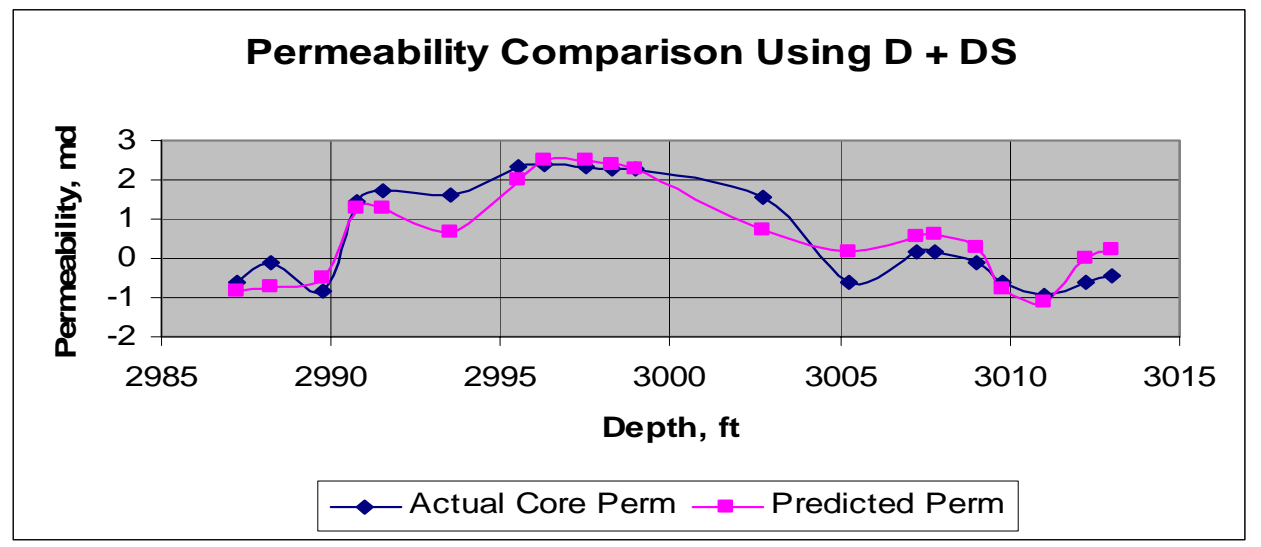

Figure B-18. Multiple Regression Results for Ball 18 (run D + GR + GS)

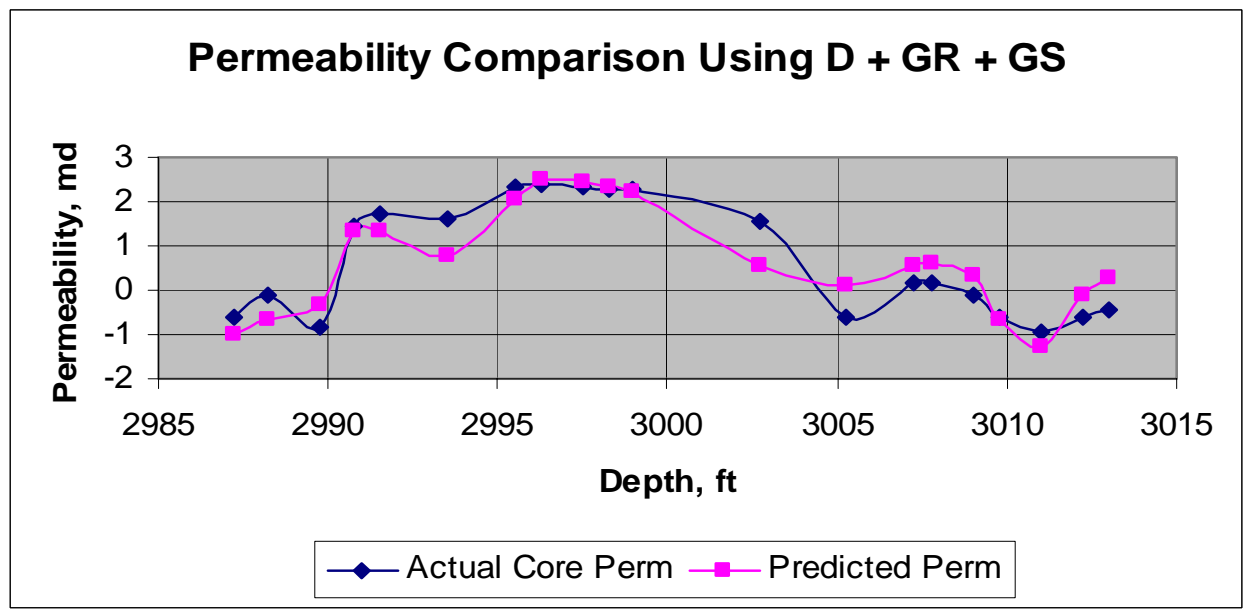

Figure B-19. Multiple Regression Results for Ball 18 (run D + DS + GR)

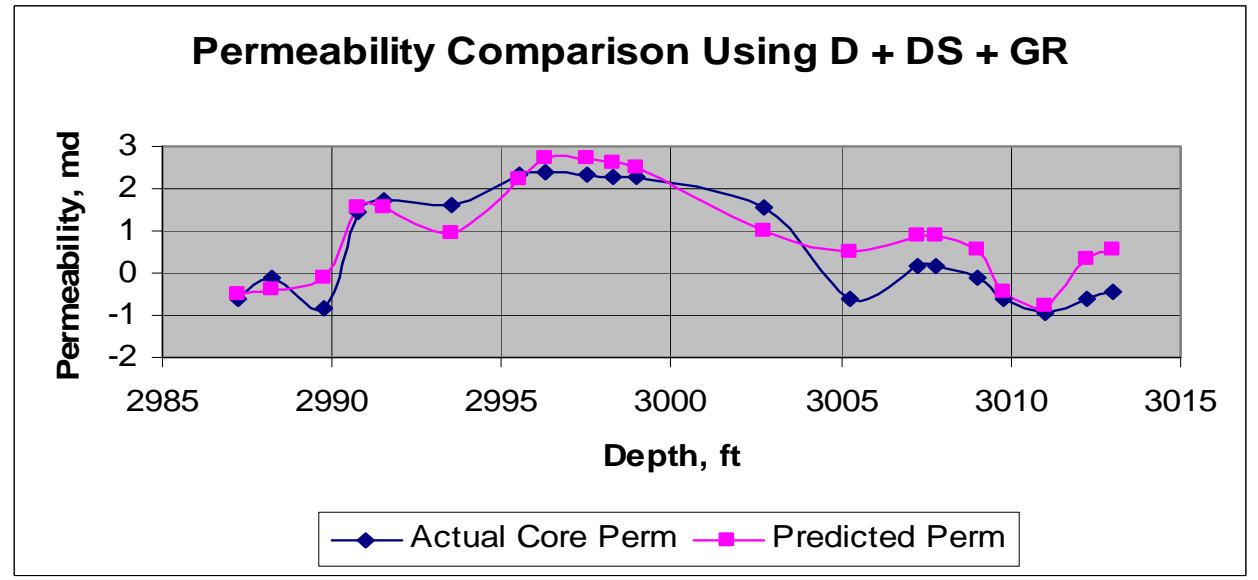


Figure B-20. Multiple Regression Results for Ball 18 (run D + DS + GS)

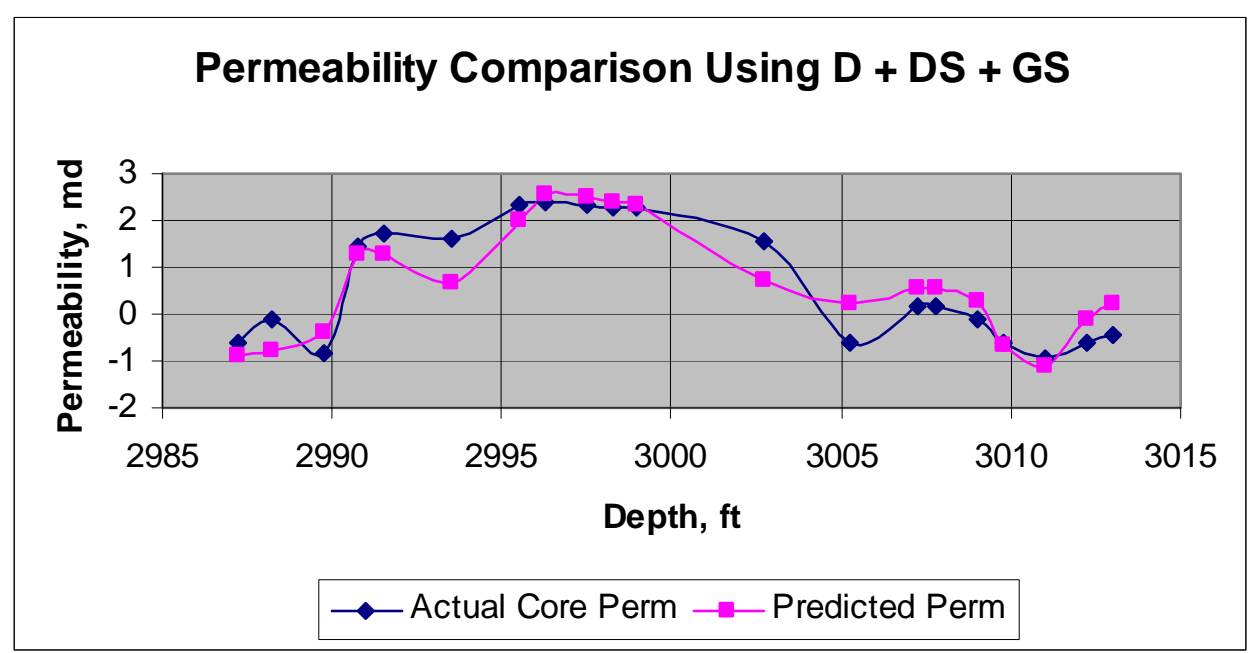


Figure B-21. Multiple Regression Results for Ball 18 Using Flow Units

(Run D + DS +GS)
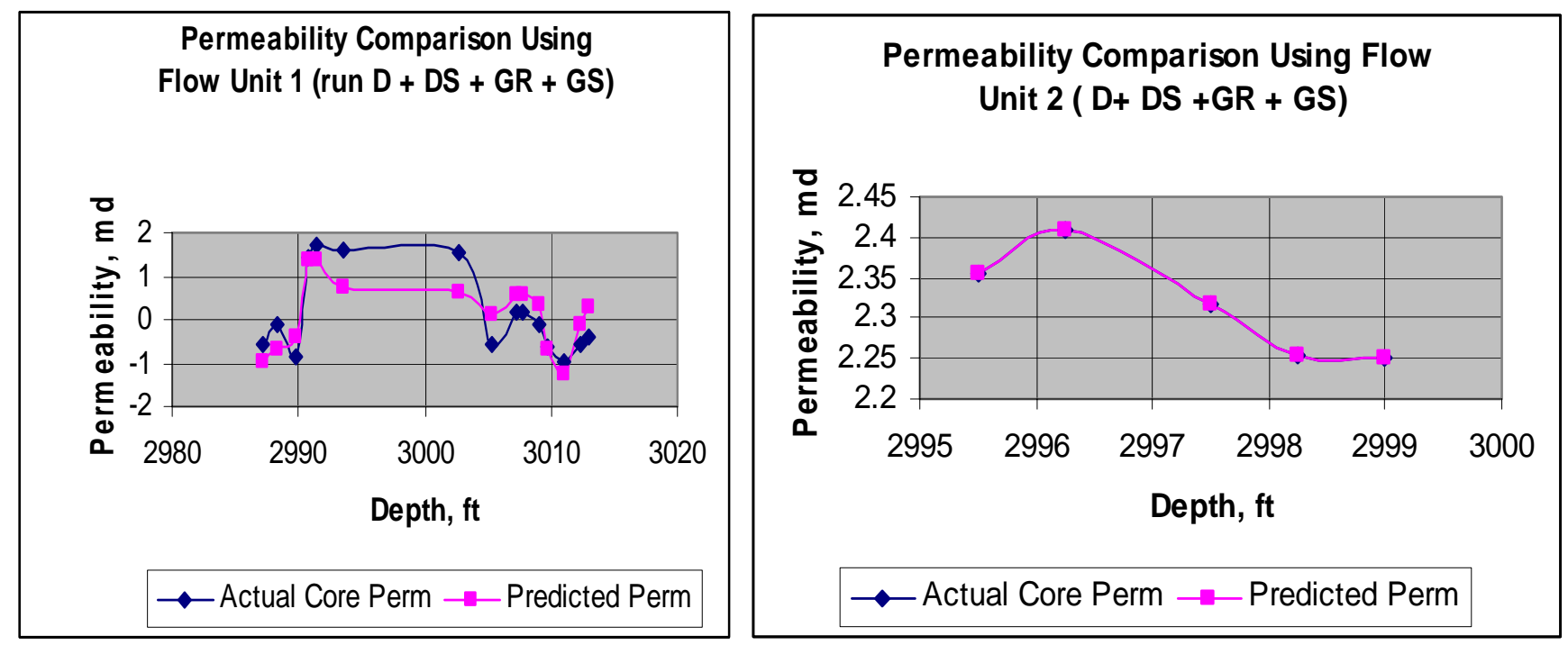

Figure B-22. Multiple Regression Results for Ball 18 Using Flow Units (D + DS)
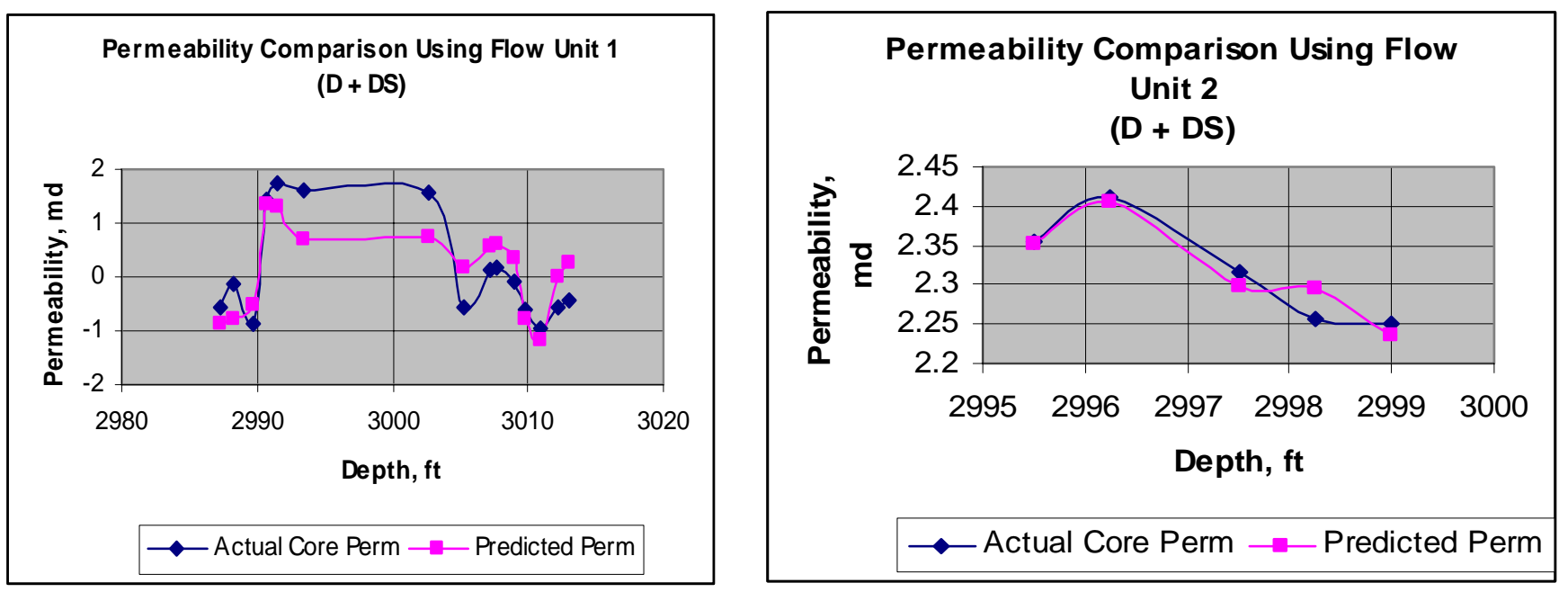
Figure B-23. Multiple Regression Results for Ball 18 Using Flow Units

$(D+G R+G S)$
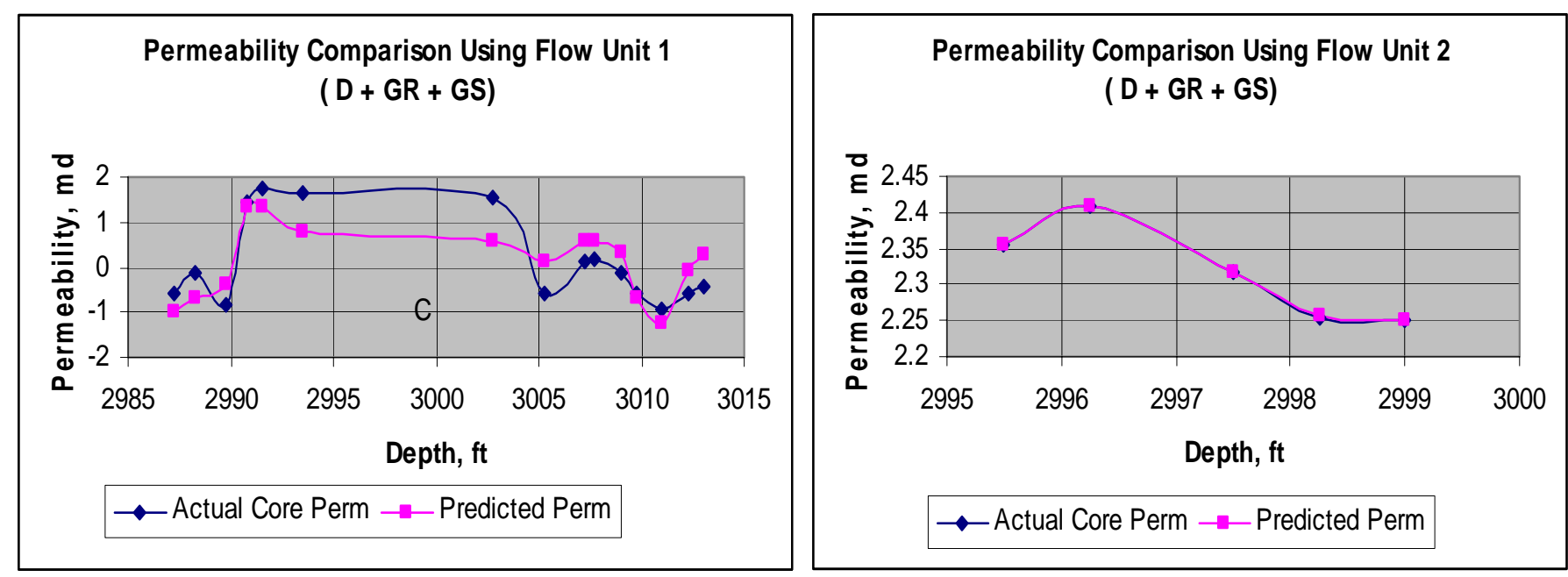

Figure B-24. Multiple Regression Results for Ball 18 Using Flow Units (D + DS + GR)
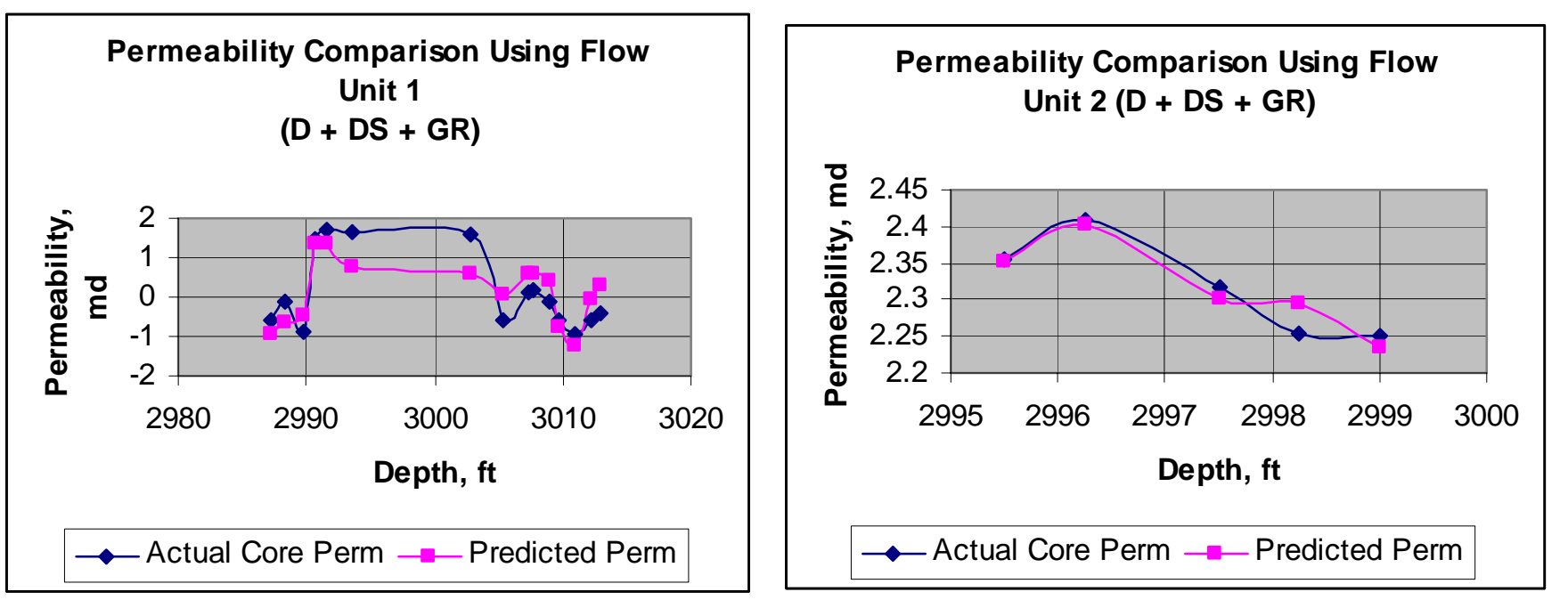
Figure B-25. Multiple Regression Results for Ball 18 Using Flow Units (D + DS + GS)
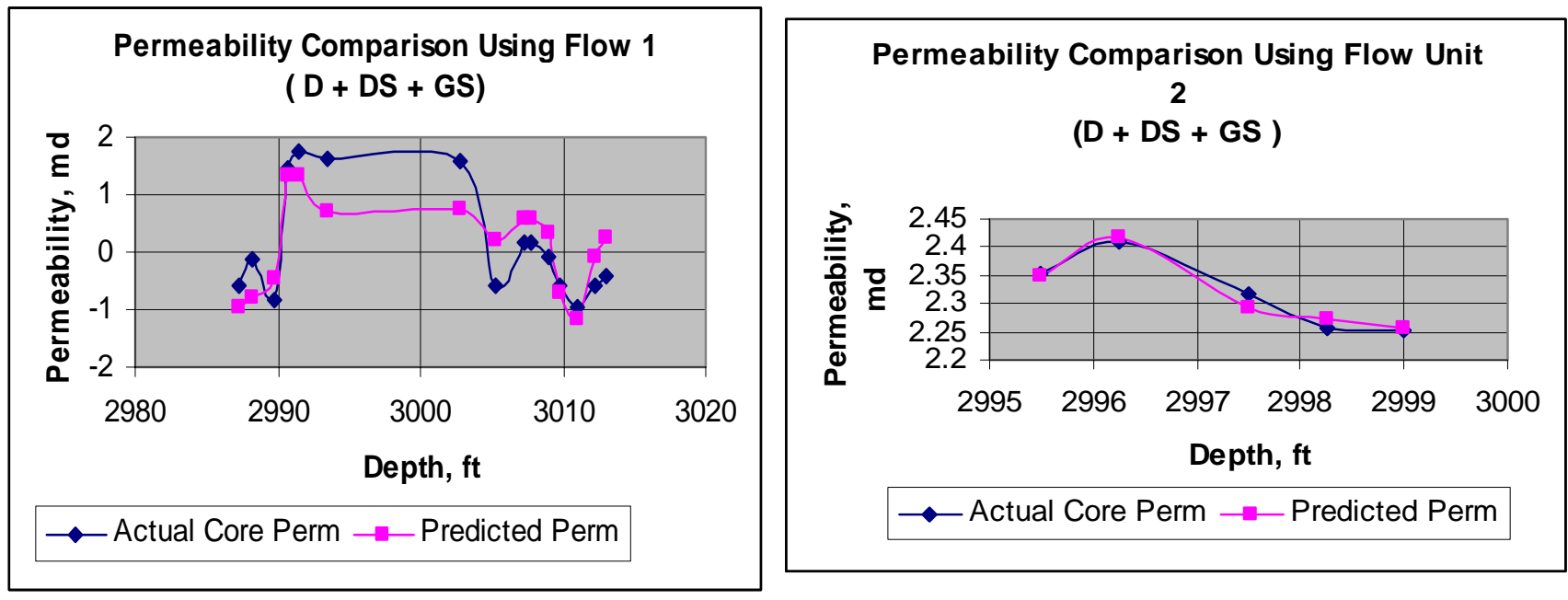
Figure B-26. Multiple Regression Results for Ball 19 (run D + DS + GR + GS)

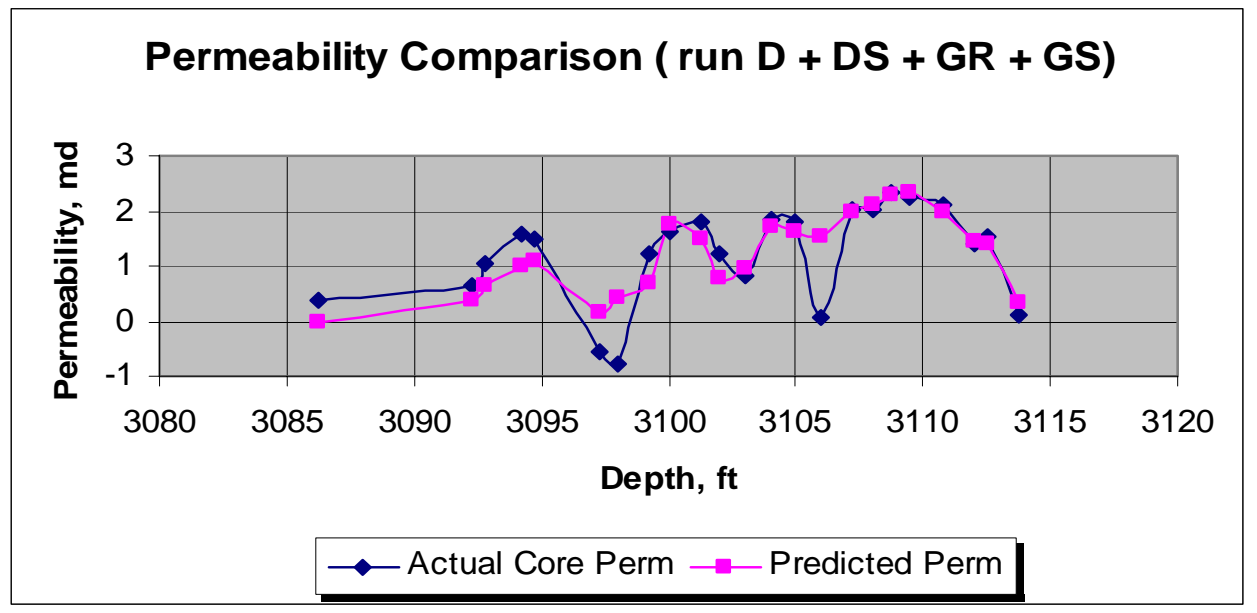

Figure B-27. Multiple Regression Results for Ball 19 (run D + GR)

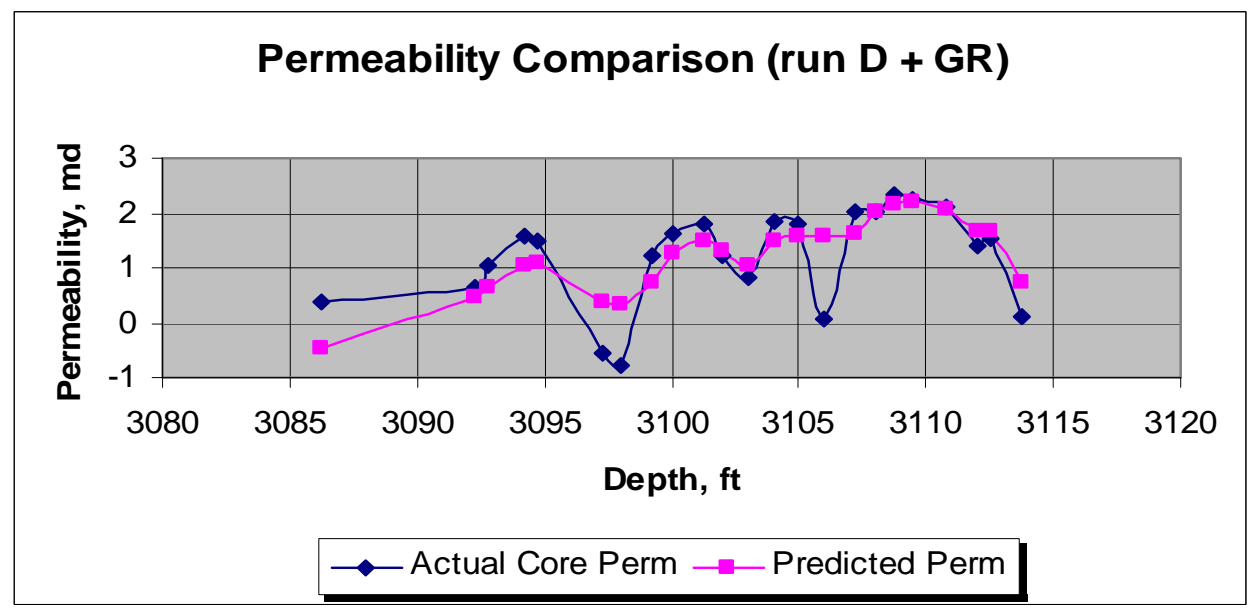

Figure B-28. Multiple Regression Results for Ball 19 (run D + DS)

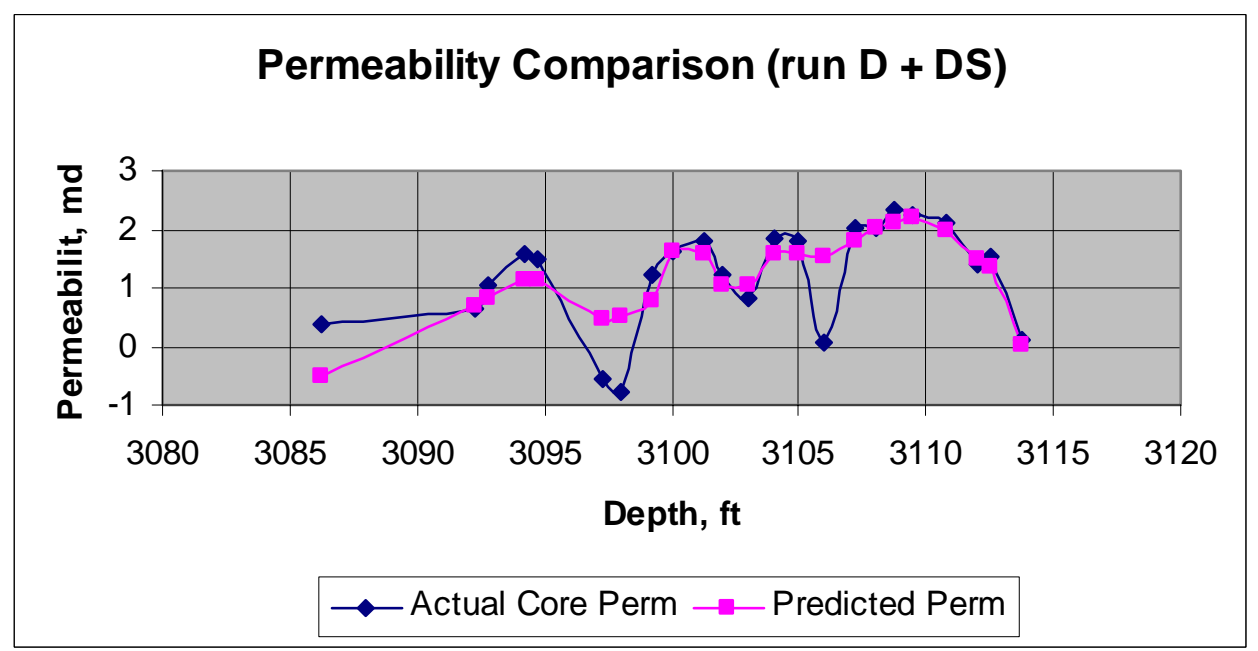


Figure B-29. Multiple Regression Results for Ball 19 (run D + GR + GS)

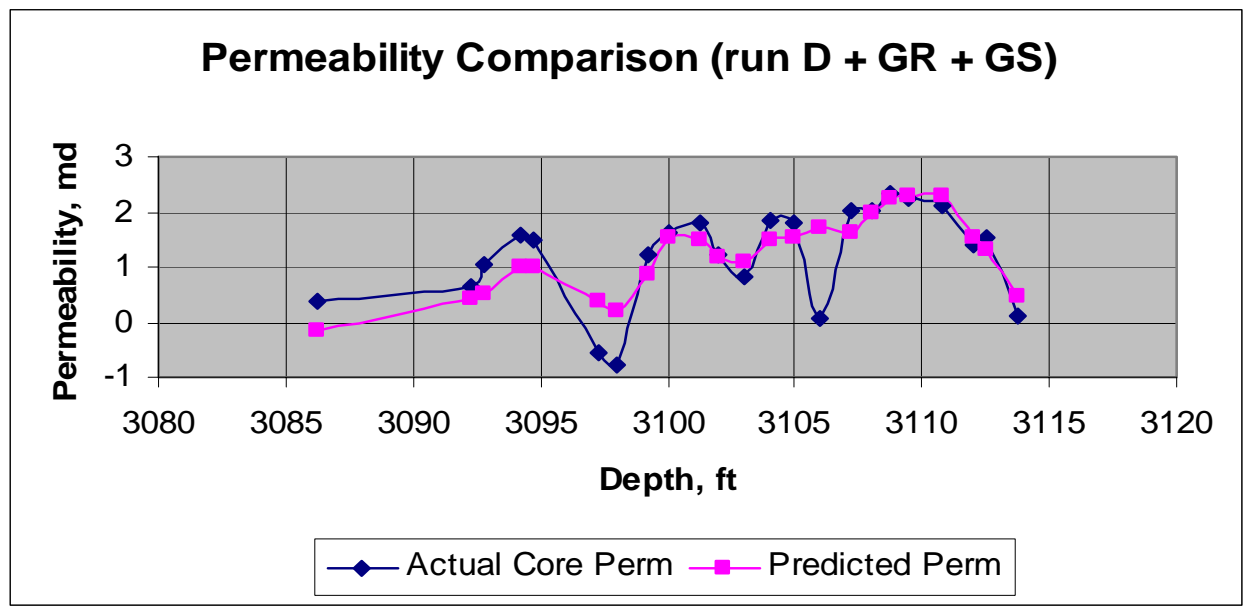

Figure B-30. Multiple Regression Results for Ball 19 (run D + DS + GR)

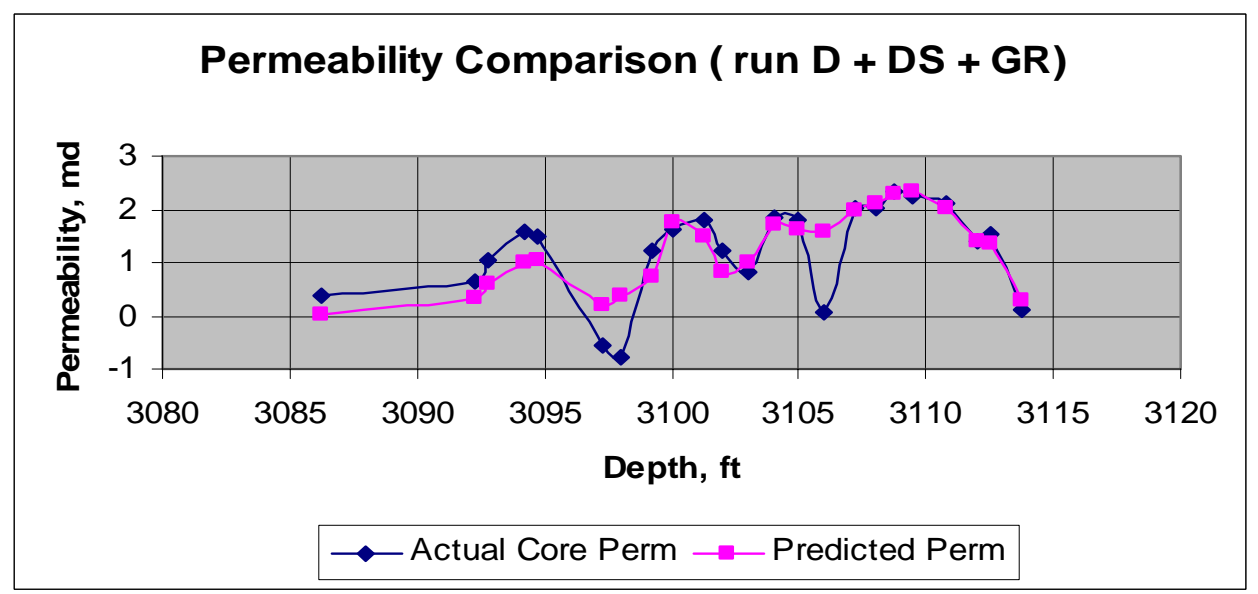

Figure B-31. Multiple Regression Results for Ball 19 (run D + DS + GS)

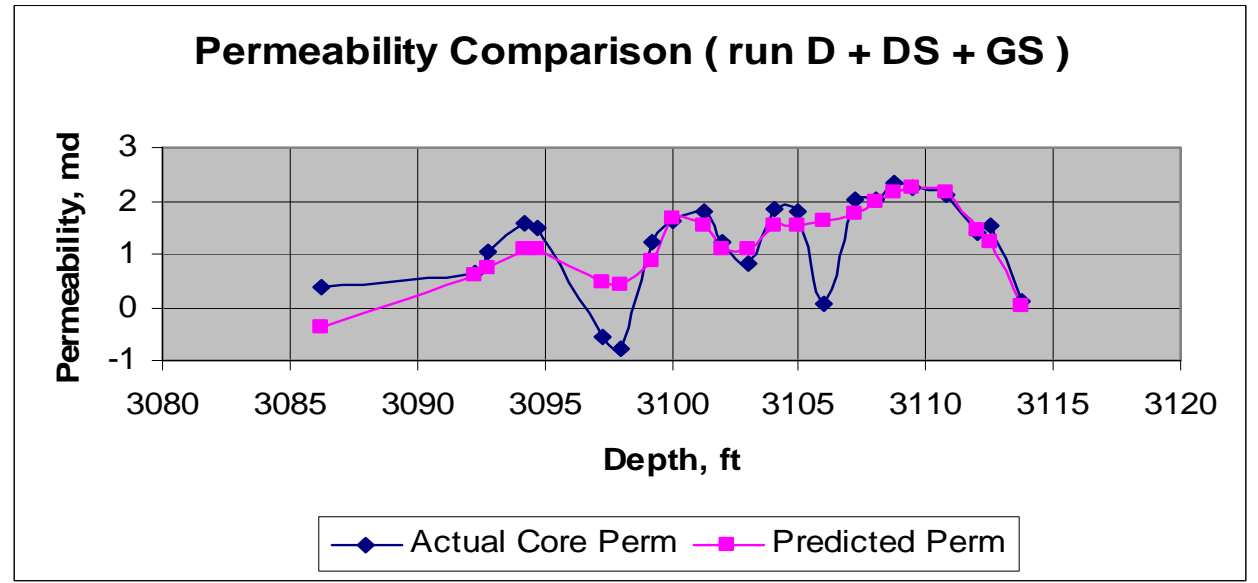


Figure B-32. Multiple Regression Results for Ball 19 Using Flow Units (D + DS + GR + GS)
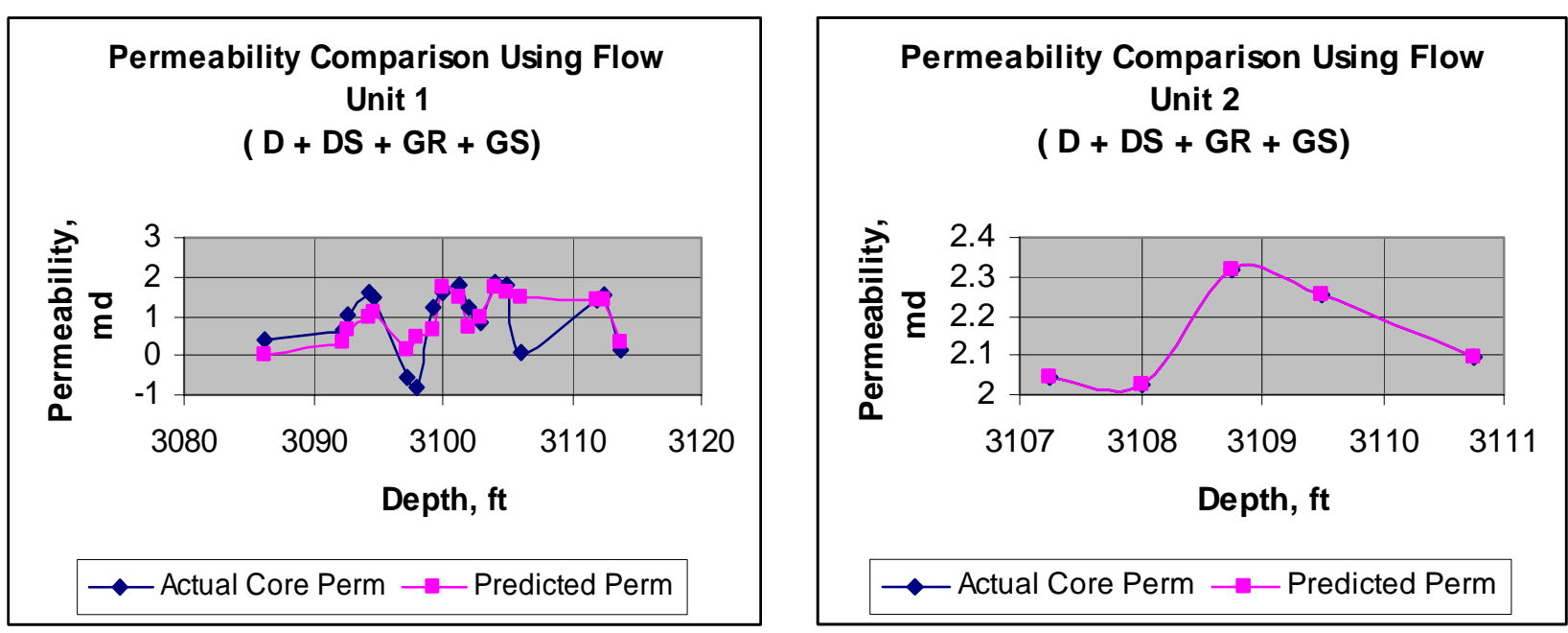

Figure B-33. Multiple Regression Results for Ball 19 Using Flow Units (D + GR)
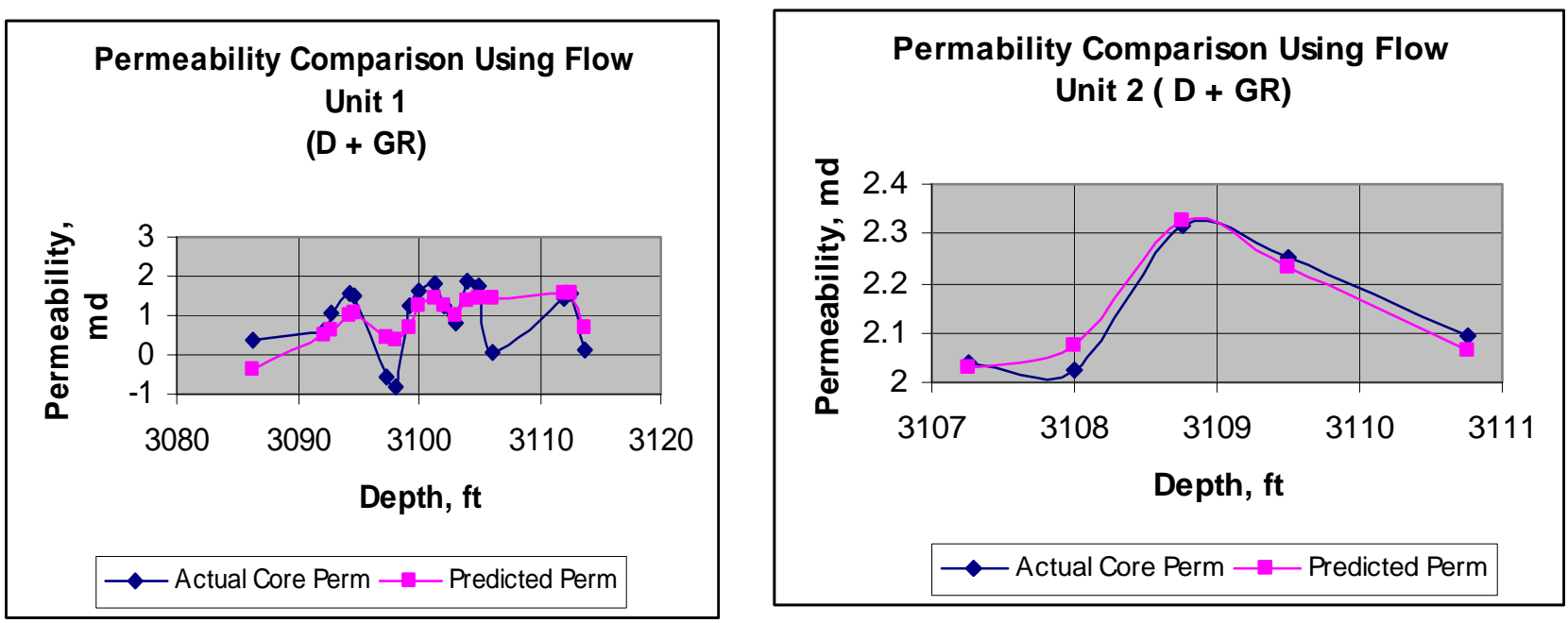
Figure B-34. Multiple Regression Results for Ball 19 Using Flow Units (D + DS)
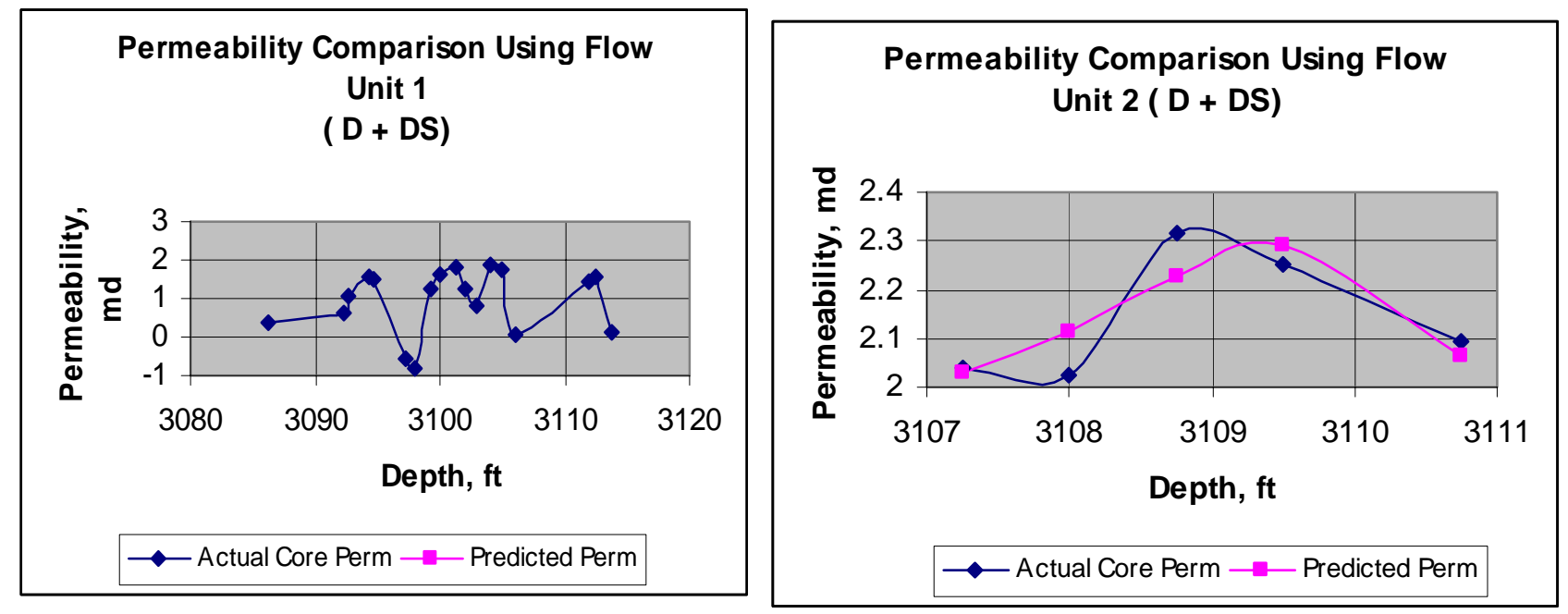

Figure B-35. Multiple Regression Results for Ball 19 Using Flow Units (D + GR + GS)
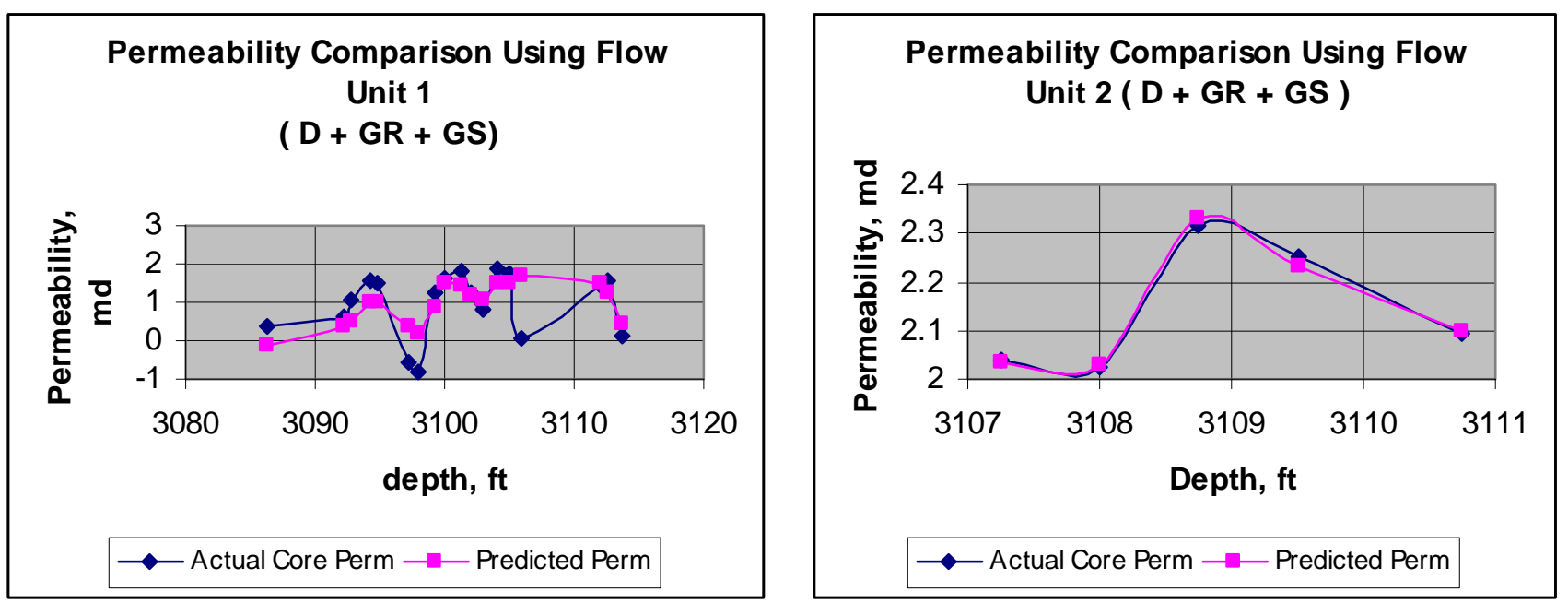
Figure B-36. Multiple Regression Results for Ball 19 Using Flow Units (D + DS + GR)
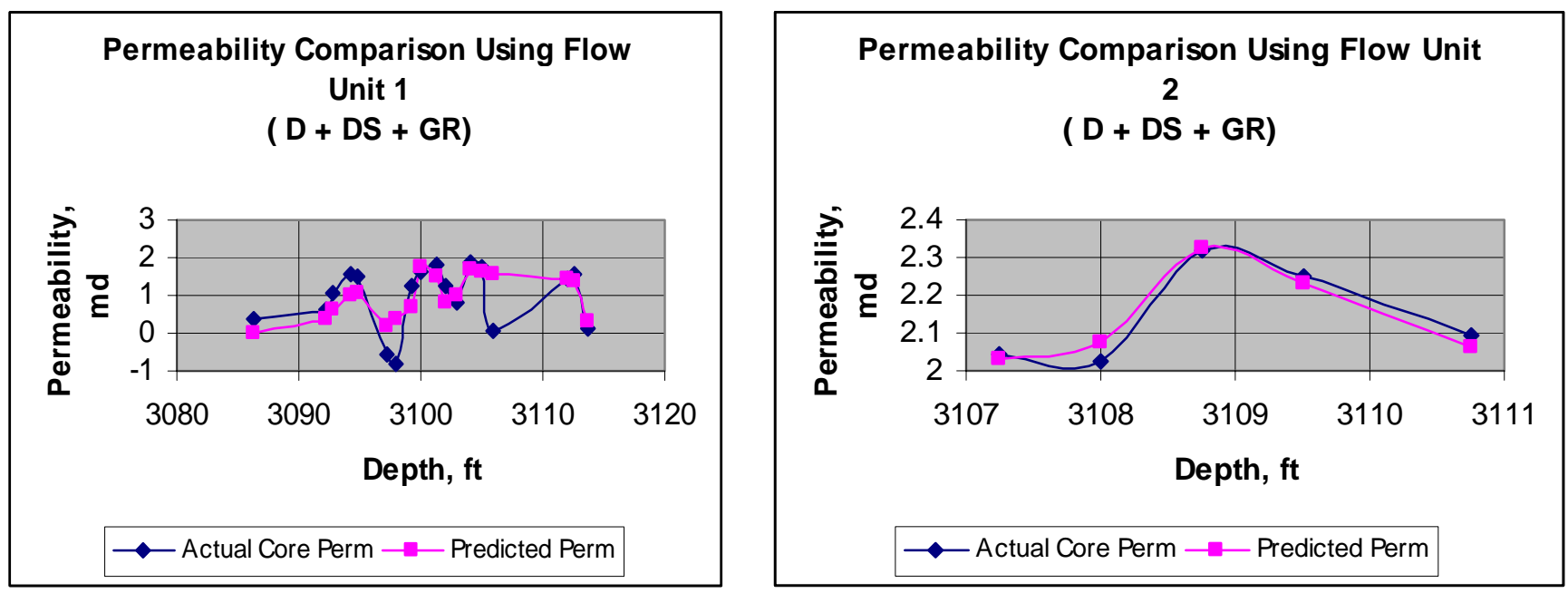

Figure B-37. Multiple Regression Results for Ball 19 Using Flow Units (D + DS + GS)
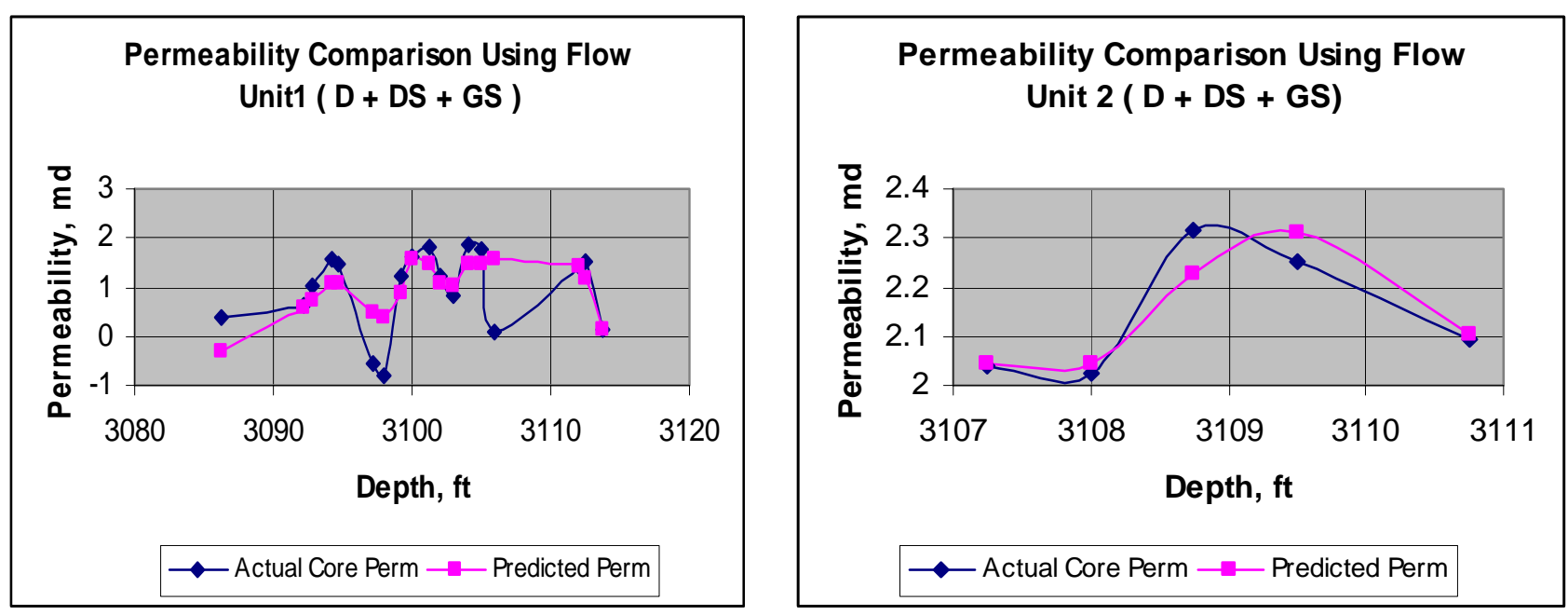
Figure B-38. Multiple Regression Results for Thompson 8 (D + DS + GR + GS)

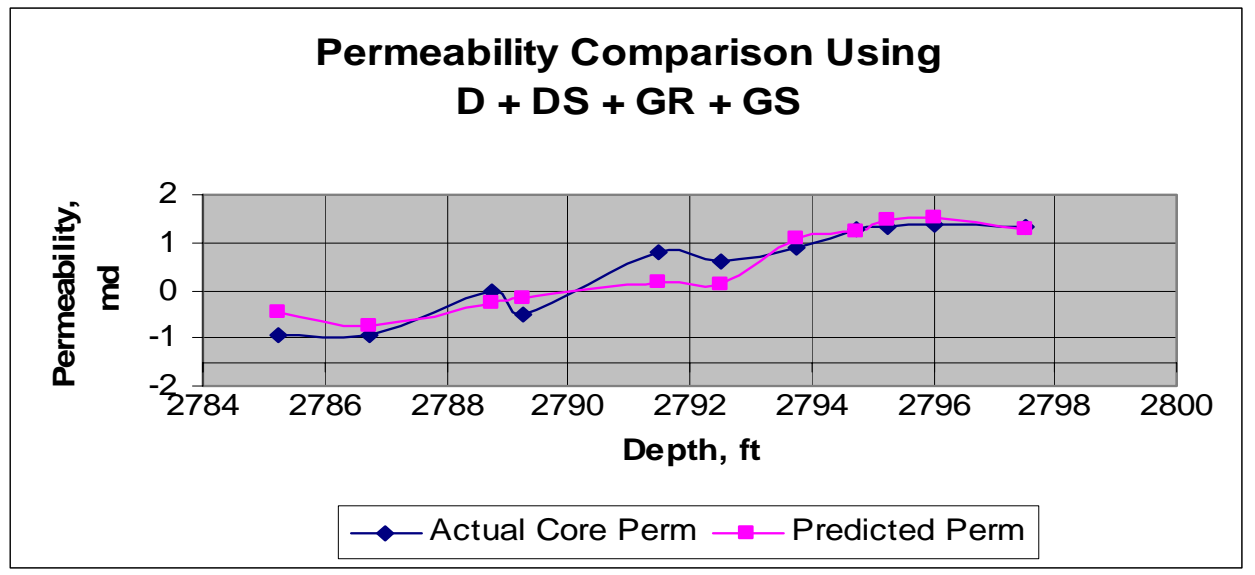

Figure B-39. Multiple Regression Results for Thompson 8 (D + GR)

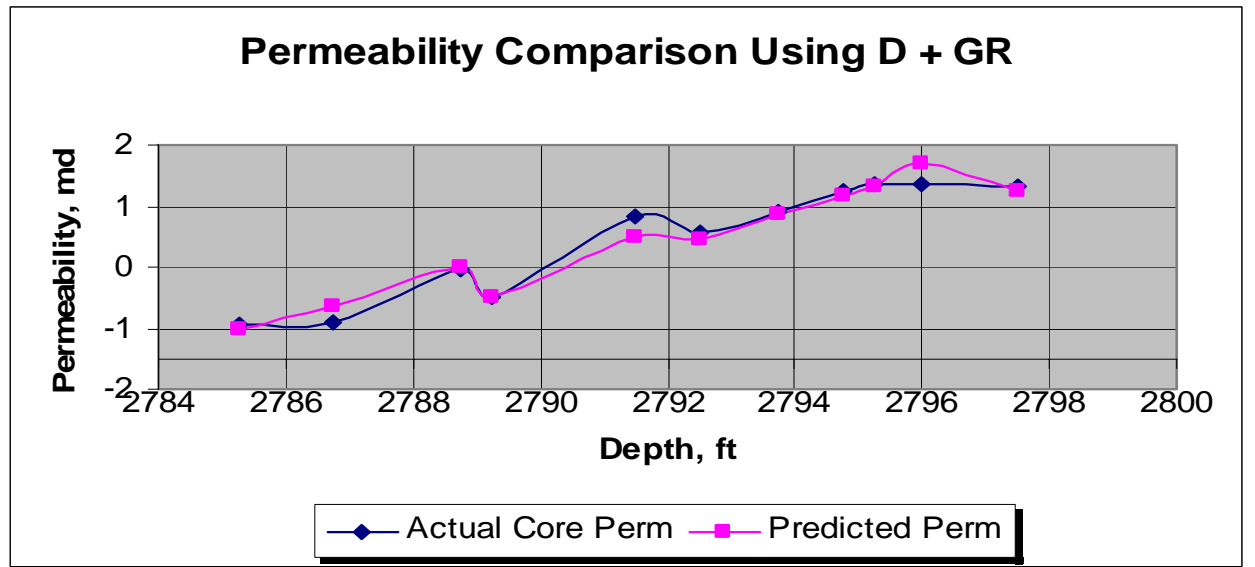

Figure B-40. Multiple Regression Results for Thompson 8 (GR + Porosity)

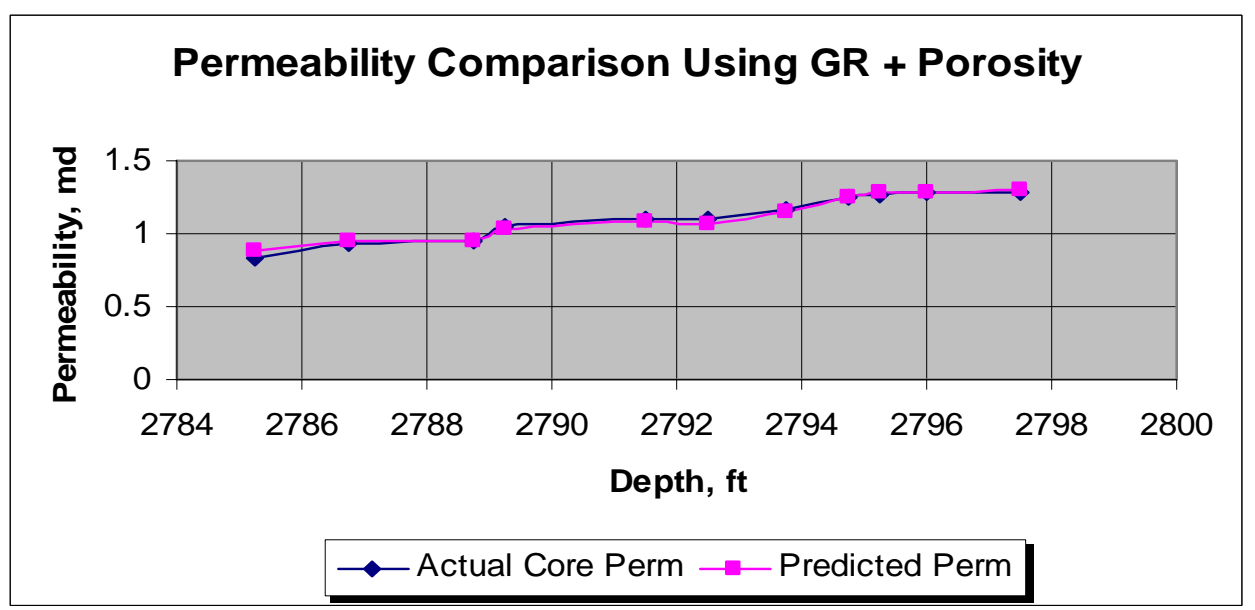


Figure B-41. Multiple Regression Results for Thompson 8 (D + DS)

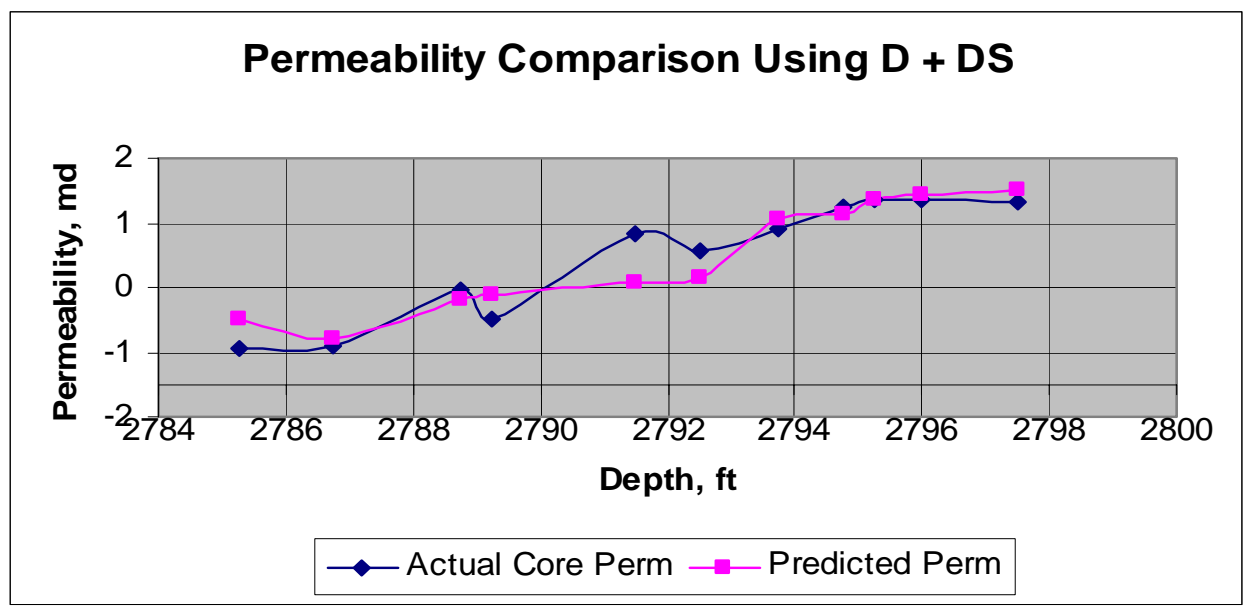

Figure B-42. Multiple Regression Results for Thompson 8 (D + GR + GS)

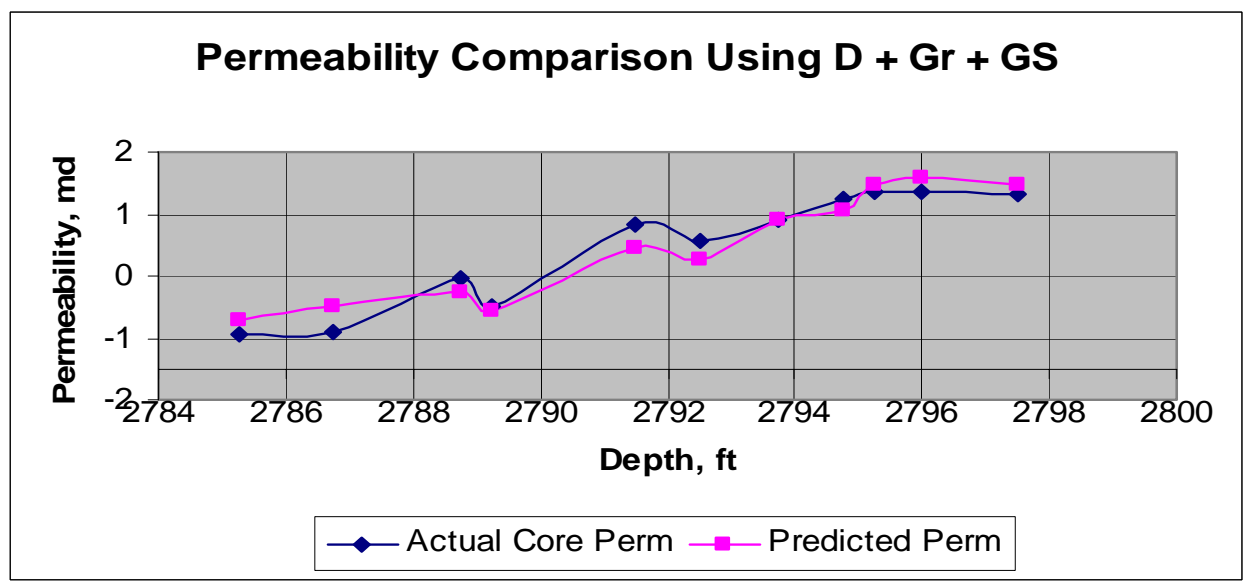

Figure B-43. Multiple Regression Results for Thompson 8 (D + DS + GR)

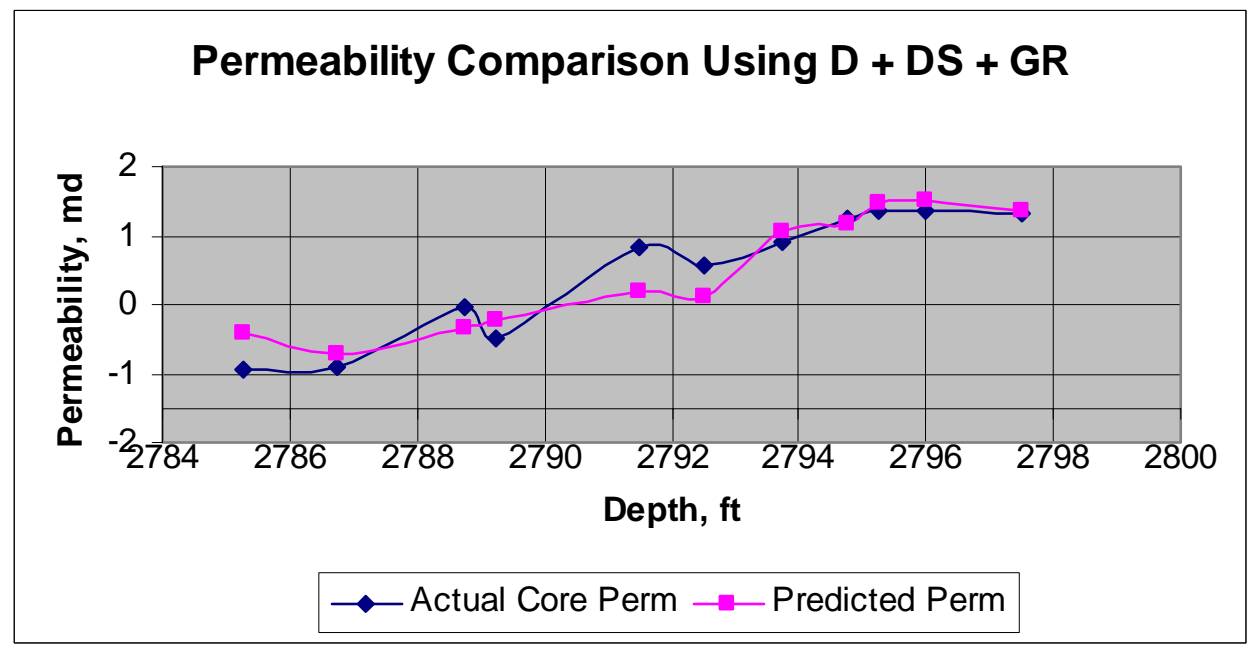


Figure B-44. Multiple Regression Results for Thompson 8 (D + DS + GS)

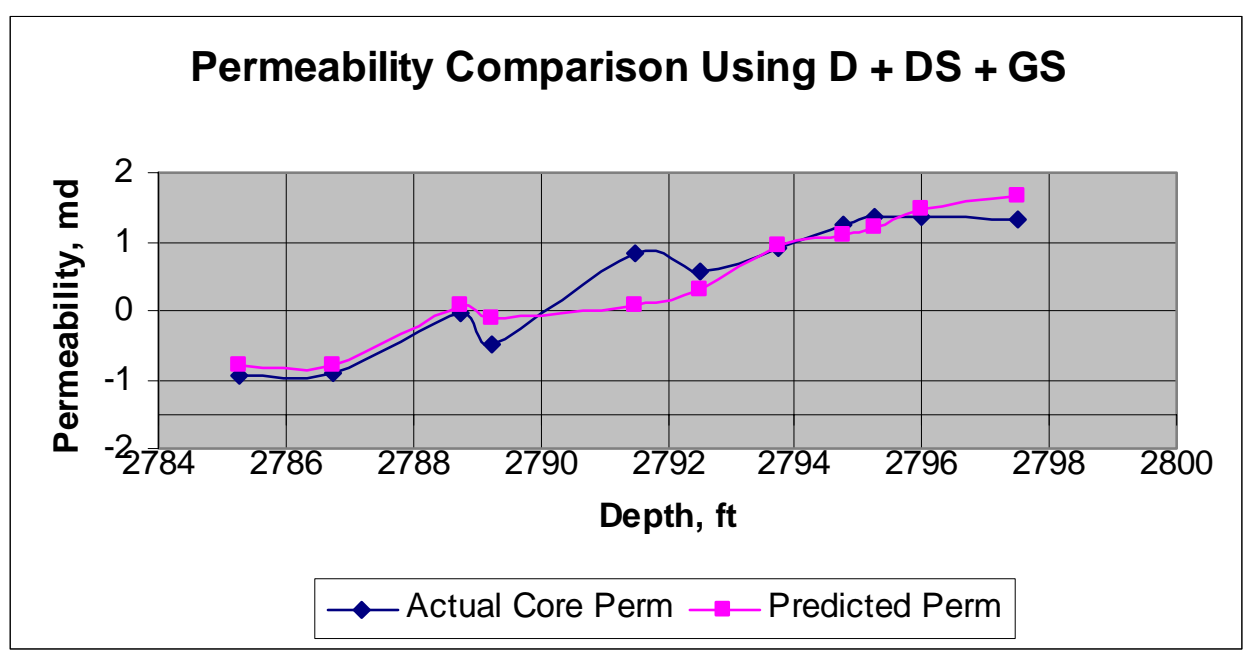


APPENDIX C

MULTIPLE REGRESSION RESULTS FOR COMBINATION OF WELLS 
Figure C-1. Multiple Regression Results for P11 + B18 (D + GR)

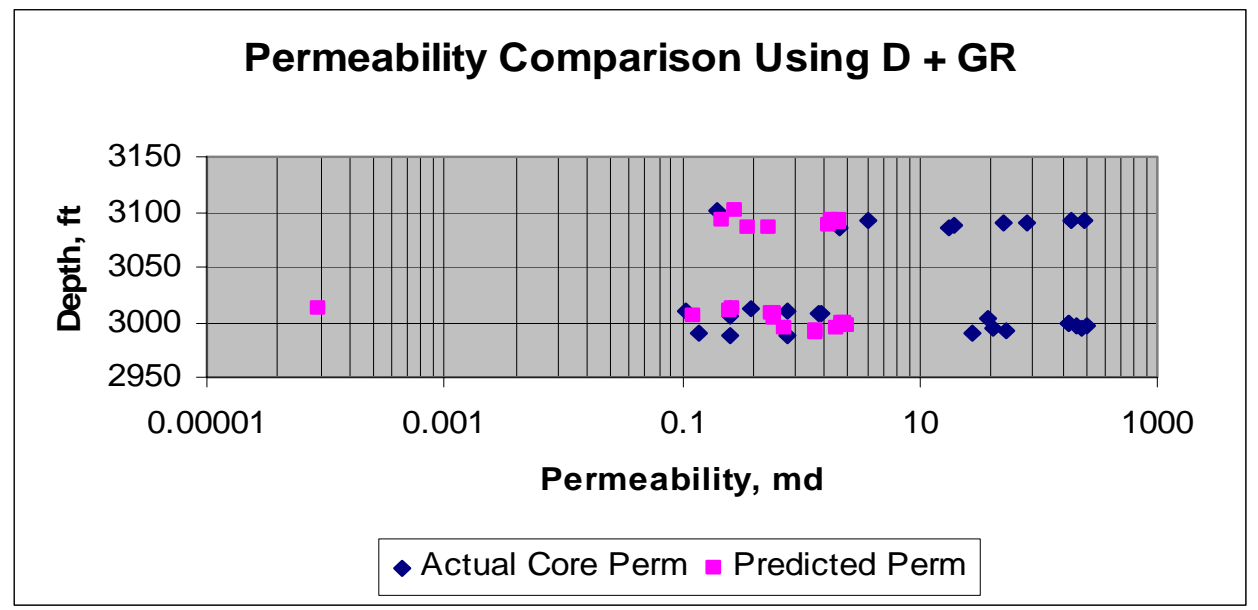

Figure C-2. Multiple Regression Results for P11 + B18 (D + DS)

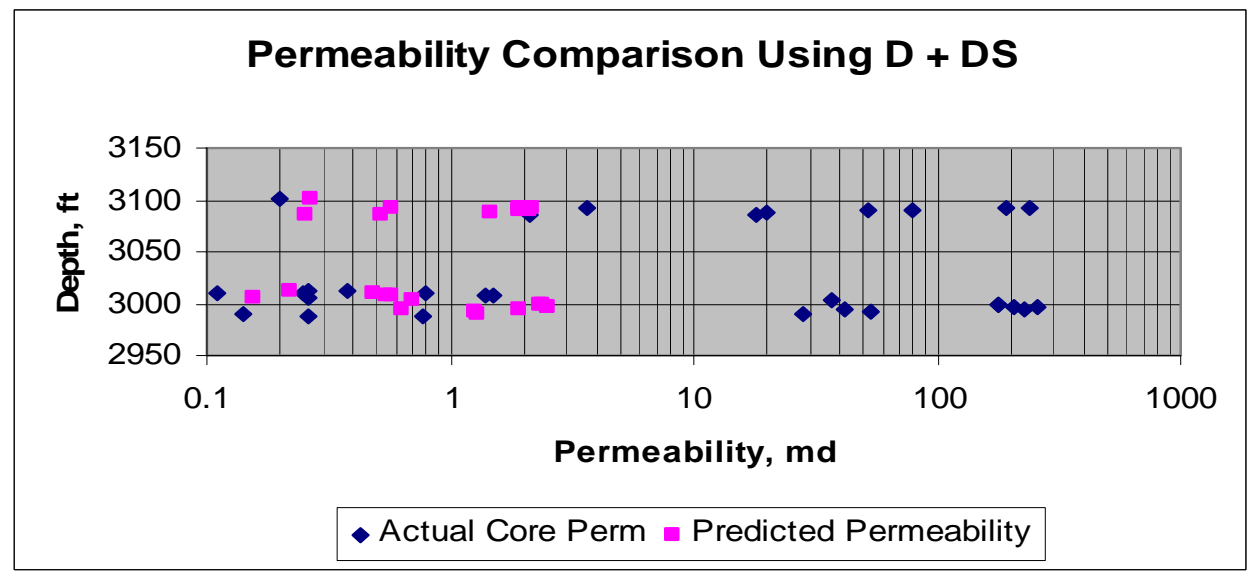

Figure C-3. Multiple Regression Results for P11 + B18 (D + GR + GS)

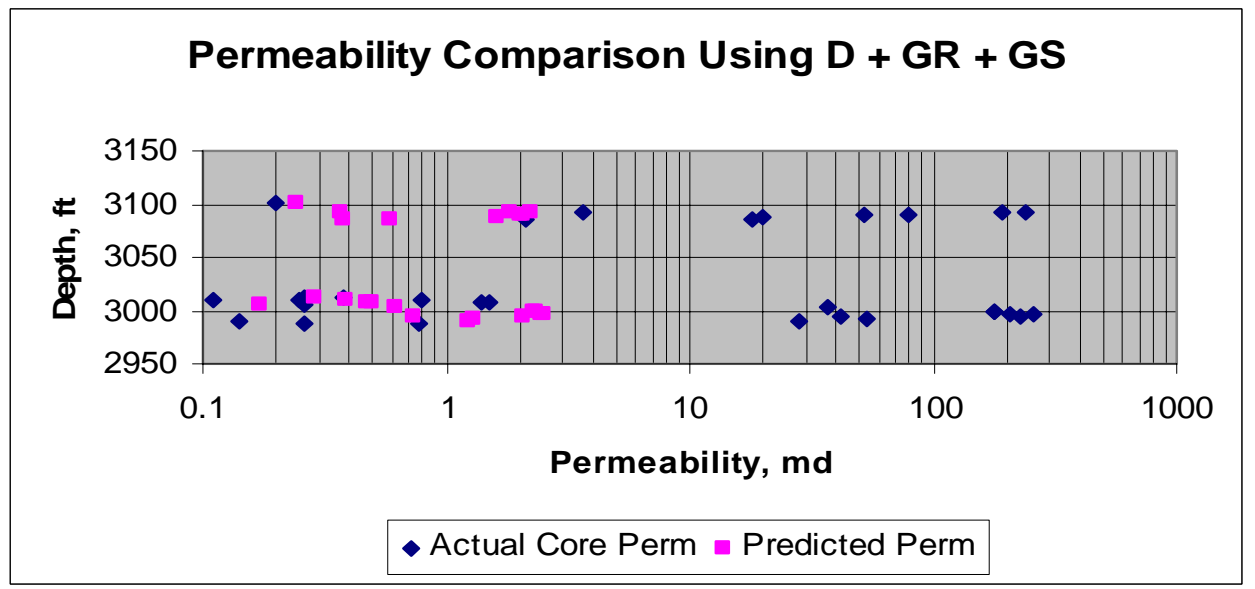


Figure C-4. Multiple Regression Results for P11 + B18 (D + DS + GR)

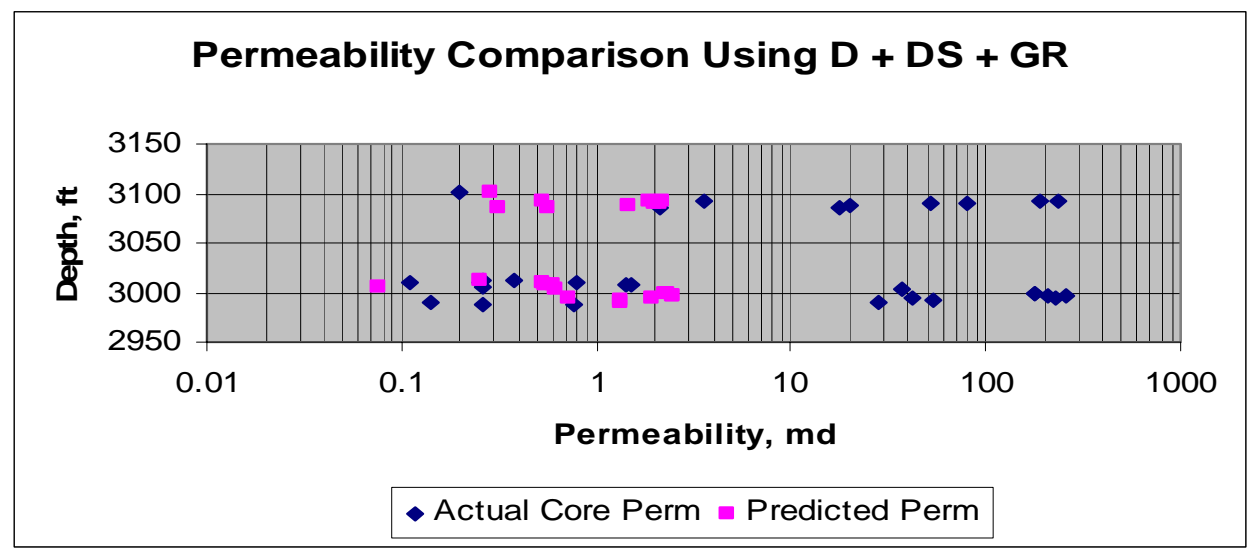

Figure C-5. Multiple Regression Results for P11 + B18 (D + DS + GS)

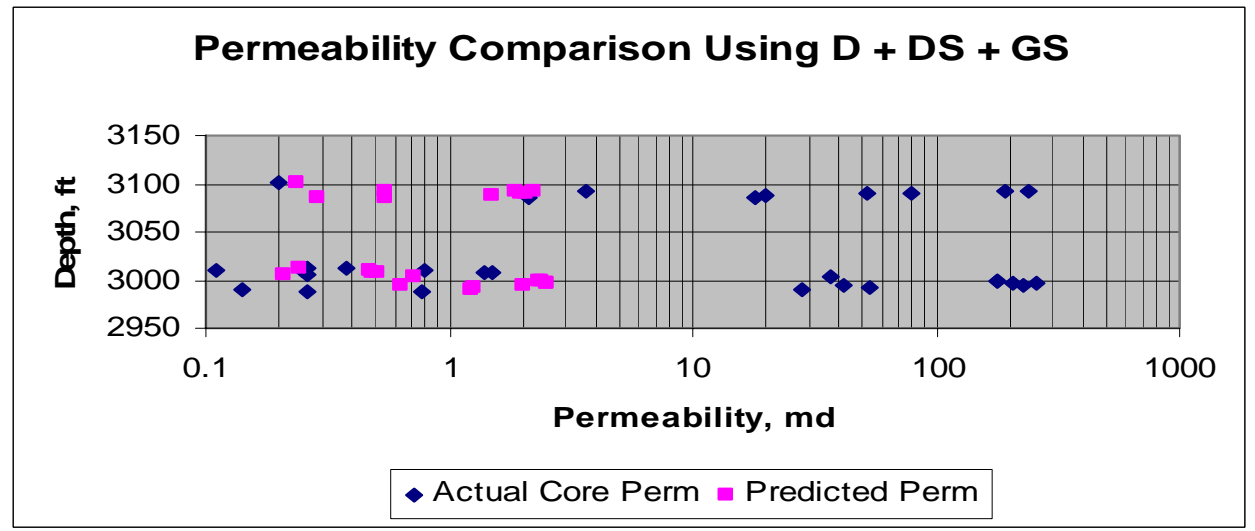


Figure C-6. Multiple Regression Results for P11 + B18 + B19 (D + GR + DS + GS)

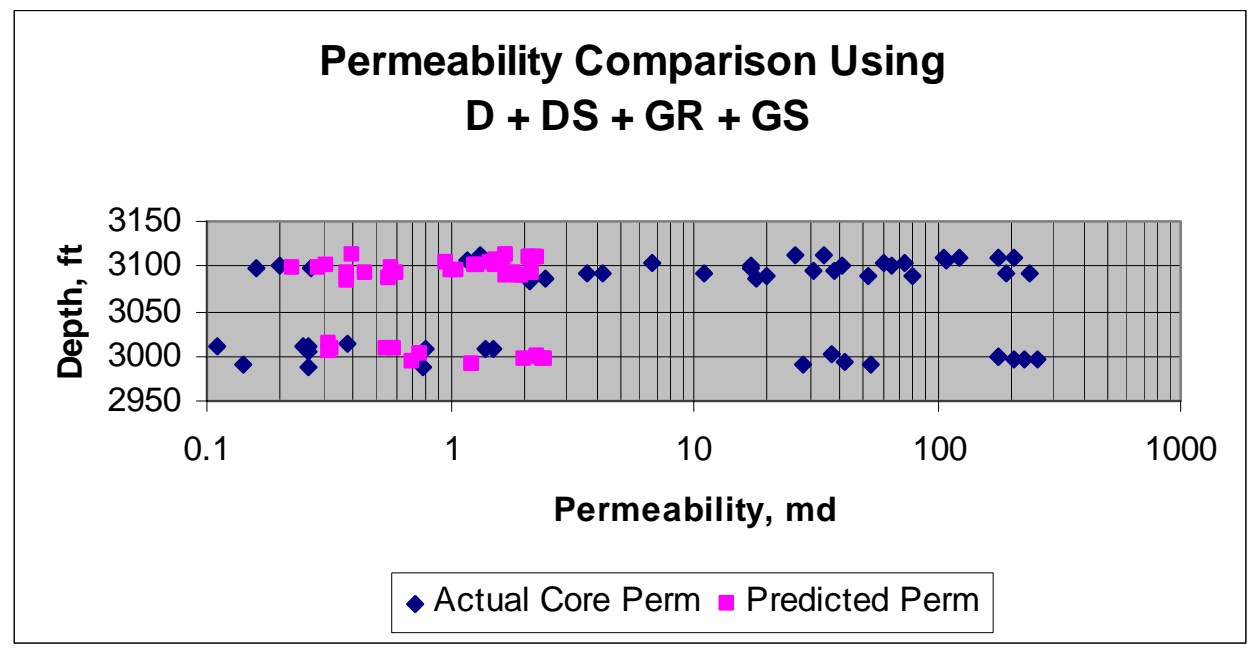

Figure C-7. Multiple Regression Results for P11 + B18 + B19 (D + GR)

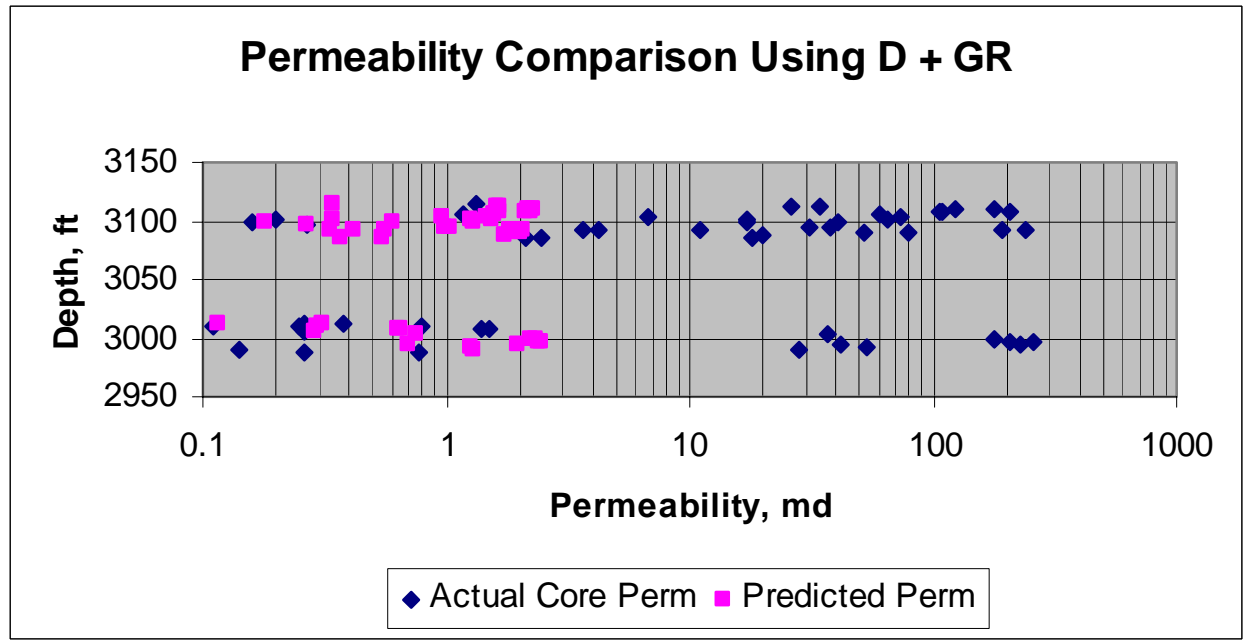

Figure C-8. Multiple Regression Results for P11 + B18 + B19 (GR + Porosity)

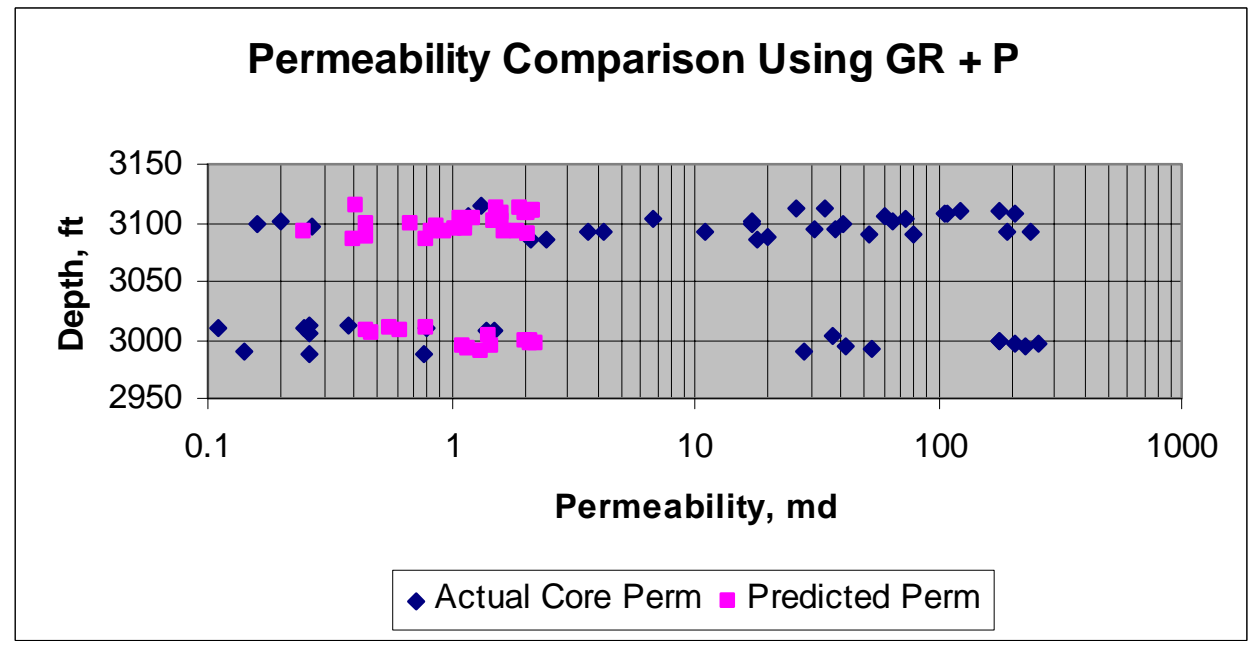


Figure C-9. Multiple Regression Results for P11 + B18 + B19 (D + DS)

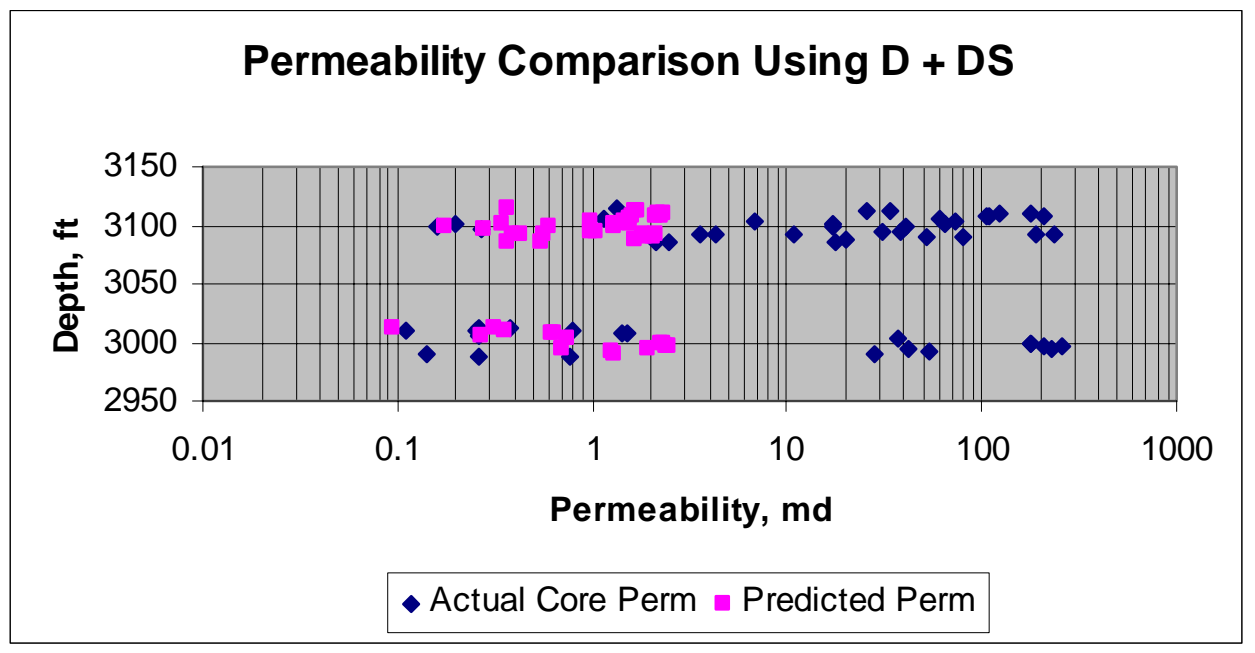

Figure C-10. Multiple Regression Results for P11 + B18 + B19 (D + GR +GS)

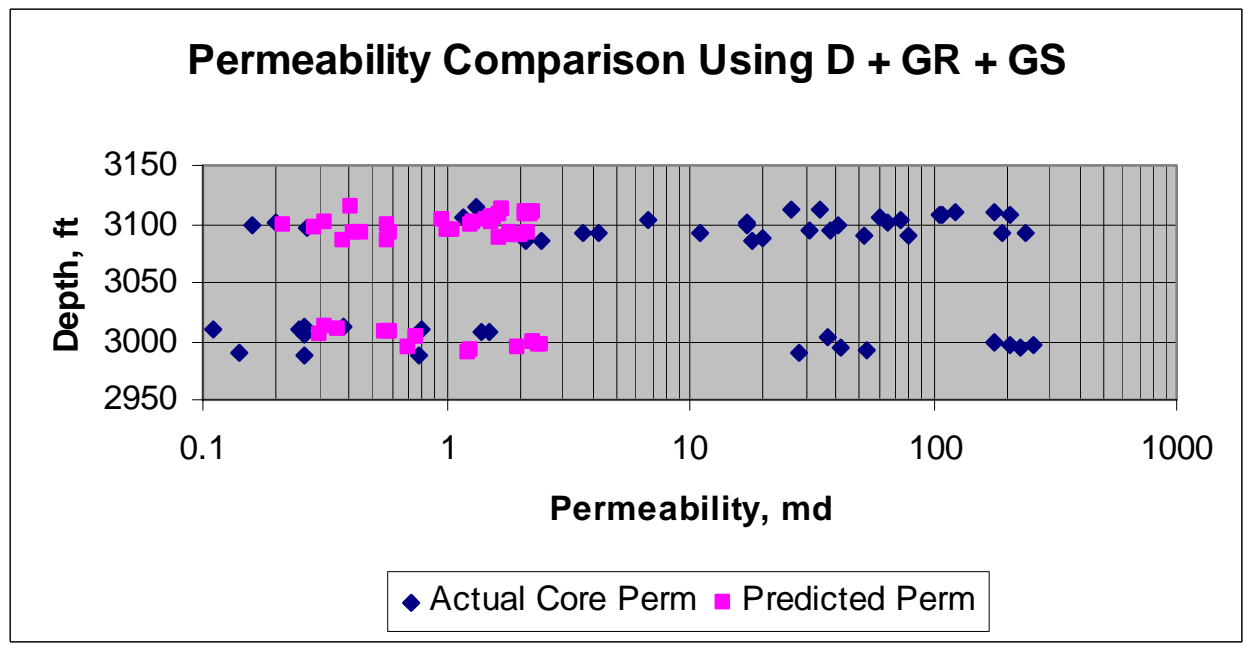

Figure C-11. Multiple Regression Results for P11 + B18 + B19 (D + DS +GR)

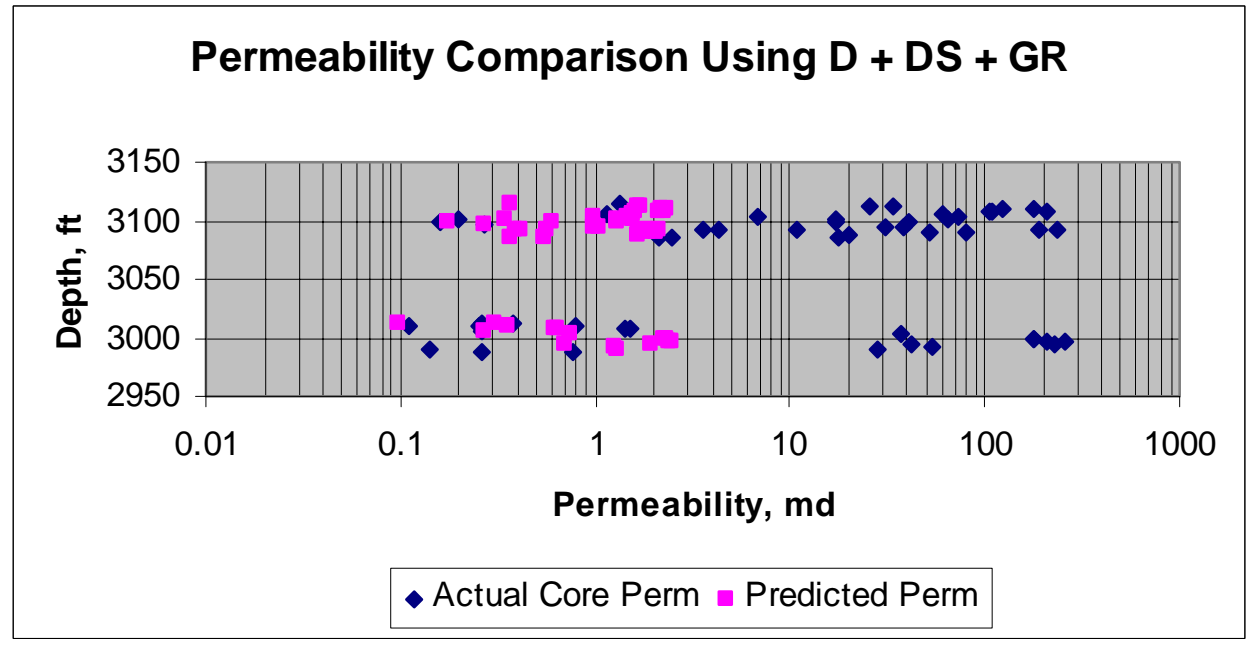


Figure C-12. Multiple Regression Results for P11 + B18 + B19 (D + DS +GS)

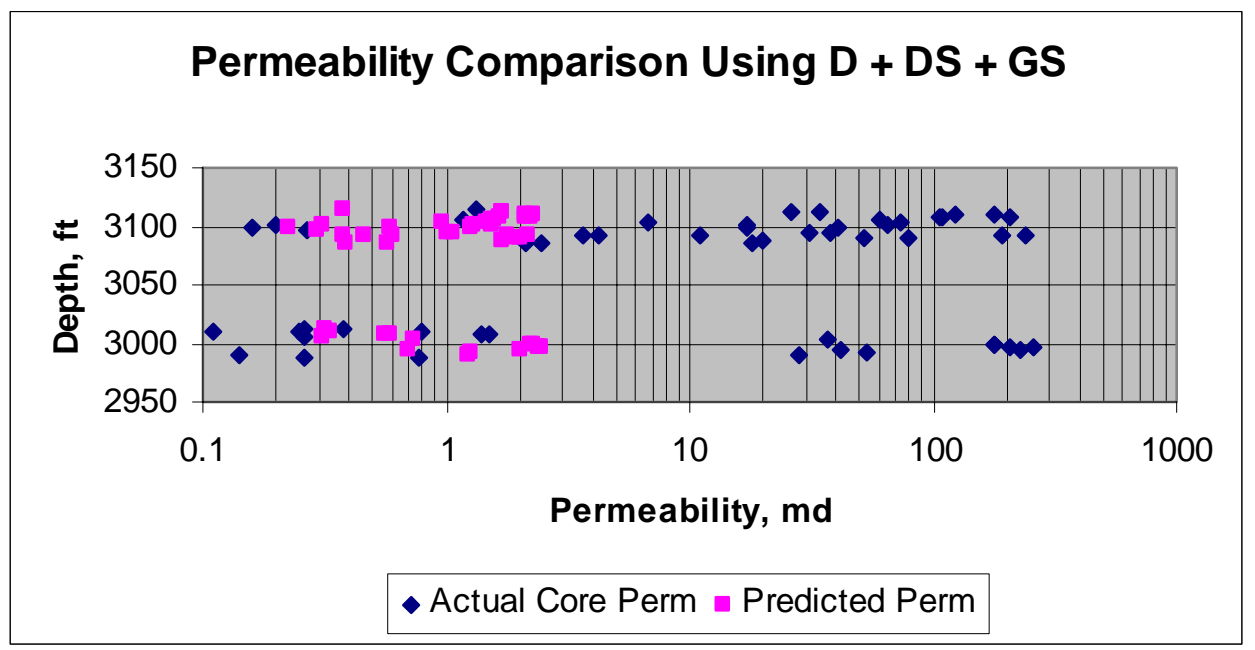


Figure C-13. Multiple Regression Results for P11 + B18 + B19 + T 8 (D + DS + GR + GS)

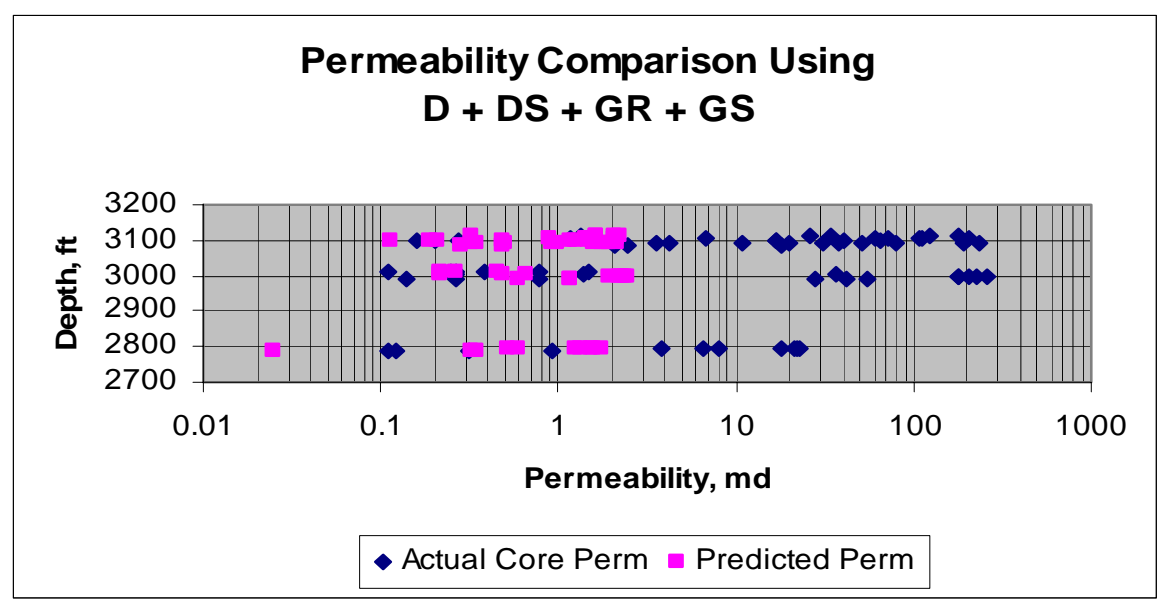

Figure C-14. Multiple Regression Results for P11 + B18 + B19 + T 8 (D + GR)

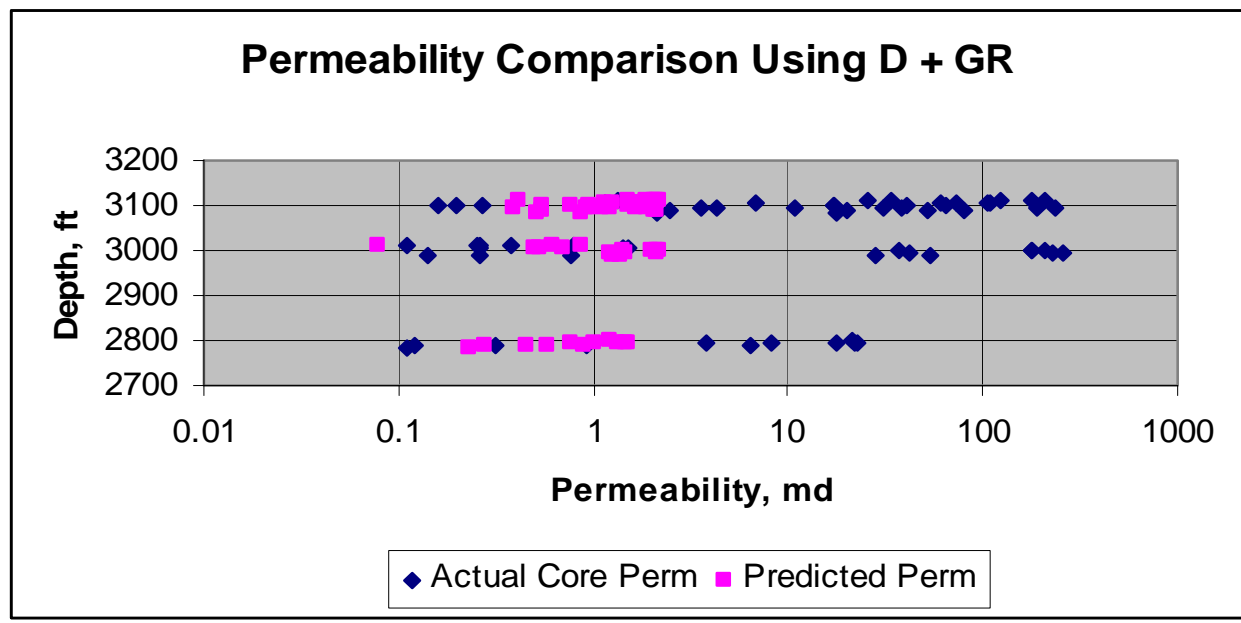

Figure C-15. Multiple Regression Results for P11 + B18 + B19 + T 8 (D + DS)

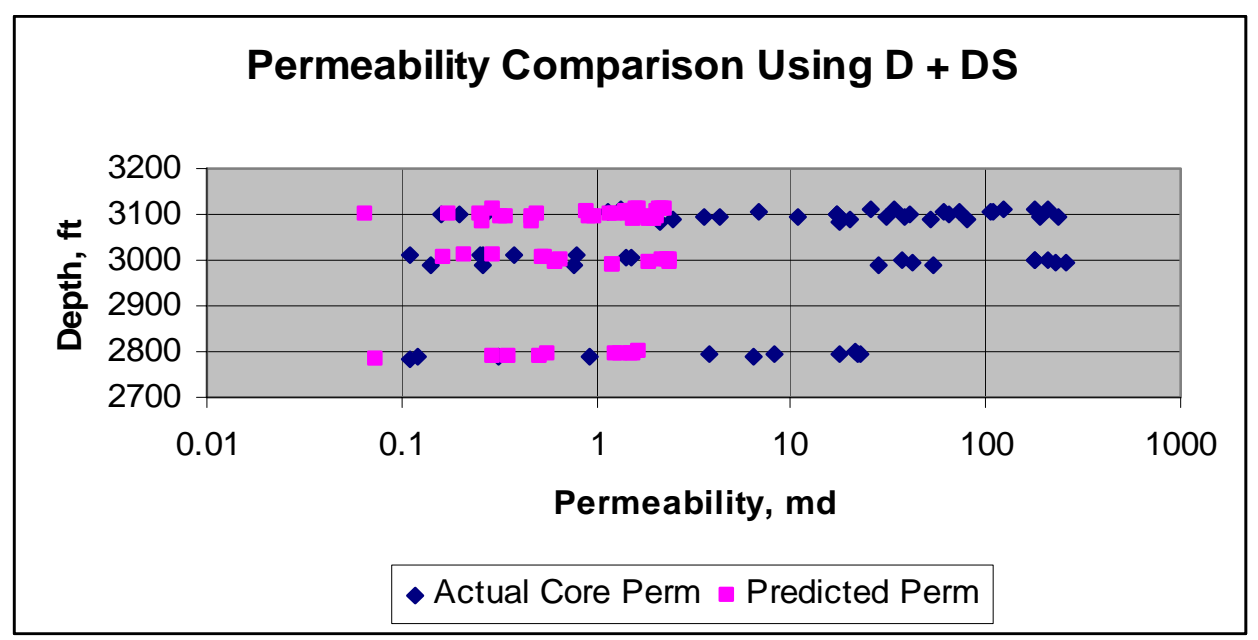


Figure C-16. Multiple Regression Results for P11 + B18 + B19 + T 8 (D + GR + GS)

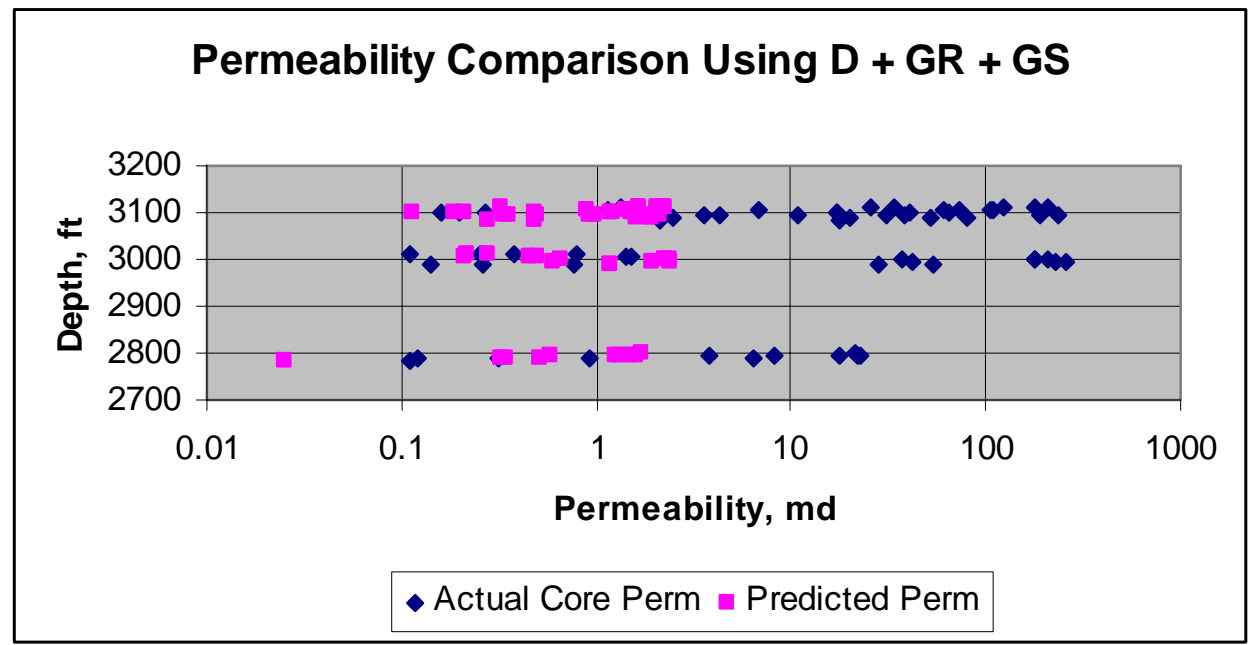

Figure C-17. Multiple Regression Results for P11 + B18 + B19 + T 8 (D + DS + GR)

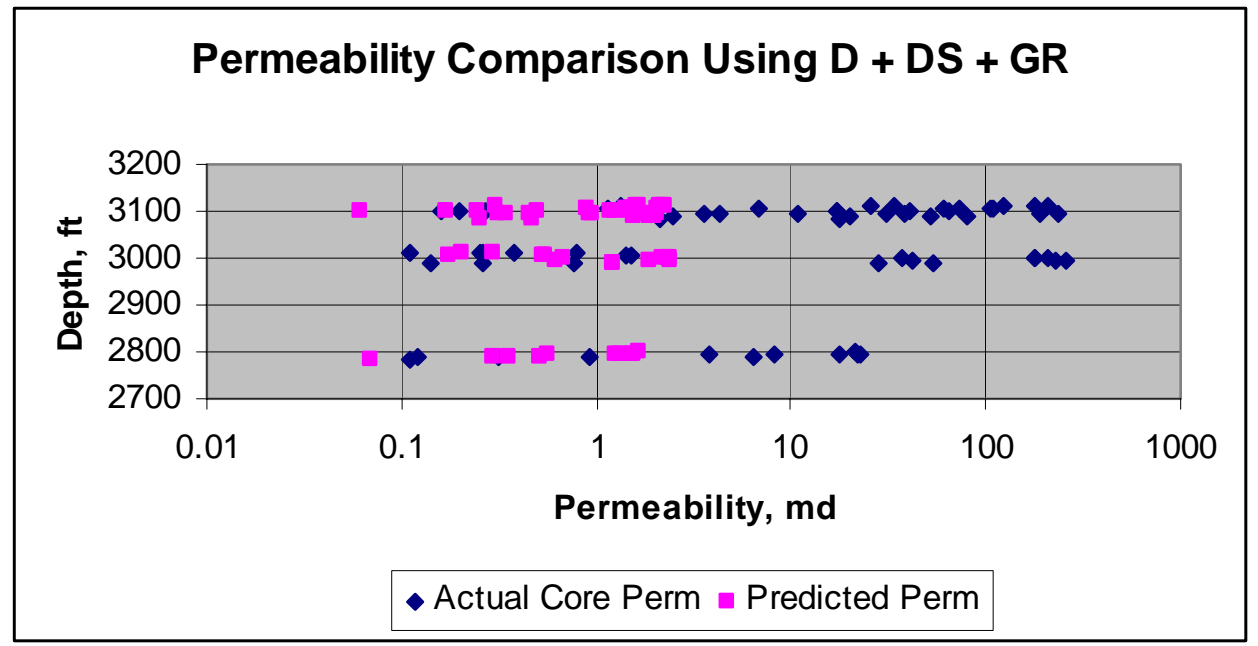

Figure C-18. Multiple Regression Results for P11 + B18 + B19 + T 8 (D + DS + GS)

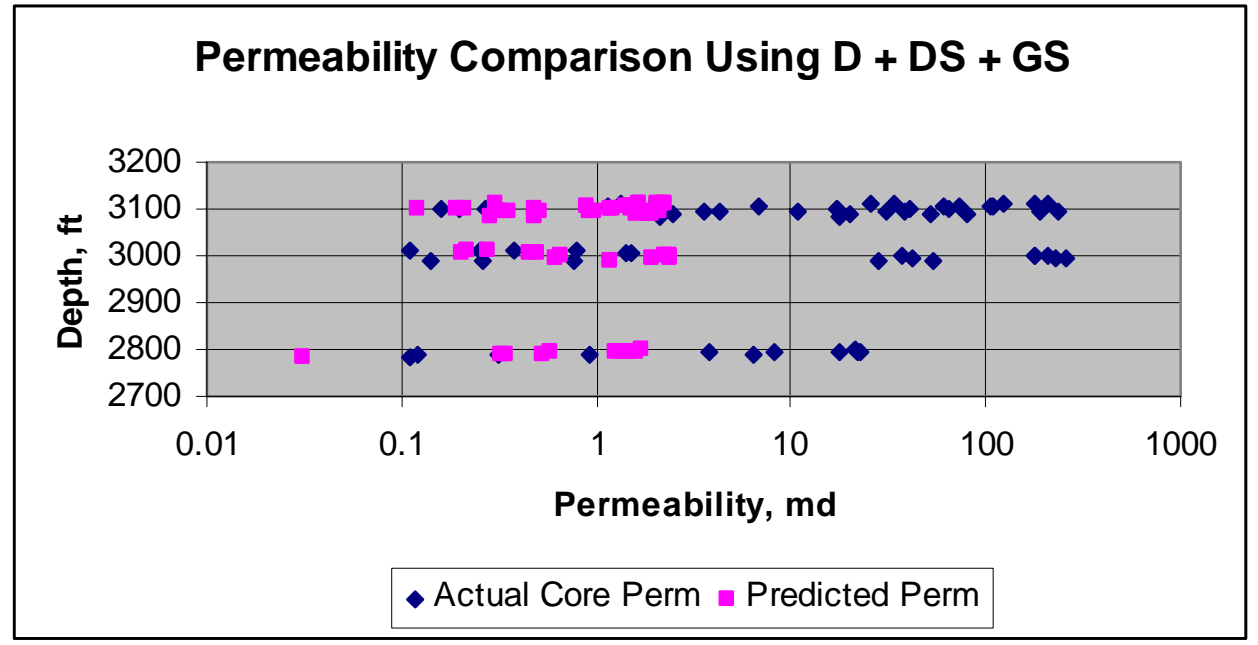


Figure C-19. Multiple Regression Results for P11 + P9 (D + DS + GR + GS)

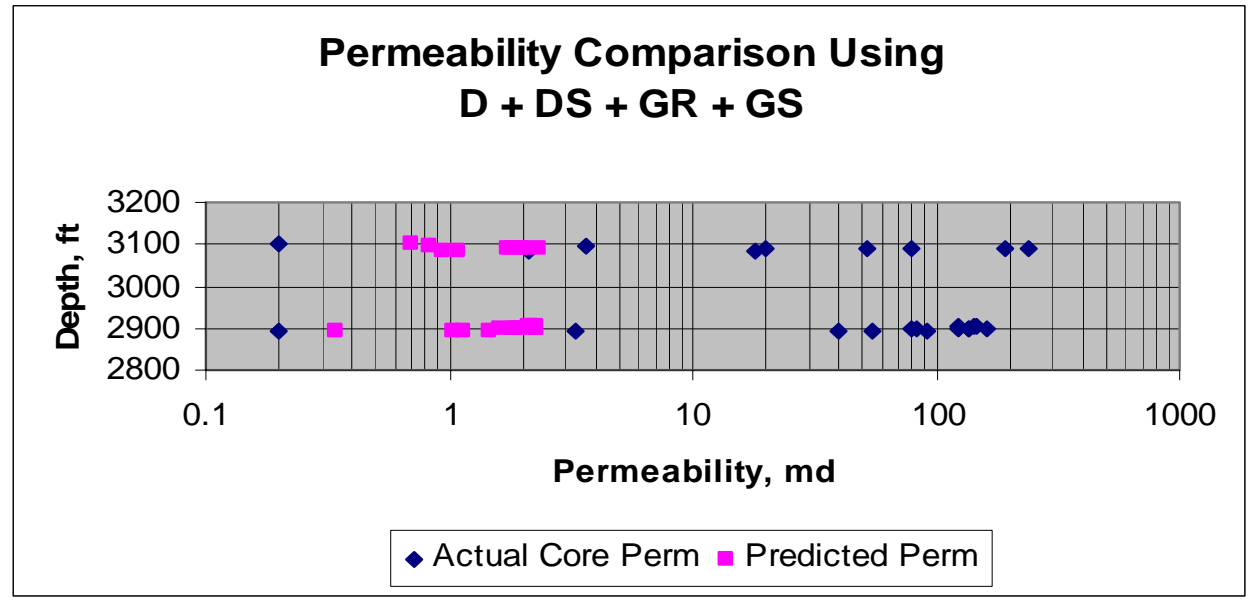

Figure C-20. Multiple Regression Results for P11 + P9 (D + GR)

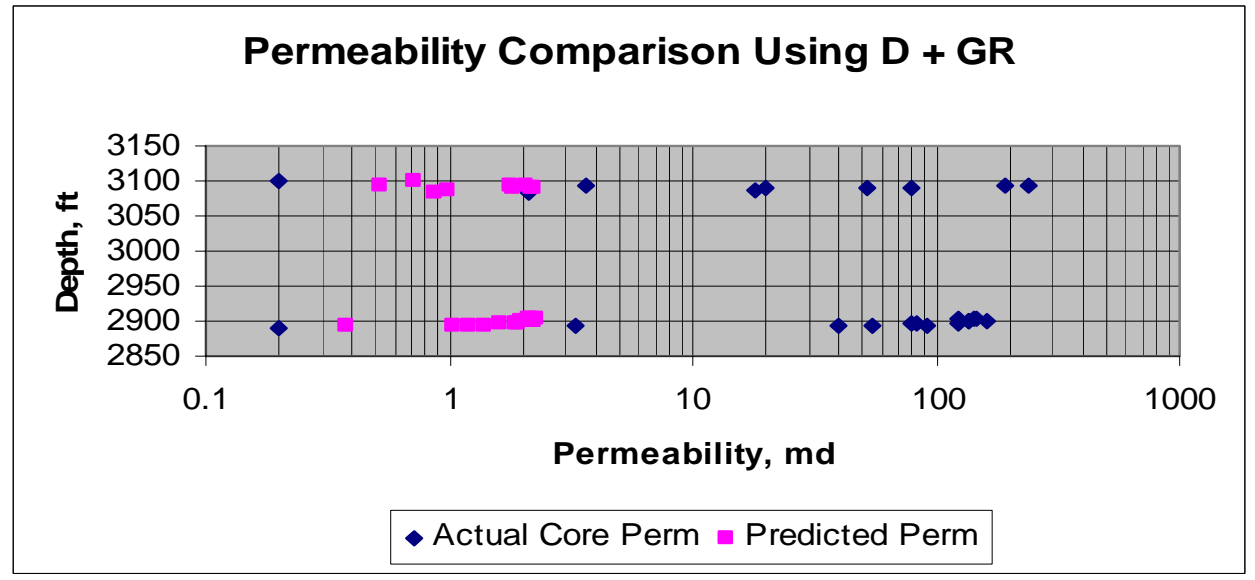

Figure C-21. Multiple Regression Results for P11 + P9 (GR + Porosity)

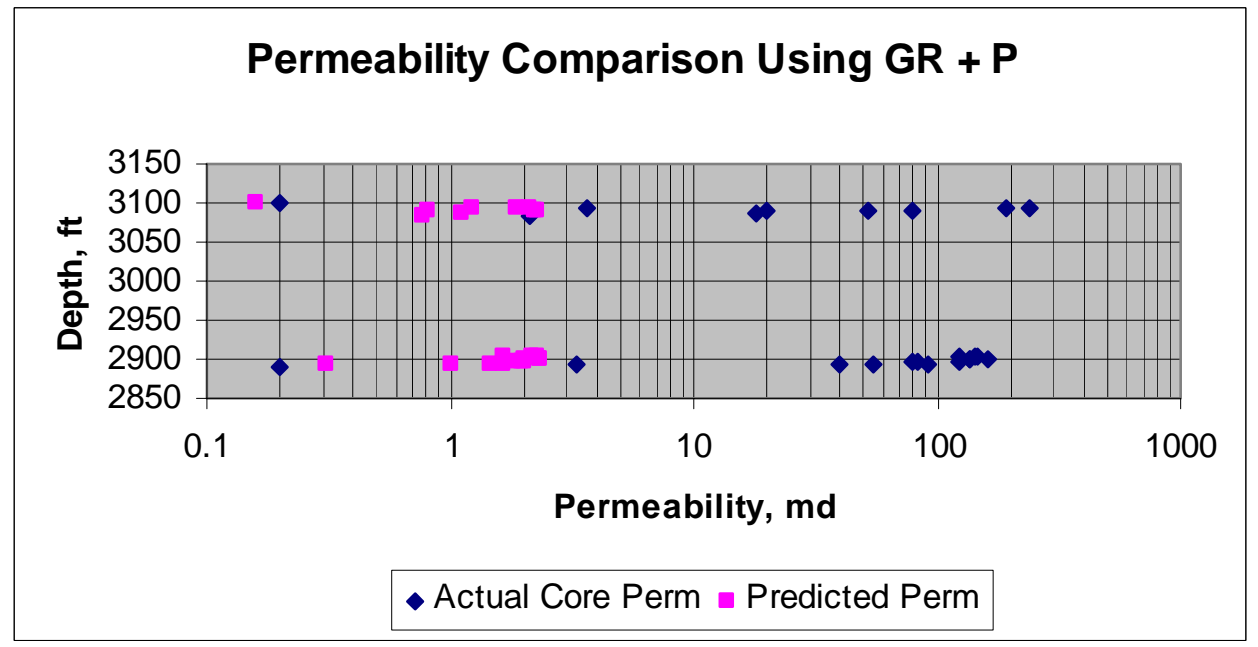


Figure C-22. Multiple Regression Results for P11 + P9 (D + DS)

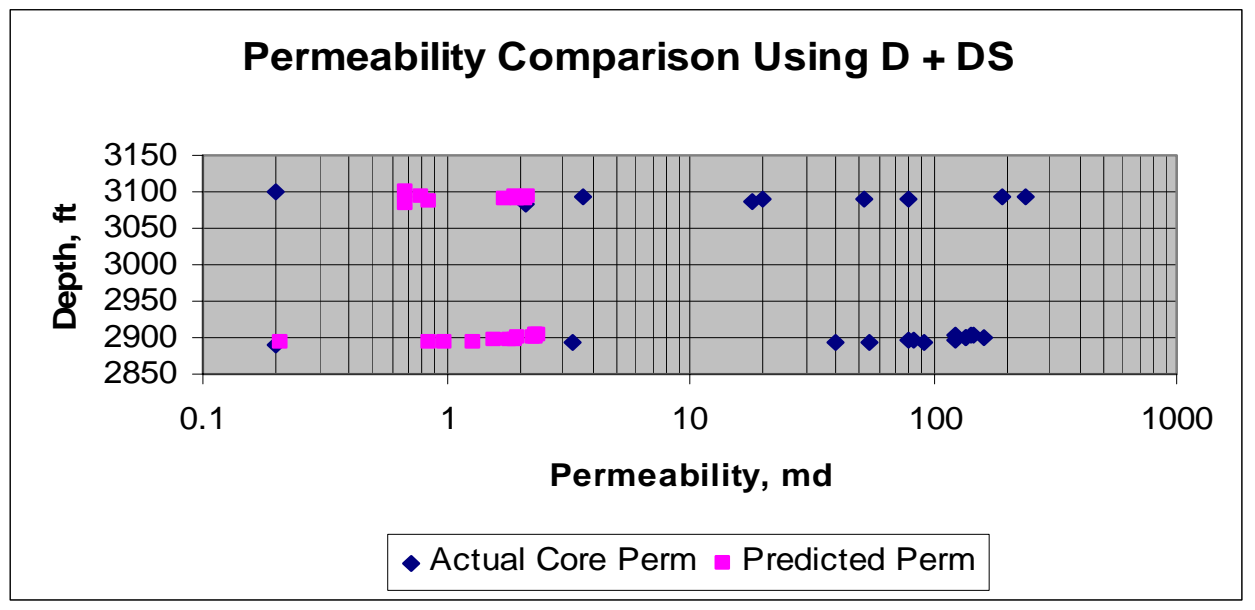

Figure C-23. Multiple Regression Results for P11 + P9 (D + GR + GS)

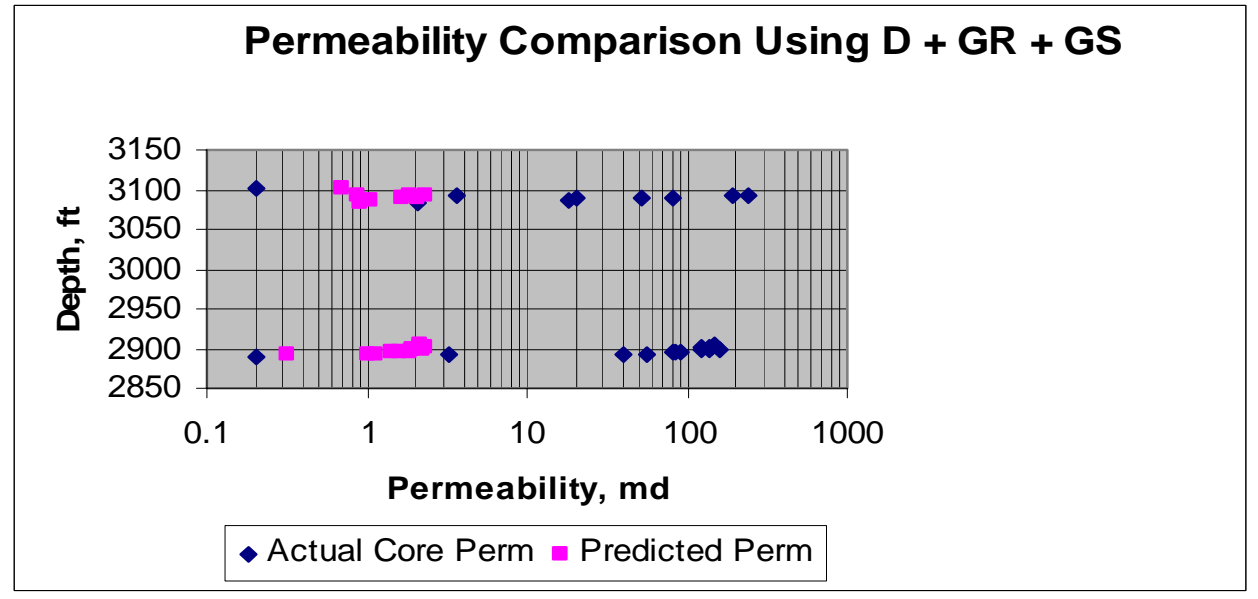

Figure C-24. Multiple Regression Results for P11 + P9 (D + GS + GR)

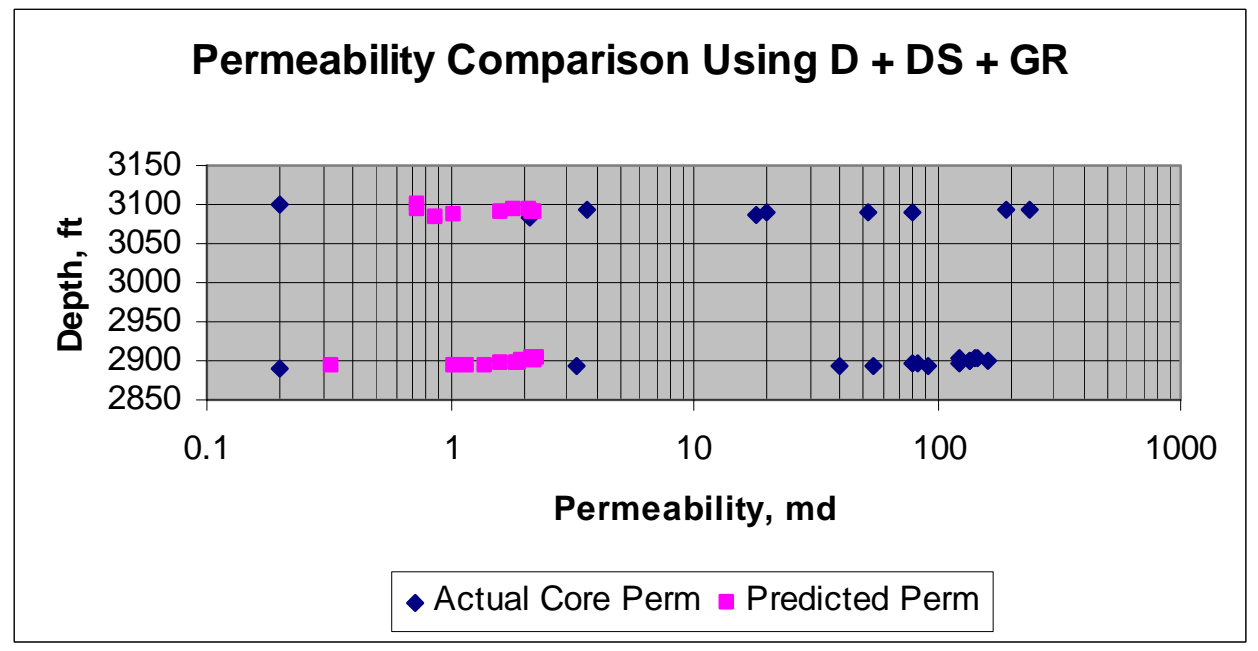


Figure C-25. Multiple Regression Results for P11 + P9 (D + GS + GS)

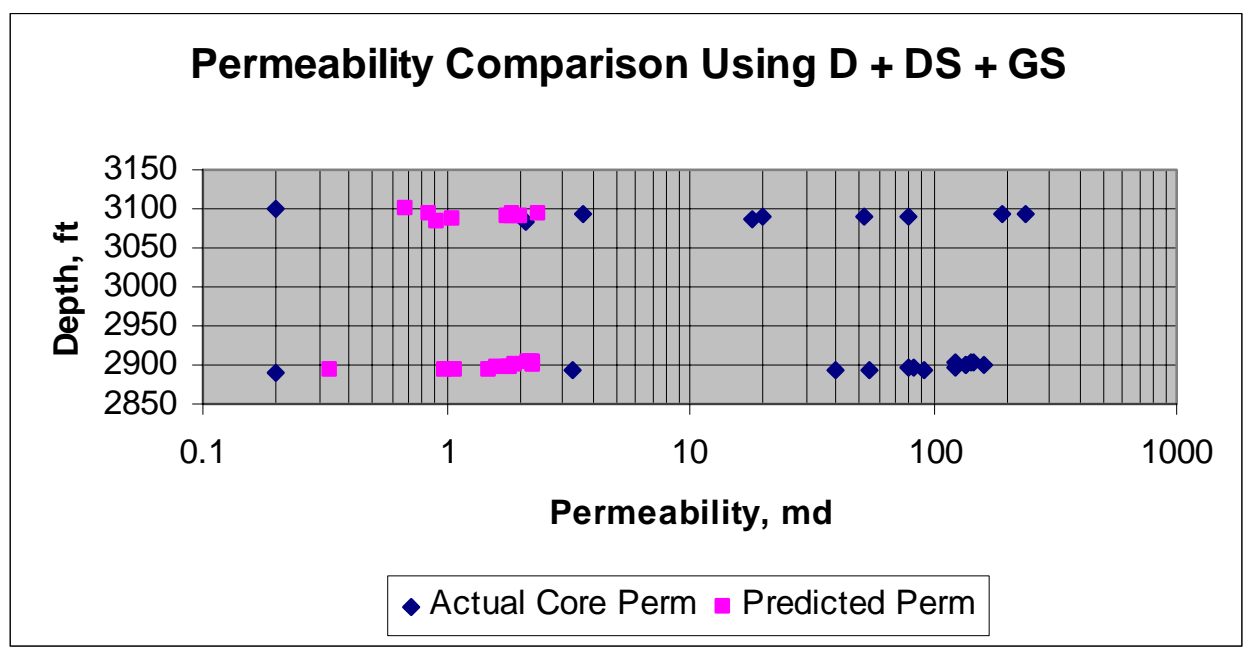


Figure C-26. Multiple Regression Results for P11 + P9 + B18 (D + DS + GR + GS)

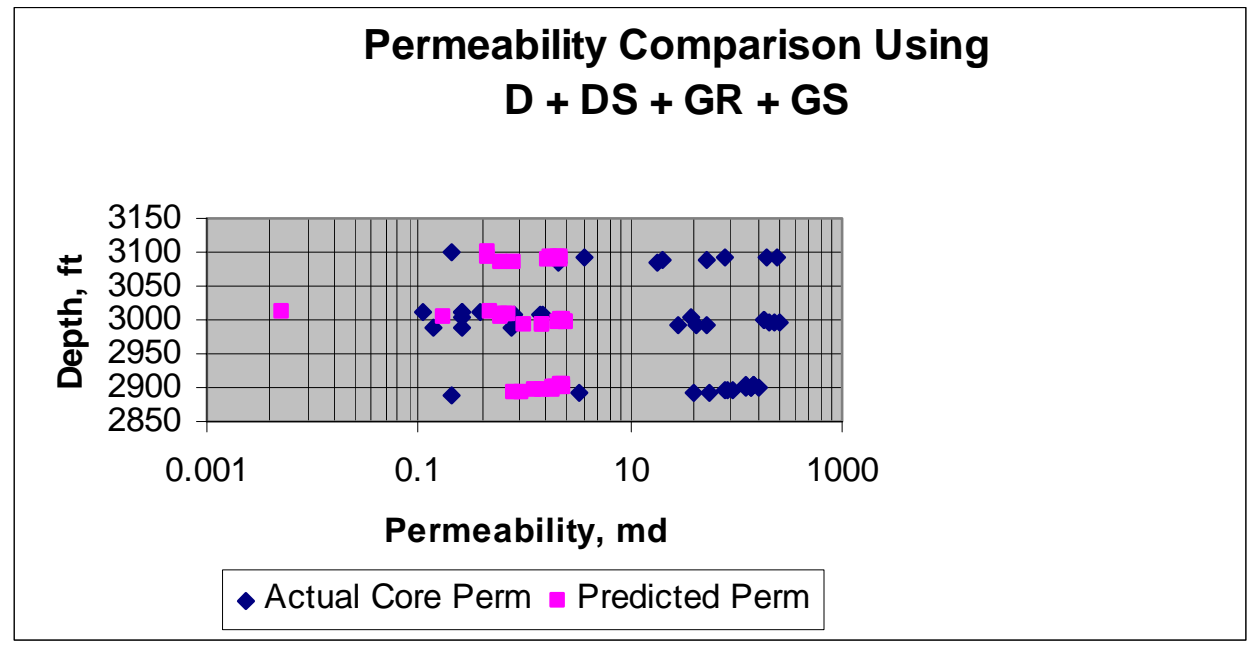

Figure C-27. Multiple Regression Results for P11 + P9 + B18 (D + GR)

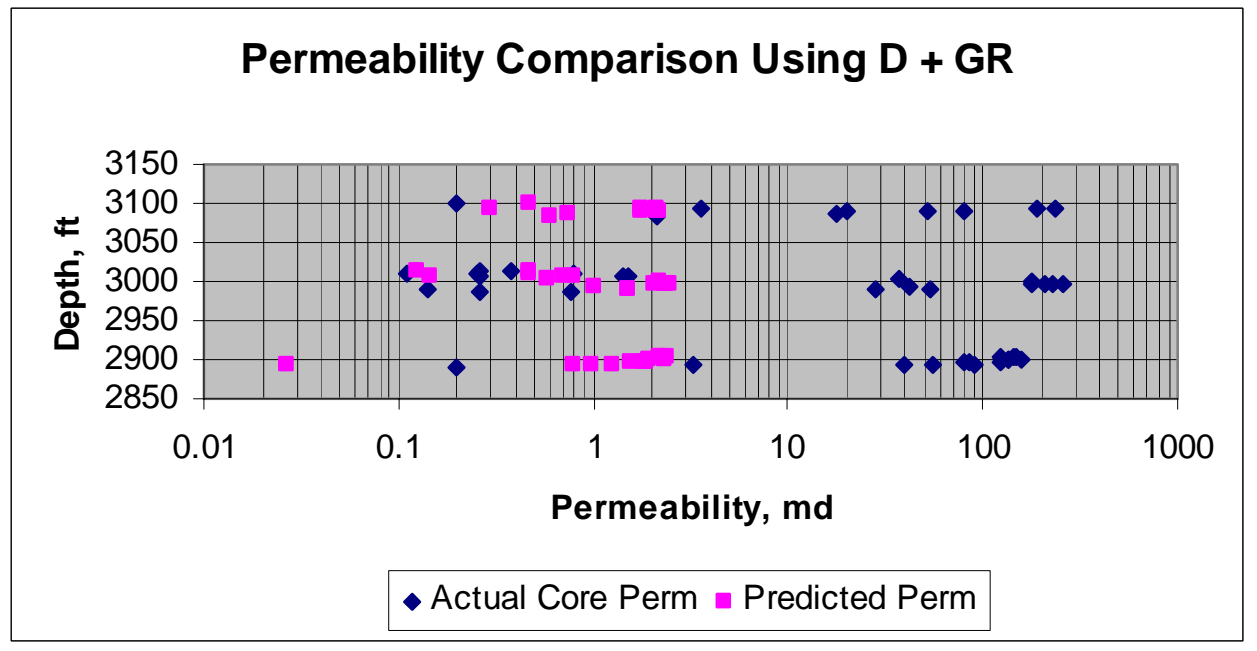

Figure C-28. Multiple Regression Results for P11 + P9 + B18 (GR + Porosity)

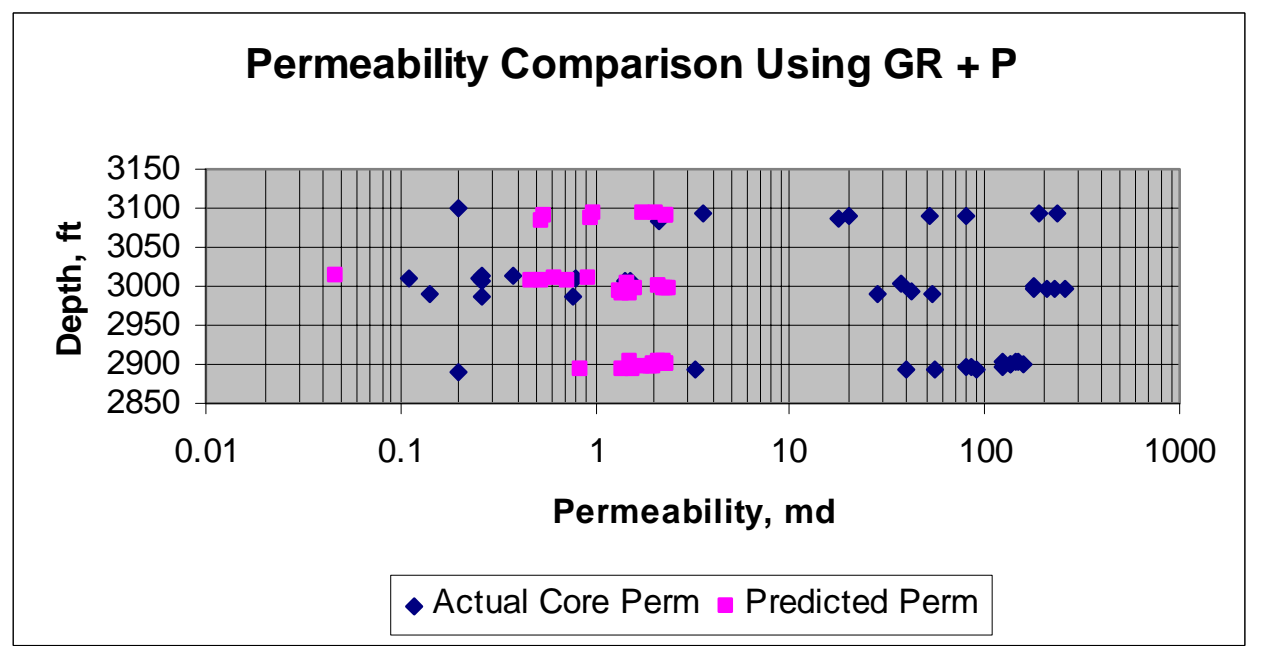


Figure C-29. Multiple Regression Results for P11 + P9 + B18 (D + DS)

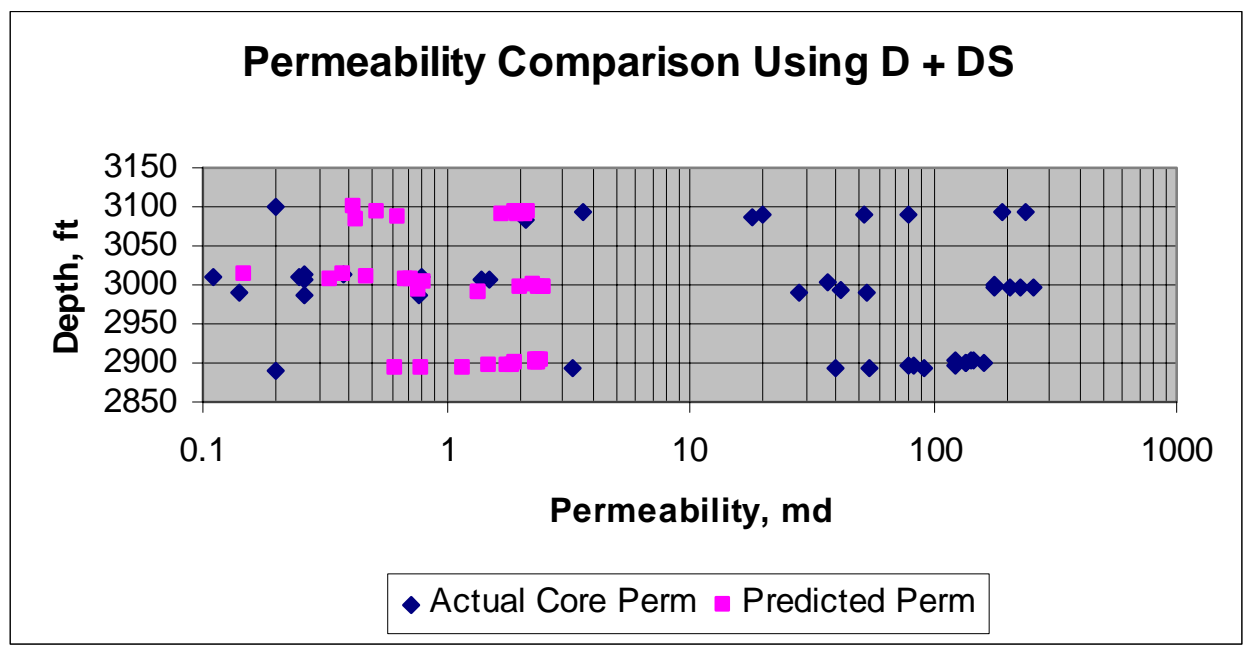

Figure C-30. Multiple Regression Results for P11 + P9 + B18 (D + GR + GS)

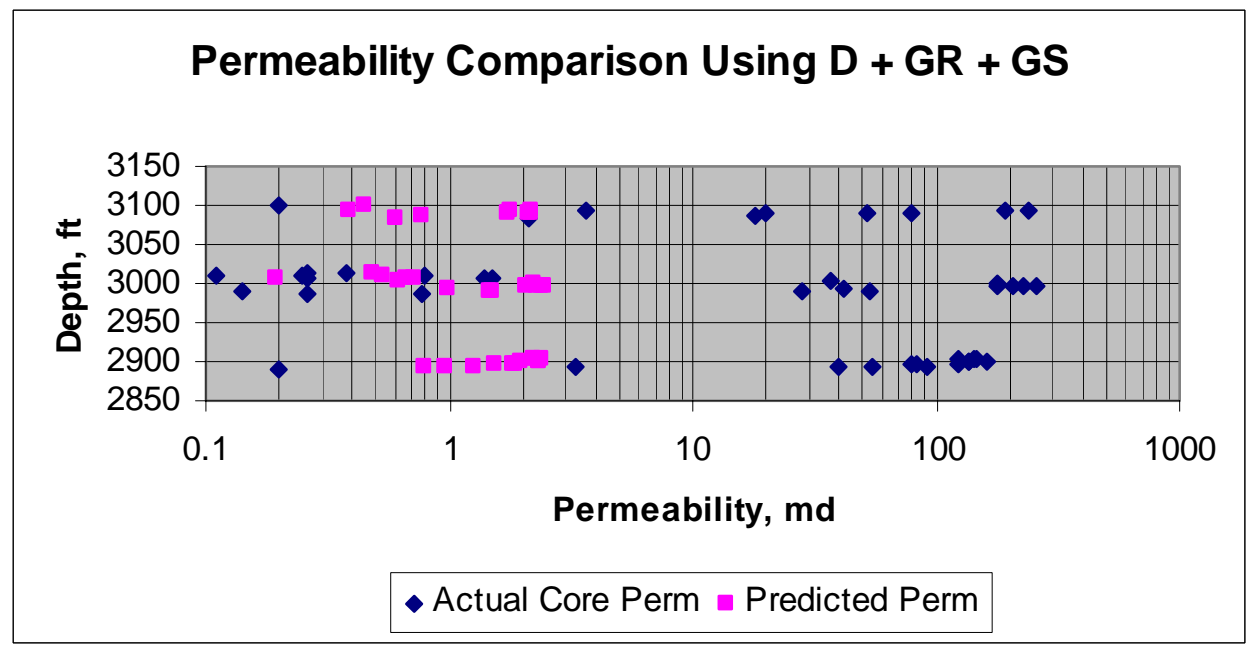

Figure C-31. Multiple Regression Results for P11 + P9 + B18 (D + DS + GR)

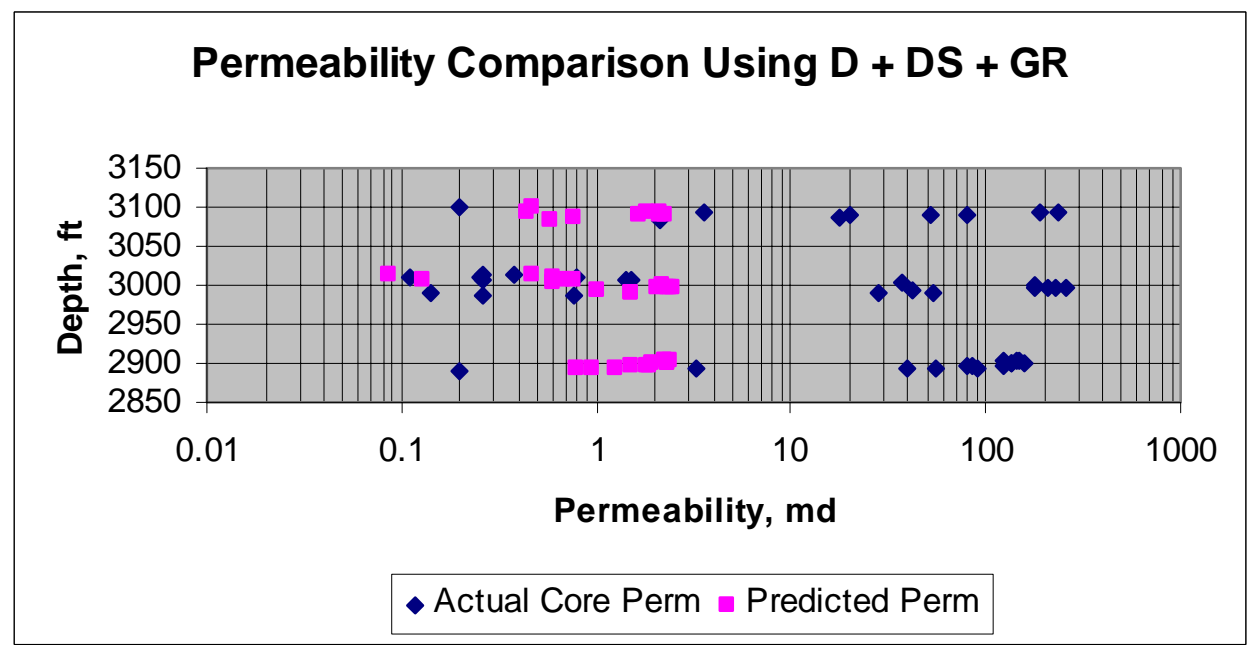


Figure C-32. Multiple Regression Results for P11 + P9 + B18 (D + DS + GS)

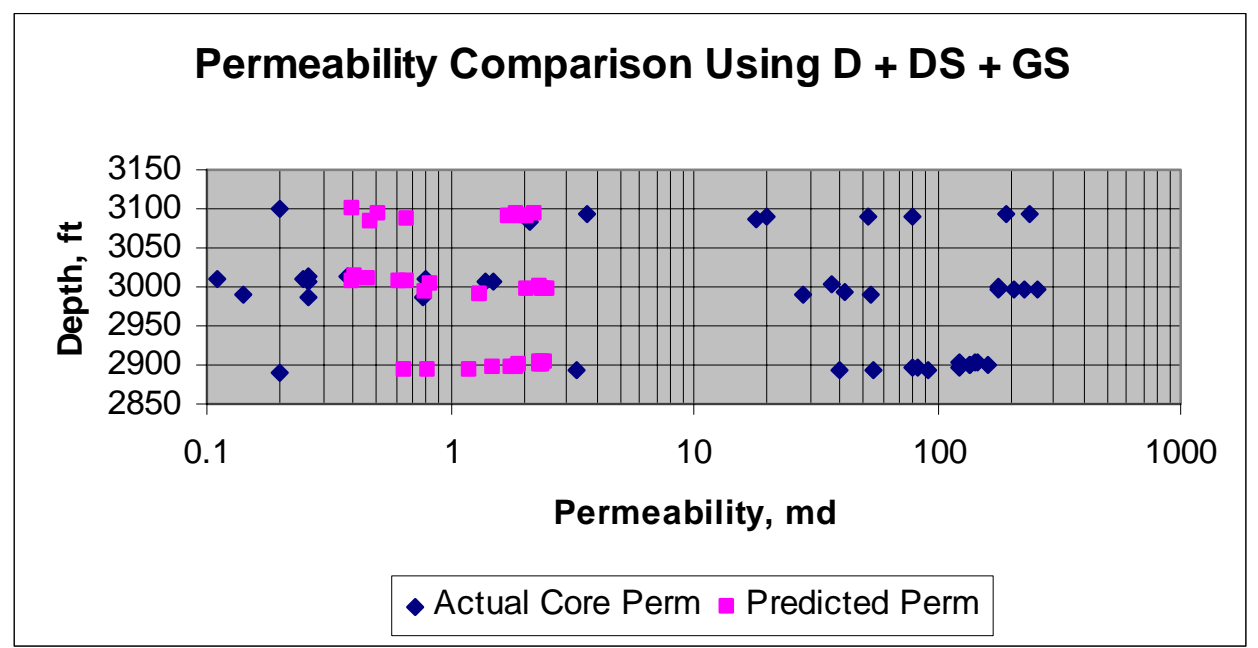

